\title{
CARACTERÍSTICAS DEL MOVIMIENTO CORPORAL NO EFECTOR Y SU RELACIÓN CON LA CONFIGURACIÓN MELÓDICA EN LA IMPROVISACIÓN MUSICAL
}

UN ESTUDIO DE CASO EN MÚSICA DE FUSIÓN ARGENTINA

TESIS DE MAESTRÍA

MARÍA VICTORIA ASSINNATO

DIRECTOR: FAVIO SHIFRES 



\section{RESUMEN}

Esta Tesis estudia el movimiento corporal no efector en la improvisación musical y particularmente, cómo se vinculan estos movimientos y los aspectos que hacen a la configuración de la melodía improvisada en música de fusión argentina. Cuando decimos movimiento no efector, nos referimos al movimiento corporal que no está vinculado con la demanda técnico instrumental que le requiere al músico tocar su instrumento. Por ejemplo, en esta Tesis se estudian, entre otros, los movimientos que un flautista realiza con la cabeza mientras improvisa su solo. Posteriormente, se analizan posibles relaciones entre las características del movimiento y de la melodía improvisada.

Aborda el problema de estudio partiendo de una concepción ampliada de la improvisación musical, realizada ad hoc en esta Tesis. Basándose en las ideas del la cognición corporeizada de la música, se plantea que la improvisación puede ser entendida como una práctica corporeizada, que incluye el modo en que se comporta corporalmente el músico durante la improvisación; enactiva, porque estos movimientos pueden ser considerados como acciones corporales que guían la experiencia del músico; situada, porque sucede en un contexto específico, en esta Tesis, en música de fusión argentina; y multimodal, porque movimiento se encuentra acoplado al sonido, la emoción y el significado que constituyen la performance.

En la etapa experimental se realizaron dos estudios exploratorios que se propusieron describir el movimiento corporal no efector y observar las vinculaciones que éste pudiera tener con la melodía improvisada. El primero de estos estudios se abocó más a la descripción cualitativa de los movimientos, en tanto que el segundo analizó de modo más cuantitativo los movimientos observados. Se encontró que los movimientos corporales realizados que no se vinculan con los requerimientos técnico-instrumentales podrían estar mapeando distintos aspectos de la configuración melódica. En algunos casos se ocuparían del mapeo de elementos más globales, como la dinámica de la melodía y la organización morfológica y en otros, de elementos más puntuales, como el ritmo. Sonido y movimiento no siempre ocurren de modo simultáneo, muchas veces uno antecede o sucede al otro. Sin embargo, estos corrimientos, dada la continuidad en la que surgen, no estarían interfiriendo para que sea posible entender la improvisación en función del sonido y del movimiento corporal que ella nuclea. 



\section{ÍNDICE}

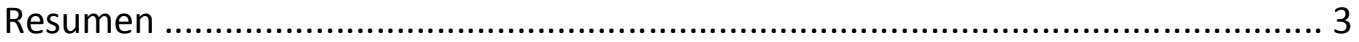

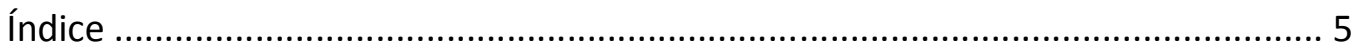

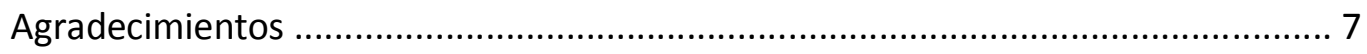

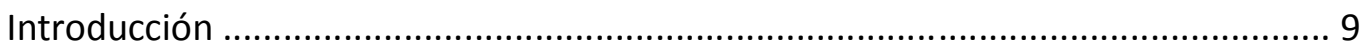

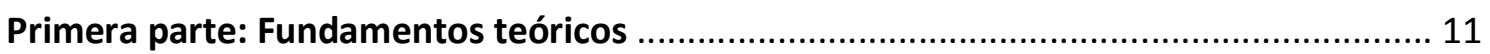

Capítulo 1: La improvisación musical: Usos, conjunciones y

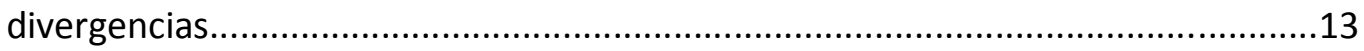

Introducción........................................................................................... 13

La experiencia performativa en diferentes contextos............................. 15

Preparación para la improvisación vs. creatividad, espontaneidad y

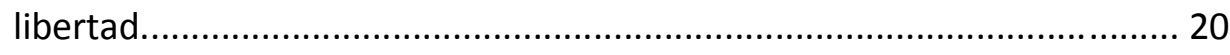

Improvisación como actividad a conocer .............................................. 23

Improvisación como modo de conocimiento............................................ 26

La habilidad de improvisar................................................................... 28

Improvisación y lenguaje verbal.................................................. 28

La improvisación como proceso psicológico.................................. 29

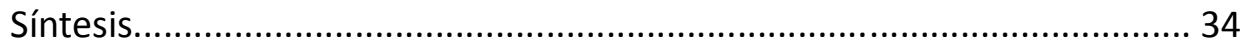

Capítulo 2: Hacia una definición de improvisación como modo particular corporeizado, enactivo, situado y multimodal de conocimiento musical ............. 36

Antecedentes del estudio del movimiento y del gesto en diferentes

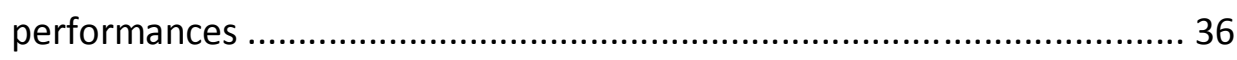

El movimiento en la danza ........................................................... 36

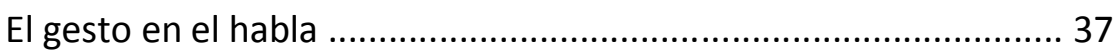

Gesto, movimiento y ejecución musical ..................................... 39

Cognición musical corporeizada ........................................................ 43

Mente-cuerpo y entorno: interacción en el proceso cognitivo ...... 43

La práctica de significado musical.............................................. 44 
Improvisación musical: sonido, movimiento y práctica de significado. 47

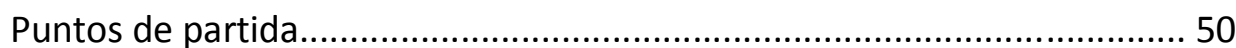

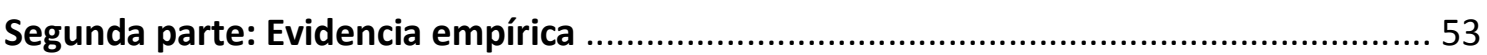

Capítulo 3: Rasgos dinámicos del movimiento corporal en la improvisación .......... 55

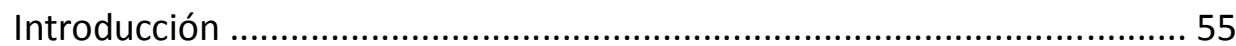

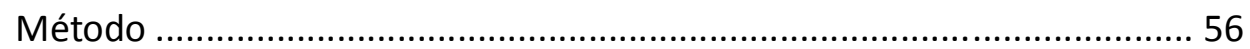

Interpretación y discusión de resultados ................................................ 57

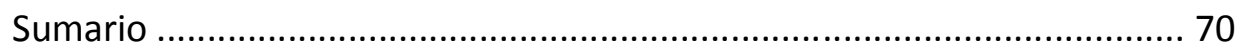

Capítulo 4: El movimiento corporal del músico y el aspecto melódico .................. 73

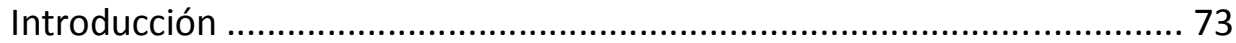

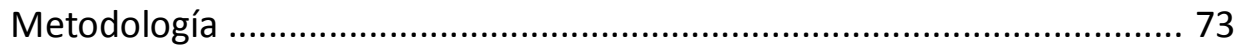

Interpretación y discusión de resultados ................................................ 74

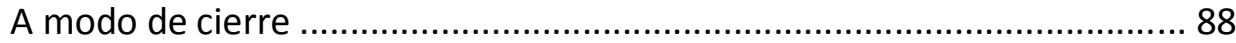

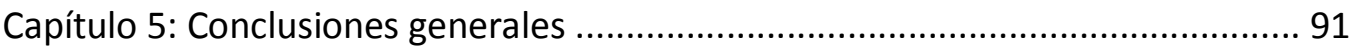

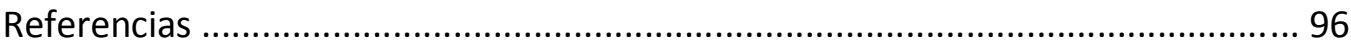




\section{AgRADECIMIENTOS}

A mi director, el Dr. Favio Shifres, por guiarme en este proceso con paciencia, dedicación y esmero.

A mis compañeros de la cátedra de Educación Auditiva I y II de la Facultad de Bellas Artes y de los equipos de investigación El oído musical y Cognición Musical Corporeizada, por ayudarme a pensar, a plantear y a entender los problemas de investigación sobre los que trabajamos.

A mi papás, a mis hermanas y a Santi, por el apoyo incondicional, la contención y el cariño.

A mis amigos, por acompañarme siempre y por la alegría de esos momentos compartidos tan necesarios.

A Juani, por el amor, la energía y la comprensión; y por hacer que la felicidad sea nuestro estado cotidiano.

A nuestro bebé, Dante, por enseñarme desde el primer momento y por permitirme experimentar este proceso de sonido, movimiento y significado de un modo inmensamente maravilloso. 



\section{INTRODUCCIÓN}

El problema de estudio que abordamos en esta Tesis surge en primer lugar de una revisión tanto de materiales teóricos como de ejecuciones musicales que se aglutinan bajo el concepto de improvisación musical. Ello me permitió advertir que los diversos tipos de ejecuciones obedecían al modo en que se ponían en juego diferentes factores musicales, sociales y/o culturales y que la mayoría de los enfoques teóricos reconocidos sobre el tema dejaban afuera muchas de las cuestiones que eran casi determinantes en la improvisación. Al mismo tiempo, esta revisión me obligó a producir una definición que tuviera en cuenta los aspectos que las perspectivas teóricas estudiadas no incluían, o al menos, no se encargaban de analizar directamente. En segundo lugar, cuando esta revisión había conseguido una buena magnitud, comenzaron a ser fuertes tópicos de investigación en los equipos a los cuales pertenezco algunas problemáticas enmarcadas en la Cognición Corporeizada de la Música. Dentro de ese enfoque teórico, pude ir encontrando algunos argumentos que me permitieron más adelante empezar a delinear una definición de la improvisación musical que atendiera al desarrollo del movimiento corporal que este tipo de práctica conlleva. De aquí que la hipótesis de la presente Tesis es que el movimiento corporal no efector realizado por el improvisador se vincula con la configuración de la melodía que está improvisando.

La estructura de este escrito se organiza en dos secciones. La primera se ocupa de los conceptos teóricos relevantes para la concreción de esta Tesis y la segunda incluye la evidencia empírica recolectada al respecto.

El capítulo 1 menciona las diferentes concepciones de la improvisación musical provenientes de campos teóricos diversos. Observa los usos del término y las semejanzas y diferencias entre un contexto y otro.

El capítulo 2 describe el estado del arte en la investigación sobre el movimiento corporal en diferentes tipos de performance, como la danza, el discurso verbal, y la ejecución musical vocal, instrumental o ambas. Plantea además nuestra definición de improvisación, que se sustenta de las observaciones realizadas en la revisión bibliográfica del capítulo anterior y el marco teórico trabajado aquí.

El capítulo 3 presenta un estudio cualitativo del movimiento corporal del músico en la improvisación y lo vincula con la melodía que está siendo improvisada en ese momento. Para ello toma un solo improvisado (en formato de video) de un flautista argentino que forma parte de un cuarteto de música que interpreta obras propias y ajenas de folclore argentino y de fusión con otros ritmos latinoamericanos.

El capítulo 4 retoma el solo analizado en el capítulo anterior pero le agrega una mirada más cuantitativa, al medir utilizando un software dos aspectos del movimiento que podrían ofrecer datos más precisos a la hora de caracterizarlo. Una de ellas es la cantidad de movimiento (la QoM) que mide sobre el video del solo cómo va aumentando, 
disminuyendo o manteniéndose los movimientos cuadro a cuadro sobre una zona determinada. La otra es la velocidad absoluta (la VA) que calcula cuadro a cuadro cómo el movimiento va acelerando, desacelerando o conservando la velocidad inicial.

Por último, el capítulo 5 ofrece una serie de conclusiones que surgen de la presente Tesis, trazando un recorrido entre la definición que elaboramos y los resultados a los que arribamos, discutiéndolos en el marco de la Cognición Corporeizada de la Música. 



\section{Primera PARTE}

FUNDAMENTOS TEÓRICOS 



\section{CAPÍtULO 1}

\section{LA IMPROVISACIÓN MUSICAL:}

\section{USOS, CONJUNCIONES Y DIVERGENCIAS}

\section{INTRODUCCIÓN}

Según el diccionario de la Real Academia Española, improvisar es "hacer una cosa de pronto; sin estudio ni preparación alguna" (2001). Entendemos entonces que improvisar musicalmente es producir un enunciado musical espontáneo, sin que necesariamente exista premeditación ni planificación de la acción a realizar. Más específicamente, The New Grove Dictionary of Music and Musicians define a la improvisación musical como:

"la creación de una obra musical, o la forma final de una obra musical que se está realizando. Puede tratarse del trabajo de la composición inmediata de sus intérpretes, o la elaboración o ajuste de un marco existente, o cualquier otra cosa. Hasta cierto punto, cada actuación conlleva elementos de improvisación, aunque su grado varía según la época y el lugar, y en cierta medida cada improvisación se basa en una serie de convenciones o normas implícitas" (Sadie, 1980).

A partir de esta definición, damos cuenta que el término se utiliza para designar tanto al proceso que implica improvisar, como al producto de una obra que ha surgido de la improvisación. Además, que la improvisación puede depender del trabajo de uno de los intérpretes o bien que puede ser el resultado de un trabajo grupal. Es interesante remarcar el final de la definición, donde se hace referencia explícita a las convenciones o normas que delimitan la improvisación y a la posibilidad de que cada actuación permita la utilización de elementos de improvisación, porque sobre estas características se apoyan muchos de los autores que vamos a tratar en este capítulo. Con respecto a las convenciones, algunos autores sugieren que la improvisación puede ser explicada atendiendo al desarrollo de dos elementos centrales, denominados base de conocimiento y referente (Pressing, 1998; Kenny y Gelrrich, 2002). En cuanto a la actuación, otros autores plantean que las músicas provenientes de contextos socioculturales diversos permiten el desarrollo de distintas formas de improvisación musical (Bailey, 1992; Nettl y Russell, 1998; Solís y Nettl, 2009).

Una de las ediciones posteriores del diccionario Grove agrega que improvisar es "el arte de pensar y tocar música simultáneamente" (Sadie, 1984). Comprendemos entonces que la improvisación alberga no sólo a la ejecución en si misma sino también al tipo de pensamiento que ella requiere. En esta línea, algunos autores proponen modelos que 
intentan describir el proceso psicológico que subyace a la improvisación (Pressing, 1987; Johnson Laird, 1991) en tanto que otros, ofrecen explicaciones basadas en la comparación entre improvisación y composición (Norro, 2008; Molina, 2008).

Finalmente, es la acepción derivada del ámbito del jazz la que se utiliza con mayor frecuencia, probablemente, porque este es el género en que ella tiene mayor presencia. Al respecto, el diccionario Grove plantea que:

"La improvisación es generalmente considerada el elemento principal del jazz, ya que ofrece la posibilidad de la espontaneidad, la sorpresa, la experimentación y el descubrimiento, sin la cual la mayor parte del jazz sería carente de interés. Casi todos los estilos de jazz dejan cierto margen para la improvisación, ya sea en un solo, un coro o algún otro pasaje corto durante el cual un solista puede improvisar sobre un acompañamiento, una secuencia de coros para diferentes solistas, o toda la pieza después de la declaración de un tema; y algunas obras de jazz se crean de forma espontánea, sin el uso de un marco predeterminado" (...) "Sin embargo, es falso que todo el jazz debe involucrar a la improvisación. Muchas piezas que son, sin duda, clasificables como jazz se componen enteramente antes de una actuación, y toman la forma de un acuerdo, ya sea fijo en notación o bien memorizado por los improvisadores" (Sadie, 1980).

Aquí aparece una contradicción importante: mientras la improvisación se asocia a los conceptos de creatividad, espontaneidad y exploración, se sabe que en muchos casos esto no es necesariamente así, sino que, por el contrario, se puede interpretar una improvisación del mismo modo en que se interpreta una obra escrita. De todos modos, en el marco del jazz es más común encontrar que las improvisaciones sean caracterizadas como creativas y espontáneas (Nachmanovicht, 1990; Smith, 1998; Gushee, 1998), lo cual nos lleva a pensar que los autores se sustentan más en la primera parte de esta definición.

Ahora bien, más allá de que muchas veces la improvisación sea reducida a esa parte de esta última la definición, como modalidad del desempeño de los ejecutantes, la improvisación ha sido una práctica musical frecuente desde la edad media hasta la actualidad. Contrariamente a lo que a veces se sugiere, no se inicia en el jazz. Un breve recorrido por la historia de la música occidental nos permitirá ver más claramente sus comienzos. Ya los primeros juglares (S. X d.C) y más tarde, los trovadores (Siglo XII d.C) acompañaban sus canciones improvisando ritmos y melodías que combinaran con lo que cantaban. También, era habitual que los músicos de la edad media improvisaran en los acompañamientos que efectuaban para la danza. Entrado el renacimiento se desarrolló una música instrumental autónoma, por el traslado de los géneros vocales y de la manera de componerlos a los instrumentos, con una concepción específicamente instrumental. Datan de entonces los primeros ejemplares de ricercares, toccatas, canzonas, sonatas, etc. (Michels, 1982). En estos géneros el ejecutante improvisaba contemplando dos reglas preestablecidas en la época por las cuales podía (i) realizar una ornamentación de una línea melódica dada; o bien (ii) adicionar una o más secciones de contrapunto a un cantus firmus dado. Este método era conocido bajo el nombre de discanto supra librum (discanto 
improvisado sobre una melodía existente), contrapunto alla mente (contrapunto mental) o sortisatio (repentización, opuesto a composición) (Grout, 1984). Más adelante, comenzaron a identificarse las obras improvisatorias de acuerdo a sus características principales. Así nos encontramos con (i) la toccata (del latín toccare, tocar, es decir la tecla), que es una forma libre compuesta de escalas, figuraciones, acordes; (ii) el preludio o preámbulo, que mantiene una forma libre con escalas; (iii) el ricercar, inicialmente libre, luego una composición polifónica según el principio del motete: por secciones con imitación desarrollada con sendos "temas" nuevos (sujeto o soggeto); (iv) la fantasía, a la manera del ricercar, imitativa; (v) la canzona, chanson cifrada, su elaboración o imitación; entre otras (Michels, 1982). Generalmente, las improvisaciones se prestaban para que el ejecutante demostrara su virtuosismo instrumental y el manejo de los pedales; ya que estas piezas eran en principio para órgano. En el siglo XVII, la música instrumental, que no era independiente, sino que servía como acompañamiento a la danza y al canto, como ilustración y entretenimiento, se improvisaba en gran medida. Durante el Clasicismo y el primer periodo del Romanticismo, la improvisación ocupó un lugar menos relevante dentro del hacer musical. Es posible relacionar esto con (i) la consolidación del sistema tonal, (ii) la afirmación de la forma sonata y (iii) el pensamiento estético de la época. Llegando a los comienzos del siglo XX, la improvisación se re-instala particularmente en el ámbito de la música popular, como práctica cada vez más corriente, particularmente dentro del Jazz. Asimismo ocurre dentro del contexto de la música académica en algunos movimientos de vanguardia, principalmente luego de los años 50. Actualmente, asistimos a la fusión de géneros y estilos, lo que permite que encontremos improvisación en el campo de la música pop; del folclore; del tango; etc.

De lo anterior se desprende que la improvisación musical como práctica musical ha tenido una presencia muy frecuente a lo largo de la historia de la música de occidente y con ello queda evidenciado que no se origina en el ámbito del jazz. Incluso, muchos de los procedimientos utilizados para improvisar en jazz son similares a los que se empleaban en algunas de las formas musicales a lo largo de la historia occidental de la música. Sin embargo, el jazz podría ser el género donde mayormente se ha llevado a cabo. Es por esto que tomamos la acepción proveniente del jazz como definición de base.

En lo que sigue vamos a ver cómo los estudios que se presentan sobre improvisación adhieren de algún modo a alguna de estas definiciones. Vamos a plantear también porque en el marco de la presente tesis estas definiciones serán consideradas incompletas y vamos a trazar los puntos principales que nos servirán de argumento para plantear nuestra definición del concepto.

\section{LA EXPERIENCIA PERFORMATIVA EN DIFERENTES CONTEXTOS}

Muchas de las investigaciones producidas en el campo etnomusicológico han procurado indagar en cómo se lleva a cabo la improvisación musical en diferentes estilos musicales, presentes en contextos histórico-culturales disímiles. Es por eso que allí encontramos investigaciones que van desde el estudio de la improvisación en el jazz, pasando por el 
análisis de improvisaciones en música académica del período clásico y de ejecuciones improvisadas en música hindú y árabe, hasta el examen de prácticas de improvisación oral (sobre recitados en el Corán y en funerales) y corporal (como sucede en la danza). Por ejemplo, el guitarrista inglés Derek Bailey (1930-2005) en "Improvisación: su naturaleza y práctica'” (1992), describe el concepto de improvisación sobre la selección de algunos géneros musicales, procedentes de distintos momentos históricos. Analiza la improvisación en la música para órgano del siglo XVII, la música hindú, el jazz, el rock y el flamenco; presenta una posible perspectiva del improvisador y de la audiencia, y deriva una pequeña propuesta pedagógica. De ello se desprende una concepción más bien amplia de la improvisación, porque la sitúa en diferentes momentos históricos y estilos musicales; la reúne con la interpretación y la composición y la explica en términos de tiempo y espacio, intentando notar exactamente qué cosas incluye esta forma de hacer música. Es por eso que sugiere que la improvisación puede explicarse como algo continuo, kinético, dinámico, equivalente, balístico, centrífugo (p. 6), intentando denotar los puntos principales que diferencian esta práctica, principalmente en lo que refiere su desarrollo temporal. Sin embargo, utiliza una dicotomía un tanto taxativa, cuando se refiere a la improvisación idiomática como aquella que se circunscribe a un idioma determinado, sea el jazz, folclore, flamenco, barroco, etc.; y denomina no idiomática, a la improvisación que no está representando ningún idioma particular, afirmando que también es llamada improvisación libre (Bailey, 1992; p. xii). Esta división es terminante, básicamente, porque no alberga a las performances actuales de fusión ${ }^{2}$, o las que se conforman a partir del lenguaje de señas ${ }^{3}$, sólo por no adscribir a ningún idioma en particular aún conteniendo elementos de ambos. A pesar de esto, es importante destacar que Bailey (1992) define la improvisación intentando abarcar la complejidad de esta práctica implica y lo hace a partir del estudio de este complejo en un momento histórico determinado; y con ello, ofrece una conceptualización más acabada del término.

Otra de las obras reconocidas en este campo editada por el etnomusicólogo Bruno Nettl y Melinda Russell (1998) ${ }^{4}$ reúne un conjunto de estudios sobre la improvisación en distintos

1 En el original: Improvisation: its nature and practice in music.

2 Desde esta perspectiva, quedarían afuera varios ejemplares. Por ejemplo, las obras del pianista argentino Carlos Aguirre, que se sitúan a medio camino entre la música del litoral y el jazz, y que estarían representando diferentes idiomas. Así, surgen preguntas en torno a qué sucede con aquellos ejemplares que exhiben la utilización de distintos idiomas, o bien a en qué categoría se ubican las improvisaciones que contienen elementos de varios lenguajes.

\footnotetext{
${ }^{3}$ Por ejemplo, en el método creado por Butch Morris, denominado conducción (en el original, conduction), un conjunto de señas son entrenados y luego se improvisa a partir de su uso. Actualmente, 'La bomba de tiempo' (dirigida por Santiago Vázquez) y ‘Choque Urbano' (dirección general de Manuel Ablin) utilizan bastante esta metodología durante el desarrollo de sus performances.

${ }^{4}$ Como uno de los precedentes de esta obra, Netll (1974) realiza sus primeras aproximaciones sobre la improvisación, alegando que en la cultura ya sea de nivel formal o informal, se transmiten los conocimientos por herencia, adquisición y aprendizaje; y con ello pasan de ser información almacenada a constituir
} 
géneros musicales que tienen lugar en diferentes lugares del mundo y con ello, admite que la improvisación no sólo forma parte del jazz, como se venía afirmando rotundamente hasta ese momento. Más allá de esto, el aporte fundamental de Nettl y Russell radica en evidenciar los diversos elementos que componen la improvisación en diferentes culturas. Así, uno de los capítulos que trata acerca de la improvisación en la música de gamelán javanés considera que el comportamiento improvisado se refleja en las decisiones que toman los músicos durante la ejecución (Anderson Sutton, 1998); mientras otro capítulo sugiere que "los desafíos a los que se enfrentan los intérpretes casi nunca son completamente imprevistos" (Blum, 1998; p. 34); y otro capítulo examina cómo sucede la improvisación en grupos de canto lírico italiano, afirmando que el comportamiento improvisatorio se basa en conocimiento que comparten los integrantes del grupo y del plan que previamente acuerdan (Magrini, 1998). Este plan delimita la gama de posibilidades y elementos, en tanto que el modo en que improvisan es adquirido bajo la práctica misma de la interacción grupal (Magrini, 1998; p. 169). Además, dentro de la edición de Nettl y Russell hay artículos que describen la improvisación en la música de Clara Schumann (Woodring Goertzen, 1998), en la música hindustaní (Slawek, 1998) y, como no podía faltar, en músicos célebres dentro del ámbito del jazz como Louis Amstrong (Gushee, 1998), Miles Davis (Smith, 1998), John Coltrane y George Russell (Monson, 1998). En el capítulo sobre la música de Clara Schumann, se analizan un conjunto de improvisaciones que ella escribió a modo de resumen de lo que había improvisado en público durante su vida. Esta colección, muestra dos tipos de preludios, los ejercicios y las introducciones, que priorizaban la demostración de su habilidad técnica. Esto era muy importante en la época, pues se esperaba que los pianistas tengan la capacidad de improvisar sobre temas determinados (Woodring Goertzen, 1998). Clara Schumann hizo un esfuerzo por documentar lo que había conseguido a través de la improvisación, probablemente porque ese era uno de los requerimientos de la época. Es de remarcar que el análisis está hecho a partir de obras escritas, lo cual podría ser un contrasentido. Sin embargo, el modo en que el autor propone el análisis de los preludios permite reconocer las características de las improvisaciones de Clara en el pasado, ya que además observa la manera en que ella inicia sus estudios, cómo realiza sus conciertos y en ellos, el lugar que le da a la práctica improvisada; todo en ese contexto histórico de comienzos de siglo XIX.

Racy (1998) estudia los procedimientos improvisatorios que tienen lugar en la música instrumental de cuerda pulsada en el norte de la India, particularmente del sitar. A partir de ello, observa que hay un conjunto de procedimientos sistematizados en la práctica improvisada, intrínsecos a la performance, que son enseñados y ejercitados, para que luego el músico pueda combinarlos durante el proceso de 'crear piezas musicales' (Racy, 1998). Este autor se interesa además por la creatividad en dicho proceso. Al respecto, plantea:

información adquirida. Hall (1976) agrega que estos cambios refieren a todo lo que hacen los seres humanos, incluyendo la música. 
"La improvisación en la música del norte de la India es un procedimiento complejo que incluye piezas fijas precompuestas, patrones ensayados, la creación espontánea de material nuevo basado en modelos convencionales -tanto en el campo paradigmático como en el sintagmático-, la creación espontánea de material nuevo mediante 'programas' dinámicos y generativos, la creatividad interactiva en la que interviene una retroacción entre el solista y el acompañante, entre los intérpretes y el público, y, por último, la consciencia introspectiva de nuestra propia actividad y expresividad compositiva durante el acto de la creación musical" (Racy, 1998; p. 345).

Sobre este mismo aspecto, Gushee (1998) se pregunta acerca de la música de Louis Armstrong (1901-1971). Sostiene que el trompetista causa un fuerte impacto no sólo por su creatividad, personalidad, versatilidad y habilidad técnica, sino también por combinar todo ello con un 'swing louiseano', que aunque no era un rasgo exclusivamente suyo, pero aparecía en todas sus interpretaciones: quizás esa combinación haya sido la gran contribución de Amstrong al jazz de esa época. También es motivo de estudio otro personaje posterior a Amstrong en el ámbito del jazz, como fue Miles Davis (1926-1991). Al parecer, la creatividad de Davis radicaba en manipular las situaciones de ensayo o de concierto, logrando la utilización de todos los parámetros allí presentes, manejando el 'mundo posible' dentro de una interpretación (Smith, 1998). Por su parte, John Coltrane (1926-1967) y George Russell (1923-2009) también han sido objeto de análisis, ya no por su creatividad, sino por las connotaciones del jazz modal, del que ambos son considerados referentes (Monson, 1998). Russell creó una teoría de organización modal basada en teorías de la música occidental, mientras que Coltrane se interesó mucho en ello y lo desarrolló al máximo, contribuyendo no solo en lo musical sino en lo espiritual y en la identidad del jazz modal. Ingrid Monson es además autora de otra obra importante en el ámbito de la etnomusicología. "Diciendo algo: improvisación e interacción en jazz" (1996), plantea la hipótesis de que la improvisación en jazz encierra un complejo proceso social, técnicamente especializado y multidimensional, que permite una forma de comunicación. Monson (1996) incluye descripciones sobre el rol de cada instrumento en la performance jazzística y exhibe síntesis teórica, ética y metodológica del estudio del jazz en la cultura afroamericana. También desde la esfera del jazz, Paul Berliner ofrece en "Pensando en jazz. El arte infinito de la improvisación" (1994) su visión sobre las problemáticas que acarrea la improvisación en el jazz. Opina que el común de los escritores e investigadores no conoce realmente la habilidad improvisatoria y por ello caen en descripciones inexactas sobre la improvisación. Propone dar respuesta a este dilema partiendo de una exploración de la creatividad en el jazz abordada desde los diversos ángulos etnomusicológicos, considerando que allí encontrará los rasgos principales que pueden servir para caracterizar esta habilidad. Sus ideas son formuladas por fuera de una mirada eurocentrista de la música, por considerar inicialmente que la distancia entre los modos de hacer música en la

\footnotetext{
${ }^{5}$ En el original: Saying something: jazz improvisation and interaction.

${ }^{6}$ En el original: Thinking in jazz. The infinite art of improvisation.
} 
tradición europea y en el jazz, puede jugar en contra de jazz, en desmedro del mismo. Es importante destacar que las obras aquí descriptas, aunque se dediquen al estudio de la improvisación únicamente en el contexto del jazz, plantean el estudio desde una perspectiva que tiene en cuenta los distintos componentes que afectan al desarrollo de la improvisación. Por eso, formulan escritos completos, abarcadores, que tienen la voluntad de atender a todos los elementos que necesariamente participan de este hecho.

Más recientemente, Gabriel Solís y Bruno Nettl editan Improvisación musical: arte, educación y sociedad"” (2009) que bien puede considerarse una continuación de la publicación que Nettl editó junto a Russell en 1998, recientemente mencionada. Al igual que en su antecesor, en este libro se presentan tres partes en las que se analiza la improvisación desde diferentes perspectivas, aunque los enfoques son substancialmente diferentes. Así, algunos autores se interesan más por las características del proceso creativo, otros por el pedagógico y otros, por las consecuencias políticas de la intromisión de las prácticas improvisadas en distintos contextos. Por eso, en esta obra encontramos desde un típico capítulo que examina la improvisación en el jazz hasta aquellos capítulos que indagan el contenido improvisado en música árabe, en obras de compositores como Cage, Mozart, Beethoven, Chopin y Schumman, en prácticas recitadas, tal como es el caso de los lamentos en los funerales ucranianos y de la oratoria del Corán, y hasta en una clase de danza. Aquí reside su valioso aporte, que en concordancia con el libro de Netll y Russell, ofrece una amplia visión de la improvisación, evitando reduccionismos y acotaciones de la misma al género del jazz; planteando por el contario, la presencia de la improvisación en diversos géneros y estilos de músicas del mundo e incluso, en prácticas no musicales correspondientes a momentos históricos disímiles. Además, este texto parte del reconocimiento de la estrecha relación entre improvisación y composición, criticando a la literatura académica sobre el tema, argumentando que sólo se ha ocupado de (i) caracterizar la improvisación; (ii) comparar proceso y producto improvisado; y de (iii) indagar los procedimientos frecuentemente utilizados en esta práctica ${ }^{8}$, dejando muchos interrogantes sobre la delimitación del concepto y las influencias del contexto en el que se efectúa dicha práctica. Por ejemplo, en la sección sobre los aspectos políticos, Monson (2009) comienza afirmando que la relación entre la música y la sociedad inevitablemente implica una relación política, que suscita un doble conflicto. Por un lado, está la relación entre la música y cuestiones sociales más generales como el poder, la ideología y la hegemonía. Por el otro, habita la relación entre el acto de hacer música y los temas sociales más locales, como la construcción de comunidades, la resistencia política y los significados simbólicos. La autora identifica la primera de estas relaciones con el ámbito

\footnotetext{
${ }^{7}$ En el original: Musical Improvisation: art, education and society.

8 Estos procedimientos son recursos compositivos que colaboran durante la elaboración de la improvisación. Por ejemplo, en el jazz, los patrones (patterns) son estructuras rítmico-melódicas susceptibles de ser utilizadas literalmente, variadas y ornamentadas. En cambio, en la música hindú, el raga es una estructura fija, pero el improvisador puede elegir el modo en que los combina.
} 
académico de enseñanza de la música, mientras que considera que la segunda se desarrolla en un contexto bastante más pequeño y disgregado de aprendizaje no formal; $y$ observa que esto traería como consecuencia un funcionamiento político dispar del jazz en cada espacio. De ahí que se propone analizar el alcance que tiene esta relación en la práctica. Otro ejemplo, ya no en una práctica musical, es el escrito que efectúa Kononenko (2009) sobre el arte verbal en Ucrania, preguntándose acerca de las actitudes hacia la improvisación que poseen los oradores. Esta autora plantea que esas actitudes pueden interpretarse como positivas o negativas, lo cual influye en las relaciones entre los distintos miembros de una sociedad. En cambio, la sección destinada a los enfoques pedagógicos, integra estudios que analizan programas de enseñanza de la improvisación en jazz (Murphy, 2009), música de Mozart (Levin, 2009) y música instrumental en la India (Slawek, 2009), que profundizaremos en uno de los próximos apartados. Por su parte, la sección dedicada a las particularidades del proceso improvisatorio, las preguntas giran en torno a las implicancias del tal proceso en distintos estilos musicales que ocurrieron en lugares y momentos históricos disímiles (ver por ejemplo Gushee, 2009; Hatten, 2009; Racy, 2009). Sin embargo, en estos textos todavía resta por esclarecer el modo en que las características de los distintos contextos donde se desarrollan las improvisaciones influencian tanto el proceso como el producto que allí se genera, a partir de ejemplos concretos, comparando performances surgidas en un mismo contexto.

A pesar de las limitaciones que poseen los ejemplares que citamos en este apartado, su aporte principal reside en evidenciar los comportamientos improvisatorios en un conjunto importante de tradiciones musicales, abonando a la idea de que esta práctica no es sólo propia del jazz, sino que también se desarrolla en músicas de distintos estilos y lugares del mundo, y con ello, nos anima para comenzar en el estudio de la improvisación en estilos diferentes al jazz.

\section{PREPARACIÓN PARA LA IMPROVISACIÓN VS. CREATIVIDAD, ESPONTANEIDAD Y LIBERTAD}

Como adelantábamos en la introducción, algunas definiciones de improvisación musical consideran la posibilidad de que antecedan a la performance improvisada algunas instancias de preparación. En esta línea, Bailey (1992) expresa abiertamente que es común encontrar que los músicos se preparan para cualquier tipo de improvisación (p. 35), y que esto parece ser algo que varios autores se encargan de negar. Pressing $(1987,1988,1998)$ explica que durante la improvisación se ponen en juego dos elementos centrales, que denomina base de conocimiento y referente. En su definición, afirma que la base de conocimiento está compuesta por materiales que el músico aprende previamente bajo la práctica sistematizada y deliberada. Kenny y Gellrich (2002) emplean una concepción similar sobre cómo se construye la base de conocimiento (ver pág. 33). Es por el alcance que le dan a la base de conocimiento que las definiciones que brindan estos autores parecen inclinarse por el hecho de que la improvisación pueda nutrirse y ser influenciada por una etapa de previa de preparación. Con esta explicación estarían quitando, en parte 
al menos, la idea de que la improvisación sea espontánea, original y creativa, que como veremos a continuación, otros autores toman para su definición.

Algunas explicaciones sobre el desempeño improvisado suelen adjetivarse con conceptos tales como creatividad, espontaneidad y libertad. Sin embargo, podríamos plantear algunos argumentos para comprender porque estos términos no están necesariamente involucrados en la improvisación. Distintas concepciones sobre el pensamiento creativo dan lugar a una serie de teorías que intentan delimitar y explicar el concepto de creatividad, atendiendo a varios aspectos. En general, este grupo de teorías se encarga de examinar que sucede, en términos de rasgos psicológicos, aptitudes o capacidades, en la resolución de un problema. Por un lado, las teorías que defienden la idea de que los procesos creativos son procesos diferentes a los que nos vemos sometidos habitualmente en cualquier tarea, consideran la creatividad como el resultado de los rasgos y facultades que le confieren a un individuo un alto grado de genialidad a la hora de realizar sus creaciones (Weisberg, 1987). Esto significa que asumen que la creatividad depende de un tipo de pensamiento extraordinario. Por el otro lado, se encuentran aquellas teorías en las que la creatividad se vincula con procesos de pensamiento a los que todos los individuos tendrían igual acceso, es decir, un tipo de pensamiento ordinario. Aquí nos inclinamos por esta última postura, entendiendo que ser creativo supone atravesar un proceso en el que convergen múltiples variantes, pero que no por ello se transforma en un pensamiento extraordinario, sino que por el contrario, se considera un proceso de pensamiento ordinario determinado por un cúmulo de componentes. Por ejemplo, pensemos en la tesis de las variaciones de Hofstadter (1981), ya que sienta de maravillas para la improvisación. Este autor afirma que los hechos creativos aparecen por el deslizamiento que sufren algunos componentes básicos de una determinada tarea. En palabras de Hofstadter,

"Una forma de imaginar cómo podría materializarse en la mente esta noción de deslizabilidad o corrimiento, es suponer que cada concepto cobra vida como compuesto de conceptos previos y que la deslizabilidad de estos conceptos hereda a su vez cierto grado de deslizabilidad" (Hofstadter 1981, p.112).

En la música, esta tesis tiene su punto de convergencia con varias teorías psicológicas sobre el proceso improvisatorio, todas ellas, motivo de uno de los próximos apartados. Por ejemplo, durante la improvisación el músico selecciona y combina elementos previamente aprendidos, a partir de criterios específicos (Johnson Laird, 1991); trabaja en función de una base de conocimiento que regula a partir de sus características internas y un referente, en función de las particularidades externas, es decir, del contexto (Pressing, 1998; Kenny y Gellrich, 2002). Sin embargo, el empleo de estos componentes parece no alcanzar para que la improvisación sea clasificada como creativa. De acuerdo con Hofstadter (1981), se podría sugerir que aquella improvisación en la que se produce un deslizamiento de los conceptos aprendidos por el músico, puede ser juzgada como creativa. 
Con respecto a la espontaneidad, de acuerdo con la vigésimo segunda edición del diccionario de la Real Academia Española, el adjetivo espontáneo remite a algo que "se produce aparentemente sin causa". La palabra 'apariencia' otorga a la definición cierto grado de incertidumbre. Luego, natural, voluntario, sencillo, abierto y desenvuelto, aparecen como sinónimos de espontáneo. También ahí hay algo dudoso, porque alguien puede ser natural y desenvuelto cuando sabe con seguridad los pasos a seguir, cuando tiene automatizada cada etapa; entonces sí hay una causa, por caso, la preparación, el entrenamiento, etc. Pensemos en el caso del lenguaje que mencionamos en el apartado anterior. Si no tuviéramos claras las palabras, frases y reglas gramaticales básicas, no podríamos hablar fluidamente, directamente, no podríamos hablar. En el caso de la improvisación, también es necesario el conocimiento de motivos, frases y reglas de composición musicales. Ellos configuran una condición sine qua non para improvisar. Quizás la confusión viene por los sinónimos 'abierto', 'sencillo' y 'voluntario, que expresan significados que bien pueden ser privativos de la improvisación o no. Digamos que, no necesariamente una improvisación es sencilla, ya que como sucede en los solos de Miles Davis (1926-1991), Bill Evans (1929-1980) o Keith Jarrett (nac. en 1945), por citar sólo algunos casos dentro del ámbito del jazz, se puede observar un alto grado de complejidad, dada por la conjunción de varios factores (por ejemplo, alta densidad cronométrica, amplia inclusión de notas ajenas, cromatismos y adornos). Inevitablemente, la improvisación puede no ser abierta, cuando denota la repetición de un patrón sobre una misma base armónica; o como sucede en la música del gamelan javanes, cuando las formas son fijas y lo importante desde el punto de vista estético no es variarlas, sino combinar y organizarlas (Anderson Sutton, 1998). Con respecto a lo voluntario, acaso, ¿es propio de la improvisación? Es tan exclusivo como lo es de hablar, tocar, caminar, mirar, entre otros. Abreviando, referir a la improvisación en términos de espontaneidad, lo sitúa en el peldaño del pensamiento extraordinario. En contraposición, nos inclinamos hacia la idea de que lo espontáneo puede ser interpretado como un tipo de pensamiento ordinario, que guarda estrecha relación con la experiencia previa del sujeto: el sujeto es espontáneo, o mejor dicho, realiza una tarea que puede clasificarse como espontánea, porque ha aprendido qué cosas debe acentuar, agregar o quitar para hacerlo.

Veamos ahora, desde un punto de vista filosófico, de qué manera se vinculan con la improvisación algunos de estos conceptos. Por ejemplo, Nachmanovitch (1990) ofrece una definición de improvisación musical que parte de la descripción de cuatro elementos centrales: (i) las fuentes, que incluyen todo aquello que pueda constituirse en el material de una improvisación (desde sentimientos e imágenes hasta patrones melódicos); (ii) la obra, entendida a través de las limitaciones, los errores y la forma que emergen en el transcurso de una improvisación; (iii) obstáculos y aperturas, que reúne tanto las sensaciones como las acciones del improvisador; y (iv) los frutos, donde se intenta una concientización del improvisador respecto de su obra, la calidad que posee y el impacto que genera. Curiosamente, algunos de estos elementos tienen un correlato con algunas propuestas de corte psicológico sobre el tema. Por ejemplo, las fuentes pueden conformar lo que ha sido denominado base de conocimiento (Pressing 1987, 1998; Kenny y Gellrich 
2002); y la obra, en términos de limitaciones, puede ser entendida como las características externas del proceso improvisatorio, socioculturales, mientras que las internas se vinculan con el proceso psicológico que transita el músico (Kenny y Gellrich, 2002). Nachmanovitch (1990) sostiene que la improvisación es un componente primordial de nuestra vida diaria, ya que en las actividades cotidianas también debemos decidir, combinar y correr riesgos, haciendo de la improvisación un modo de vida. Es verdaderamente importante para este autor el concepto de juego en ello, como una de las posibilidades más veneradas que ofrece la improvisación para su desarrollo. En cambio, los conceptos de libertad y creatividad, tan típicamente asociados a la improvisación, no gozan de la misma valoración en su obra. A partir de variadas preguntas, por ejemplo, cómo se aprende a improvisar; qué impide hacerlo; cómo equilibrar estructura, espontaneidad, disciplina y libertad ( $p$. 19), Nachmanovitch alcanza a una definición de improvisación que pone el énfasis sólo en las vicisitudes que atraviesa el músico en esta práctica. En otras palabras, este autor se ocupa de esclarecer los aspectos internos, propios del sujeto que improvisa, que involucra la práctica de improvisar. Al igual que algunos autores dentro del ámbito de la etnomusicología, Nachmanovicht también observa que la improvisación ha sido una práctica frecuente por lo menos desde el siglo XVII en las tradiciones de música occidental y reconoce su existencia en músicas de distintas partes del mundo actuales. En concordancia con su planteo, Peters (2009) brinda su perspectiva de la improvisación acudiendo a diferentes elementos que considera indispensables para dicha práctica. Así, la libertad, el origen, la ironía, la mímesis, la crueldad, la creación y la renovación son elementos vitales de la improvisación, que se configura así en un modo de pensamiento musical que se caracteriza por tener una dosis mínima de cada uno de estos elementos. Desde su punto de vista, la improvisación es un tipo de performance que se origina en libertad, y a partir de allí permite ironizar lo hecho, imitarlo, con caridad o con crueldad, o renovarlo, así como también permite crear algo diferente; es una práctica influenciada por las condiciones materiales, técnicas, políticas y estéticas. Consecuentemente, sugiere que la improvisación 'no parte de la nada', sino que implica re-apropiarse, asociarse con las formas culturales anteriores, y en este sentido, implica una renovación, preguntándose desde el presente hacia el pasado. Si bien Peters (2009) no ofrece una definición de la improvisación, brinda en su análisis un enfoque que permite describirla atendiendo a estos conceptos.

\section{IMPROVISACIÓN COMO ACTIVIDAD A CONOCER}

Desde un punto de vista pedagógico, se ha considerado que la improvisación puede ser una habilidad que puede desarrollarse a través de ciertas instancias de aprendizaje, siguiendo una serie de pasos y/o etapas, que persigan el objetivo de alcanzar un grado de desarrollo de la habilidad considerado superior. Como consecuencia de estas ideas han surgido numerosos métodos de aprendizaje y entrenamiento de la improvisación, claro, que sobre la base de una definición de improvisación que por un lado, atiende a los materiales necesarios para improvisar (esto es, aquellos que conforman la base de conocimiento); y por el otro, a los conceptos señalados en el apartado anterior. Por 
ejemplo, sobre el final del siglo XIX, el compositor y pedagogo suizo Emile Dalcroze (18851950) creó un método que bautizó con su apellido, en el que pretendía que los niños puedan acercarse a la música de un modo creativo. Dicho método nació de la unión de tres elementos primordiales: el movimiento, el solfeo y la improvisación. Dalcroze procuraba allí el desarrollo musical del niño a través de la gimnasia rítmica', sea el desarrollo del oído musical o el desarrollo instrumental. Continuando en esta línea, una de las precursoras en Argentina que se ha dedicado a estudiar e introducir la improvisación en los métodos de enseñanza musical es la reconocida pedagoga Violeta Hemsy de Gainza (nac. en 1930). A diferencia de Dalcroze, Gainza ha partido de la analogía entre el habla en el lenguaje verbal nativo y la improvisación en el lenguaje musical y a partir de ello, ha propuesto una didáctica de esta práctica, dispuesta en un orden creciente de conocimientos (Gainza, 1983). Otra autora que también intentó la inclusión de la improvisación, específicamente en el campo de la educación audioperceptiva, fue Emma Garmendia (1929-2012). Esta autora proyectó un cambio en las conductas de los alumnos, desde una postura sumamente pasiva hacia una activa, atendiendo a la intuición, al contenido emocional y afectivo del alumno. Por eso, las metodologías para la educación del oído musical que formuló, comprendían el uso de distintos movimientos para el aprendizaje de diversos parámetros del lenguaje musical, de la improvisación melódica, rítmica o ambas, y del arreglo vocal y vocal e instrumental a una, dos o más voces (Garmendia, 1981). La crítica que puede hacerse a estos métodos es en el cómo promueven el uso del cuerpo. Si bien intentan sortear el paradigma cartesiano proponiendo la unión entre la mente y el cuerpo, finalmente terminan poniendo al cuerpo al servicio de la mente. Esto queda evidenciado cuando reducen el rol del cuerpo a la realización de tareas ordenadas por la mente, ella es la que sigue gobernando el proceso cognitivo. Esto bien puede ser observado en los enunciados de estas propuestas teóricas y en el modo en que se solicita se pongan en práctica las diferentes actividades propuestas para el aprendizaje musical.

Procurando nuevas perspectivas pedagógicas sobre el tema, Kenny y Gellrich (2002) proyectan una aplicación del modelo de procesamiento mental que desarrollan para la improvisación musical (ver pág. 33). Estos autores aseveran que el control atencional consciente presenta limitaciones, pues no sería posible controlar conscientemente dos aspectos diferentes durante la práctica improvisada. Dicho de otro modo, mientras un aspecto monopoliza el control consciente, el otro, procede de forma subconsciente. Viendo estas limitaciones, proponen que la enseñanza de la improvisación necesita ser dividida en distintas áreas que desarrollen sistemática y paralelamente los aspectos que convergen en la improvisación musical. Al igual que Gainza, recurren la comparación entre música y lenguaje, remitiendo al uso de reglas en uno y otro. Además, plantean que la inspiración para la improvisación, puede ser un derivado de recursos presentes en otras

\footnotetext{
${ }^{9}$ El sentido del buen ritmo o eurhythmics es para Dalcroze un componente ineludible en el proceso de desarrollo musical del niño y está dado a partir de sus movimientos espontáneos, que le permiten desarrollar habilidades y comprender los diferentes parámetros que intervienen en el lenguaje musical.
} 
áreas, como la danza, la poesía, el cine, los comics y la pintura. Es por eso que proponen que una pedagogía de la improvisación debería ser abordada de modo interdisciplinario y le correspondería ganar en una instrucción que combine los mejores aspectos de la práctica deliberada con los conceptos teóricos culturalmente establecidos. Básicamente, la propuesta consiste en la realización de pasos sucesivos y progresivos, pero también simultáneos e interconectados: (i) entrenamiento de lo que estos autores denominan el hardware (progresiones acórdicas, patrones, digitaciones, procesos sobre los acordes ${ }^{10}$ ) y el software de la improvisación (creación de motivos, frases y melodías, estructuras breves y extensas, coordinación melodía y acordes, melodía y bajos); (ii) ejercicios para estimular la creatividad (durante la aplicación de hardware y software); (iii) improvisaciones asociativas (al cuerpo, movimiento, pinturas, películas, etc.); y (iv) ejecución y análisis de composiciones (para aprender el hardware y el software de cada estilo y luego, generar ideas para la improvisación). Estos pasos pueden sucederse, pero para los autores es más beneficioso que se presenten interrelacionados, considerando que cada uno puede ejercer su influencia en el desarrollo del otro.

Asimismo, aunque desde el marco etnomusicológico, otros autores han dado su opinión sobre los aspectos educacionales y pedagógicos de la improvisación. Escuetamente, Bailey (1992) observa la dificultad de enseñar improvisación, afirmando que los profesores instruyen sobre cómo improvisar más a partir del relato de su propia experiencia como improvisadores que a través de un método. Por su parte, Campbell (2009) sugiere que en la improvisación ocurren tres fenómenos igualmente importantes: (i) improvisar para aprender música, supone que durante esa práctica es posible comprender los distintos aspectos que constituyen la música; (ii) aprender a improvisar música, expresa la especificidad de la práctica; y (iii) improvisar música para aprender, que conlleva el aprendizaje sobre uno mismo, sobre los demás y sobre lo que hay detrás de la propia música (Campbell 2009, p. 120). En cambio, Murphy (2009) nota que en los programas de enseñanza de jazz en la Universidad del Norte de Texas, si bien hay algunos aspectos que deberían ser modificados, ofrecen una educación en el marco del jazz que combina una variedad de experiencias dentro y fuera del currículum, que reflejan lo que sucede a nivel cultural y permiten el desarrollo y la búsqueda individual. Finalmente, es en el contexto de la ópera cantonesa en China donde se afirma que la improvisación es esencial para el desarrollo de la ópera, pero no se aprende de los maestros (Chan, 1998). Lo interesante de estos estudios es que se centran más en la experiencia del improvisador, en relación con las características contextuales.

También Berkowitz (2010) dedica casi enteramente la primera parte de su último libro 'La mente improvisando" a la pedagogía de la improvisación. Uno de ellos es propuesto

10 En la literatura de jazz, el proceso de producir distintos ordenamientos de las alturas que componen los acordes, tanto en el plano horizontal como en el vertical, recibe el nombre de voicing.

${ }^{11}$ En el original, The improvising mind. 
desde una perspectiva histórica, ya que estudia los prerrequisitos para improvisar en distintos tratados publicados entre mediados de siglo XIX y principios de siglo XX. Sería interesante utilizar su método para indagar, ya no en los tratados, sino en los espacios donde se enseña la improvisación, observando el modo en que las instrucciones, las acciones y los propósitos exhiben los prerrequisitos que subyacen en esa enseñanza. Otro capítulo, denomina estrategias pedagógicas a la transposición, la variación y la recombinación ${ }^{12}$; y observa las implicancias que el uso de las mismas tendría en lo cognitivo, en términos de memoria y de ahorro de recursos cognitivos. Otros autores han planteado que tales recursos pueden ser entendidos como mecanismos que favorecen el procesamiento cognitivo que suscita la improvisación (Johnson Laird, 1991; Pressing, 1998). Además, se advierte la presencia de estos mismos recursos en diferentes tradiciones de improvisación musical. Se encarga también de analizar las capacidades de aprendizaje de la mente humana utilizadas en el desarrollo de este tipo de experticia ( $p$. 81), partiendo de la comparación entre un conjunto de estudios sobre el proceso de aprendizaje de la improvisación en diferentes culturas. Allí, el autor identifica tres aspectos comunes que tienen lugar en dicho proceso: la incubación (también llamada internalización y asimilación), el ensayo y el desarrollo conseguido posteriormente a través de los actos de improvisación (p.82). Entre esos aspectos, se destacan la práctica deliberada (fórmulas, patrones), la consciencia (al menos al comienzo) de las reglas (del estilo, del lenguaje musical), y la relevancia de lo armónico y lo sintáctico como aspectos ineludibles para aprender a improvisar. Concluye en que primeramente hay un proceso de memorización de un pequeño repertorio de patrones y formulas que luego, van siendo internalizados y configuran lo que este $\mathrm{y}$ otros autores denominan la base de conocimiento (Pressing, 1998; Kenny y Gellrich, 2002).

\section{IMPROVISACIÓN COMO MODO DE CONOCIMIENTO}

Eleanor Stubley (1992) presenta el concepto de modo de conocimiento musical no proposicional. Allí, sostiene que la música es un dominio cognoscitivo que incluye, en principio, tres diferentes modos no proposicionales de conocimiento: la audición, la composición y la ejecución. Sin embargo, la autora menciona además una modalidad cognoscitiva particular, la improvisación, que se halla en la intersección de los modos de ejecución y composición, y sugiere, de esta manera, el origen de una vía de conocimiento de la música independiente (Stubley, 1992). Más allá de constituirse epistemológicamente como modo de conocimiento, es válido decir aquí que la improvisación puede ser entendida como una actividad que pone en juego y aúna los modos básicos propuestos por Stubley. Veamos entonces alguno de los vínculos posibles entre las distintas modalidades no proposicionales de conocimiento musical. El concepto de improvisación se asocia directamente a la noción de composición en tiempo real (Norro, 2008). Es complejo abordar el alcance de este concepto, en primer lugar porque su uso es relativamente reciente (todavía se mantiene un debate acerca de su significación) y en segundo lugar por

\footnotetext{
${ }^{12}$ En la literatura clásica musical, estos elementos son denominados recursos o procedimientos compositivos.
} 
la naturaleza propia de los términos compuestos. El mismo ha sido acuñado para nombrar una práctica particular que aúna dos modos de conocimiento musical diferentes, como lo son la composición y la improvisación, pero estrechamente relacionados. La composición en tiempo real refiere por un lado, a la tarea por parte del compositor de "estructurar el material sonoro en una forma coherente y orgánica" (Norro, 2008; p.203) y por el otro, a la efectuada por el improvisador en relación a la dimensión temporal, donde "el tiempo de concepción y el de ejecución se unifican" (Norro, 2008; p.203). Para lograr una comprensión cabal del concepto de composición en tiempo real, podríamos observar las semejanzas y diferencias entre los modos de conocimiento musical que lleva implícitos. En la composición, el compositor puede someter su obra a revisión una o más de una vez de manera continua o interrumpida, ya sea a través de lo que ha escrito, de lo que tiene registrado en su memoria, o de lo que ha grabado. En la improvisación, el improvisador realiza su performance e indefectiblemente la misma se transforma en la obra. Además, en general, no se utiliza algún tipo de notación previa que la ordene, aunque a menudo puedan existir esquemas de acción o planes predeterminados, tales como ocurre por ejemplo en el lenguaje del Jazz, con los estándares. Así, mientras que en la composición, se puede escribir, reeditar y corregir, porque se dispone del tiempo necesario, en la improvisación, sucede lo contrario, porque, generalmente, no queda un registro escrito de lo que se ejecuta; la performance debe garantizar los valores de coherencia y unidad en una acción directa con acuerdo a la lógica de la secuencia dada, y la adscripción al estilo determinado. De este modo, resulta relevante el hecho de que la improvisación conlleva de manera implícita a la composición, pero con la característica particular de su formulación instantánea dentro la realidad musical. Por otra parte, la práctica de la improvisación ofrece un feedback perceptual inmediato. Entonces, el músico escucha lo que toca, recuerda lo que ha escuchado y continúa el curso de su improvisación influido por esa escucha. En la composición, el proceso de feedback es de naturaleza conceptual y reflexiva, porque el compositor repasa los diversos aspectos estructurales de la obra a partir de su background conceptual. Es por eso que no existe un feedback perceptual real. En cambio, cómo se sugiere anteriormente, en la improvisación los procesos de composición y ejecución suceden de manera simultánea (Norro, 2008; p.203). Sin embargo, en la improvisación parecería ser necesaria una capacidad de reacción inmediata y destreza técnico-instrumental que es prescindible en la composición. Partiendo de la hipótesis de que un modo de conocimiento musical podría influenciar el desarrollo de otro, en este caso la improvisación incidiría en el avance de la audición, se han llevado a cabo distintos experimentos (Assinnato, 2009; Assinnato, 2010; Assinnato y Silva, 2010a; Assinnato y Silva, 2010b) en los que se pudieron observar diferentes cuestiones, comparando los desempeños en la transcripción de una melodía luego de efectuar tareas de improvisación, de lectura y de imitación. En primer lugar, quizás la transcripción no sea la mejor herramienta para la medición de tal influencia, ya que se cuelan otras variables (como el uso del código escrito y la desvinculación entre ese código y la improvisación). Sin embargo, fue posible advertir que la improvisación puede tener una incidencia en comprensión por audición de la estructura musical (Assinnato, 2009) y que pudo contribuir 
al desarrollo de aspectos melódicos, rítmicos y estructurales de acuerdo con el pensamiento metacognitivo de los músicos (Assinnato, 2010). En segundo lugar, se observó que, probablemente, no sea posible estudiar el modo en que incide un modo en otro en una tarea de esta naturaleza, apareciendo así la necesidad de examinar tal cuestión en un procedimiento a largo plazo (Assinnato y Silva, 2010a). Por último, se sugirió la improvisación implicaría unos requisitos diferentes de los que supone una tarea de lectura y a una de imitación, y se avanzó en la descripción de tales requisitos (Assinnato y Silva, 2010b), dado que representarían micro-modos de conocimiento musical, dentro del conocimiento de la ejecución.

\section{LA HABILIDAD DE IMPROVISAR}

\section{IMPROVISACIÓN Y LENGUAJE VERBAL}

Existe amplio consenso sobre la idea de que la improvisación sostiene una estrecha vinculación con el lenguaje hablado (Gainza, 1983; Molina, 1998; Terrazas, 2006; Johnson Laird, 2002; Berkowitz, 2010). De hecho los estudios en pragmática abordan el análisis de muchos elementos que pueden considerarse afines a la problemática de la improvisación en música. Pensemos cómo hacemos para llevar a cabo una conversación con otra persona: mientras escuchamos lo que nuestro interlocutor pregunta, procesamos y casi instantáneamente elaboramos una respuesta coherente; debido a que comprendemos cada silaba, cada palabra, el sentido de las frases, los modismos típicos, etc., del idioma en el que hablamos. En este sentido, lenguaje verbal e improvisación encuentran un punto en común y así, muchas formas de improvisación pueden pensarse como una conversación musical entre sujetos, puesto que los ejecutantes manejan un mismo código, el lenguaje musical, mediante el cual se comunican. Al utilizar el lenguaje verbal cotidiano hacemos uso de diferentes estructuras ya adquiridas, que van modificándose a medida que lo creemos conveniente para proseguir con la conversación. Se supone que la improvisación es un proceso similar en este sentido, ya que en el acto de improvisar procedemos con estructuras previamente aprendidas, combinándolas y variándolas, de acuerdo a nuestros intereses y posibilidades. De esta relación se desprenden algunas propuestas respecto de la utilización como recurso en la enseñanza y el aprendizaje de la música. Por ejemplo, el pedagogo español Emilio Molina (1998), propone pensar el proceso de enseñanza y aprendizaje del lenguaje musical en comparación con el desarrollo de la adquisición de una lengua extrajera. $Y$ en este sentido, plantea que en la enseñanza de un idioma, existen tres conceptos bien diferenciados: hablar, leer y escribir (Molina, 1998). En relación al lenguaje musical, observamos que históricamente en los ámbitos de educación musical, se ha puesto el acento en el leer y escribir; pero no en el 'hablar musicalmente' que podría ser tomado como sinónimo de improvisar.

Más recientemente, Berkowitz (2010) analiza cómo ocurre la adquisición y la producción en el lenguaje verbal y en el lenguaje musical, estableciendo paralelismos y analogías entre ambos. Sostiene que el factor común entre la adquisición del lenguaje verbal y del 
lenguaje musical es que en ambos se adquieren esquemas, únicamente, a través de la producción. Encuentra que mientras el lenguaje verbal incluye la fonología, la morforlogía, la sintaxis, la semántica y la pragmática; el lenguaje musical presenta un correlato para estos componentes. Es por eso que en el nivel fonológico en la música nos encontramos con alturas, intervalos, duraciones y timbres; en el morfológico y semántico, con formulas y esquemas; y en el sintáctico y pragmático, con convenciones estilísticas y con un rango de variaciones y posibles combinaciones. Posteriormente, considera la existencia de analogías claras entre los procesos que involucran hablar e improvisar, ya que ambos implican conceptualizar, formular, articular, monitorearse y reparar si algo no saliera bien. De modo similar a los planteos que describíamos en el párrafo anterior, Berkowitz presenta la comparación entre el proceso de producción en la improvisación y el de producción en un lenguaje foráneo. Para finalizar, propone que la los procesos involucrados en la producción en el lenguaje verbal y en el musical, podrían superponerse, esto significa que podrían compartir, por ejemplo, recursos para la producción sintáctica.

\section{LA IMPROVISACIÓN COMO PROCESO PSICOLÓGICO}

Un grupo considerable de autores se han encargado de formular planteos que atañen a la improvisación como proceso psicológico. Entre ellos, vamos a mencionar los autores que han sido más elocuentes para la génesis de esta tesis. En primer lugar, vamos a revisar los escritos del compositor, músico e investigador austríaco Jeff Pressing (1947-2002), especialmente las publicaciones de 1984, 1987 y 1998, debido a que son los estudios más interesantes dedicados a la temática. En segundo lugar, consideraremos las propuestas del psicólogo cognitivista inglés Philip Johnson Laird (1991, 2002), que si bien no tiene una prolífera actuación en este campo, en estos escritos se ocupa de indagar y explicar detalladamente cómo la mente humana es capaz de improvisar. Por último, presentaremos una reseña del planteo, breve pero substancioso, de Kenny y Gellrich (2002). Pressing (1984) comienza preguntándose cómo la gente improvisa, como aprenden la habilidad improvisatorio y cómo se origina el nuevo comportamiento. A partir de allí, caracteriza las propiedades que posee el proceso cognitivo que involucra la improvisación, sobre la base de escritos musicológicos, pedagógicos y de distintos artistas; y los conceptos de la ciencia cognitiva clásica, en pos de establecer una teoría general de la improvisación musical. Es en el artículo de 1987, donde luego de una descripción minuciosa de los aspectos que implica la improvisación, que este autor presenta su teoría sobre el comportamiento del improvisador. Dicha descripción muestra que el comportamiento del improvisador (y del músico en general) incluye acciones musculares, rapidez visual, táctil y propioceptiva, producción sonora traducida a representaciones cognitivas y evaluaciones y procesos cognitivos amplios que permiten generar y designar la próxima acción a realizar. Pressing se ocupa básicamente de estos dos últimos ítems, ya que afirma que las diferencias entre improvisar y tocar una 'performance fija' (p. 2) probablemente se hallen en esos puntos, partiendo de que es posible establecer analogías entre lo que sucede en la conducta improvisatoria en términos psicológicos y lo que sería un modelo de procesamiento de información sobre comportamiento humano. Por esto, 
expresa que el comportamiento improvisatorio comienza con la entrada de información a través de los órganos sensitivos; continua con el procesamiento y toma de decisiones que está a cargo del sistema nervioso central; y finaliza con la salida de la información procesada, llevada a cabo por algunas glándulas y el sistema muscular ${ }^{13}$; participando en dicho comportamiento diferentes tipos de feedback (auditivo, visual, táctil y propioceptivo). Este comportamiento está afectado por el desarrollo motor y la capacidad del sujeto en términos de corrección de errores, memoria motriz y nivel de desarrollo de la habilidad. Pressing concibe la improvisación como una serie de situaciones donde se combinan objetos, mediadas por la limitación del tiempo, sobre la base de los eventos anteriores y en función de un referente (si lo hubiera) que actúa como guía o esquema que el músico utiliza para facilitar la generación de la improvisación. Tal situación tiene lugar a partir de lo que el músico percibe, la decisión que toma al respecto y la resultante de esa situación. De acuerdo con el componente temporal, en esta situación pueden distinguirse tres tipos de representaciones: (i) las del objeto, que implican una entidad cognitiva o perceptual, (ii) las de características, que son las que describen detalladamente al objeto y (iii) las del proceso, que indican cambios en las características y por lo tanto también en el objeto. Por ejemplo, el objeto puede ser un acorde, que se caracteriza por contener relaciones interválicas, disposiciones y sonoridades determinadas, y sobre el cual es posible realizar diferentes procesos, tales como ejecutar un arpegio ascendente, descendente, combinar ambos, integrar notas de paso, valores rítmicos irregulares, etc. En suma, el modelo que presenta este autor se caracteriza por ser reduccionista, ya que las estructuras cognitivas de procesamiento y control que presenta se dividen en distintos aspectos (acústicos, musicales, motrices) que conllevan cada uno un tipo de representación (objetos, características, procesos). Dicho modelo es capaz de generar novedad en el comportamiento improvisatorio, debido a la redundancia que comparten las representaciones y el carácter distribuido y no lineal de los procesos de control, a lo que se suman la presencia de distintas manifestaciones de feedback. De este modo, Pressing (1987) ofrece una explicación sobre cómo se activarían en el tiempo las representaciones mentales suscita la improvisación.

En un artículo posterior (Pressing, 1988), este autor construye un aparato que es capaz de transcribir en el código de notación occidental una improvisación y a partir de las transcripciones allí obtenidas, realiza un micro-análisis, que incluye estudios sobre el timming, la dinámica y la articulación; y un macro-análisis, que examina la improvisación en términos de las categorías derivadas de la teoría occidental de la música, y por ello, comprende los procedimientos tonales, diseños motívicos rítmicos, melódicos, etc.; para finalmente, correlacionar los resultados entre ambos análisis, interpretados en términos del modelo anteriormente propuesto. Encuentra que, según el tipo de improvisación (más libre, más pautada), existe una coherencia estructural que se observa en la coordinación

\footnotetext{
${ }^{13}$ En el original, input, processing and decision making, output.
} 
entre los elementos que se corresponden con lo micro y los que integran lo que tiene que ver con lo macro.

Más recientemente, Pressing (1998) continúa la explicación iniciada en el artículo de 1987 acerca de la habilidad improvisatoria, sosteniendo que durante las prácticas improvisadas, supone la puesta en juego de un tipo de habilidad que muestra claras coincidencias con los principios que delimitan el concepto de destreza: el entrenamiento, la práctica y la adaptación. Estos principios configuran las bases de lo que el autor define como habilidad improvisatoria, donde además, intervienen la base de conocimiento, conformada básicamente por materiales musicales (alturas, ritmos, motivos, frases) susceptibles de ser trabajados mediante diferentes procedimientos (secuenciación, variación, ornamentación) y el referente, que incluye distintos tipos de limitaciones. En otras palabras, mientras la base de conocimiento está construida por elementos musicales, el referente se constituye a partir de constreñimientos culturales, de estilos musicales, del instrumento utilizado para la improvisación, de la armonía y la forma de una canción, del marco que brinda el lenguaje tonal, entre otros. A pesar de presentar diferentes composiciones, base de conocimiento y referente colaboran con el desarrollo de la competencia improvisatoria, que para Pressing se vincula con la teoría estándar de la destreza.

Asimismo, desde una perspectiva psicológica, la improvisación puede ser entendida como un proceso en el que se seleccionan y combinan elementos en tiempo real mediante el empleo de un conjunto de criterios (Johnson Laird, 1991). Este es el punto de partida de la teoría computacional de la improvisación en jazz formulada por Johnson Laird (1991), en la cual, se asevera que es un error común entender que la improvisación depende de la adquisición de un repertorio de motivos que se modifican según el contexto. En contraposición, plantea la hipótesis de que durante la práctica improvisatoria un software, al igual que un músico, debe ocuparse principalmente de dos tareas: una de ellas es generar un patrón, es decir, una secuencia de notas y silencios; y la otra, consiste en organizar en forma correlativa esos patrones. Sostiene que estas dos tareas no son completamente independientes, sino que están reguladas por un conjunto de criterios que son resultado de la combinación de dos tipos de alogritmos. Por un lado, los algoritmos neo-darwinianos, que en analogía con los conceptos darwinianos, son los encargados de los procesos selectivos que tienen lugar en la improvisación. Por el otro, los algoritmos neo-lamarkianos, que en conexión con los principios lamarkianos, permiten combinar y variar los elementos existentes. Los algoritmos neo-lamarkianos proveen al improvisador de una combinación constreñida y de este modo, la selección allí es arbitraria. En cambio, los neo-darwinianos, alimentan el modo de selección natural. De la utilización de estos algoritmos se desprenden un conjunto de criterios que son empleados para construir la improvisación. Las sucesivas utilizaciones de estos criterios son, al mismo tiempo, responsables de la conformación del paradigma dentro de un ámbito determinado y generadoras de nuevas ideas. Resumiendo, Johnson-Laird (1991) propone que el proceso improvisatorio se origina mediante la selección, combinación y variación de materiales 
pre-existentes, reguladas por un conjunto de criterios aplicados por el individuo al improvisar.

Si bien en el artículo de 1991 Johnson Laird hizo algunas especulaciones respecto de la creatividad en la improvisación, es en el de 2002 donde, a partir de la pregunta sobre cómo improvisan los músicos de jazz, formula el algoritmo central que demanda ese tipo de improvisación, que se vincula fuertemente con el concepto de creatividad. Este algoritmo se produce en un solo paso, comprendido entre la creación de una secuencia acórdica y de una melodía en tiempo real, la habilidad para 'sacar fuera' el contenido de la improvisación, y la evaluación crítica; todo ello mediado por la utilización de la memoria de trabajo que redunda en una baja de la carga cognitiva, siendo de este modo, un algoritmo computacionalmente potente. Luego, sugiere que una teoría sobre la creatividad, puesta en marcha en la improvisación, debe ser computable. Dicho de otro modo, debería ser posible diseñar un software cuya tarea sea la de improvisar. Considera que hasta ahora, en el campo de la inteligencia artificial hay algunos programas, pero que tienden más a ser ejercicios que modelados cognitivos. Consecuentemente, expone las razones para que aún no se haya desarrollado tal programa. Detrás de su planteo, subyacen dos cuestiones. La primera se refiere a la ambigüedad que presenta desde un principio respecto de la creatividad, dado que deja entrever que subyace tanto una concepción en términos de pensamiento extraordinario como ordinario (ver pág. 22). La segunda cuestión, reside en la asunción de que la improvisación en jazz es creativa. Puede que en algunos casos sea más creativo un solo que en otros, sin embargo, parece demasiado arriesgado plantearlo de modo generalizado. Con todo, la tesis fundamental de este escrito denota una continuidad respecto del artículo de 1991, al presumir que la composición de secuencias melódicas necesitaría de cálculos intermedios en la memoria de trabajo, convirtiéndose así en dependiente de un algoritmo neo-darwiniano. Por el contrario, la improvisación, esto es, los procedimientos tácitos para la improvisación, obedecerían al algoritmo neo-lamarkiano que no requiere de resultados intermedios y con ello, de la utilización de la memoria de trabajo.

En términos bastante más generales, se ha señalado que la improvisación consta de características internas, también denominadas psicológicas, relativas al sujeto que improvisa; y externas, vinculadas al contexto socio-cultural (Kenny \& Gellrich, 2002). Coincidiendo con Pressing (1998), Kenny y Gellrich (2002) afirman que la base de conocimiento reúne el conjunto de habilidades, sub-habilidades, repertorio, estrategias y resolución de problemas que fueron adquiridos bajo la práctica deliberada, alegando que estos se transforman en el idioma dentro de un contexto. Además, aseveran que el referente se traduce en el marco impuesto por el género. Pero a diferencia de Pressing, estos autores integran la base de conocimiento junto con las características internas, que involucran un orden cognitivo (memoria) y otro psicológico (habilidad motora); y el referente, a las particularidades del contexto socio-cultural en el que se desarrolla la improvisación. Específicamente, estos autores formulan un modelo de procesamiento mental durante la improvisación que incluye cuatro procesos: anticipación, recuerdo, 
estado de flujo y feedback. En primer lugar, la anticipación a corto plazo, posibilita al sujeto anticipar los eventos en un lapso de entre 1 y 3 segundos; a medio plazo, entre 3 y 12 segundos; y a largo plazo, le admite hacer proyecciones para el resto de la improvisación. En segundo lugar, el recuerdo, también puede ser dividido de acuerdo con el tiempo trascurrido posteriormente al evento. Entonces, un recuerdo a corto plazo es aquel que puede retenerse unos pocos segundos después de producido un acto, siempre y cuando, durante el mismo se haya puesto el foco en eso. En cambio, un recuerdo a medio plazo resuena entre 4, 8 y 16 compases, y con ello, permite recordar una frase musical previa. Por su parte, el recuerdo a largo plazo viabiliza la remembranza de una improvisación, desde la génesis hasta el presente. En tercer lugar, cuando los improvisadores están concentrados, abstraídos únicamente en lo que están creando, se encuentran en un estado de flujo, es decir, un estado óptimo de atención y entrega en la tarea. En cuarto lugar, el proceso de feedback implica que los improvisadores pueden, una vez que recolectaron el material substancioso de la performance a través del recuerdo, programar cómo continuar la improvisación, reiterando, variando o quitando lo que consideren necesario. Es oportuno mencionar, que los autores sostienen que estos procesos son cometidos incesantemente por los improvisadores, que pasan de realizar uno a otro, pero que no pueden efectuar dos o más de estos procesos en forma simultánea. Finalmente, presentan las implicancias que este modelo puede tener en la enseñanza de la improvisación, que fueron descriptas en el apartado sobre los aspectos pedagógicos que concierne dicha práctica.

\section{SÍNTESIS}

En los planteos que revisamos a lo largo del capítulo, subyace la idea de que la improvisación es una habilidad en la que el músico puede alcanzar un alto nivel de destreza mediante la práctica deliberada y sistematizada. Estos enfoques han significado valiosos aportes para el entendimiento del proceso improvisatorio en términos de la cognición clásica, fundamentalmente porque el modo en que presentan y proponen sus planteos deja entrever que se basan en una concepción de mente escindida del cuerpo y del entorno, donde la mente es la única encargada de llevar a cabo el procesamiento cognitivo. Ahora, la visión de este paradigma no permite incluir otros acontecimientos que tendrían lugar en la performance. Por ejemplo, el modo en que los estados de flujo que experimentan los improvisadores influencian la improvisación (Csikszentmihalyi, 1988; Kenny y Gellrich, 2002); el establecimiento de una interacción comunicativa en la performance (Schögler, 1999); y la estrecha relación que une los procesos improvisatorios a los compositivos (Sloboda, 1985; Netll y Russell, 1998; Nettl y Solis, 2009). Quizás estas sean algunas de las cuestiones que podrían abordarse en el estudio de la improvisación situado en una perspectiva diferente del paradigma clásico, por caso, una que atienda al movimiento corporal que efectúan los músicos durante la improvisación, asumiendo con esto que los procesos cognitivos involucran de algún modo el cuerpo. He aquí la preocupación central del próximo capítulo. 



\title{
HACIA UNA DEFINICIÓN DE IMPROVISACIÓN COMO MODO PARTICULAR CORPOREIZADO, ENACTIVO, SITUADO Y MULTIMODAL DE CONOCIMIENTO
}

\author{
ANTECEDENTES DEL ESTUDIO DEL MOVIMIENTO Y DEL GESTO EN \\ DIFERENTES PERFORMANCES
}

\section{EL MOVIMIENTO EN LA DANZA}

Hacia la mitad del siglo XX, el movimiento en la danza comenzó a constituirse en un objeto de estudio en constante expansión. Uno de sus precursores de la sistematización de este tópico fue Ruldolf von Laban (1879-1958), fue quién sentó las bases del labannotation ${ }^{14}$. Partiendo de este sistema, Bartenieff y Lewis (1980), establecieron 5 categorías para el análisis del movimiento del bailarín: (i) dimensión, (ii) cuerpo, (iii) esfuerzo, (iv) forma y (v) flujo. En (i), se describe la utilización del cuerpo en el espacio circundante, denominado kinesfera. La kinesfera es la esfera que rodea al cuerpo, cuyo espacio total se alcanza extendiendo las extremidades, sin producir ningún cambio en la postura del cuerpo, y sirve para determinar las direcciones del movimiento en relación al espacio que lo circunda. Los movimientos pueden explicarse a partir de su desarrollo sobre las 3 dimensiones: vertical (arriba-abajo), horizontal (derecha-izquierda) y sagital (adelante-atrás). En (ii), se enumeran las partes del cuerpo que participan del movimiento. En (iii), se remite a la cualidad del movimiento, que queda determinada por la entrega o la resistencia del cuerpo en movimiento a 4 factores: el peso, el espacio, el tiempo y el flujo. En esta actitud de lucha dada por la entrega o la resistencia del cuerpo durante el movimiento, se clasifica mediante la descripción del comportamiento durante el movimiento de cada uno de estos factores. Es por esto que podemos describir como liviano o pesado el peso de un movimiento; como súbito o sostenido el tiempo en que se desarrolla un movimiento; como directo o indirecto el espacio al que se dirige un movimiento; y como libre o conducido el flujo que posee un movimiento en términos de tensión (Laban, 1970/1981; Español et al. 2011). En (iv), se alude al cambio constante de la forma del cuerpo en movimiento, atendiendo a las posiciones y los cambios que ellas implican a través del tiempo. Por último, en (v), también se hace referencia al aspecto cualitativo del movimiento, pero ahora en términos de la direccionalidad que implica el fluir de un

\footnotetext{
${ }^{14}$ Sistema de anotación diseñado para el análisis de los movimientos del bailarín.
} 
movimiento determinado, y por eso, se describe al flujo como libre o conducido. Estas categorías vienen siendo metódicamente utilizadas no sólo en el campo de la danza, sino también en estudios sobre el movimiento en música (ver por ejemplo Martínez y Epele, 2008; Shifres y Wagner, 2008; Martínez y Pereira Ghiena, 2011) y en psicología del desarrollo (ver por ejemplo Español, 2007; Español, Martínez y Pattin 2008; Español et al. 2011). Por ejemplo, Martínez y Epele (2008) analizan el modo en que movimiento y producción discursiva de la música se vinculan desde la observación de la danza. En otras palabras, las autoras se proponen explicar el grado de coherencia, esto es, la correspondencia entre el movimiento corporal del bailarín y la articulación discursiva de la obra musical. Ya en el campo de la ejecución musical más concretamente, Shifres y Wagner (2008) intentan encontrar evidencia empírica que sustente la relación entre pensamiento y movimiento, partiendo de la hipótesis de que "el pensamiento emerge dentro de un mundo que es esencialmente cualitativo" (p. 25), es decir, a través de la experimentación de contenidos no proposicionales que dan lugar a una experiencia sentida, no lingüística. En el ámbito de la psicología del desarrollo, se han indagado los movimientos que escoltan al habla dirigida al bebé, hipotetizando que tales movimientos son ligados, continuos, fluidos; semejantes a la danza (Español, 2007), comparando escenas de habla y de canto dirigido al bebé (Español, Martínez y Pattin, 2008) y analizando también escenas de juego musical (Español et al. 2011). Estos estudios sobre movimiento y performance se analizan los movimientos en relación con lo que está sucediendo en la escena, sea una díada adulto-infante, una ejecución musical, o una danza; en términos estructurales en algunos casos, y descriptivos en otros. A pesar de esto, los primeros estudios que desarrollaron categorías de observación, es decir, que diseñaron instrumentos de observación basados en sistemas de categorías con el objeto de clasificar los movimientos provienen en la mayor parte de los casos en estudios de otros ámbitos (principalmente de estudios en pragmática, y sistemas de categorización de los gestos que acompañan el habla).

\section{EL GESTO EN EL HABLA}

Durante la segunda parte del siglo XX, algunos autores (Ekman y Friesen, 1969; Hjortsjö, 1969; Ekman, Friesen y Tomkins, 1971; McNeill 1992, 2000) se encargaron de estudiar lo que acontece a nivel gestual mientras se desarrolla el habla. Para ello, Ekman y Friesen (1969) elaboraron cinco categorías que les permitieron categorizar los gestos corporales que allí tienen lugar: (i) emblemáticos, son aquellos gestos que poseen un significado determinado por convención, por ejemplo levantar el pulgar para indicar ok; (ii) ilustrativos, son los gestos que intentan manifestar el significado de lo que se está diciendo; (iii) gestos que expresan estados emotivos, reflejando el estado emocional momentáneo; (iv) reguladores, aquellos que se utilizan para alternar turnos en la conversación y ( $v$ ) gestos adaptativos o adaptadores, que son utilizados para habituarse a la situación, por ejemplo, para calmar nervios. Paralelamente, Hjortsjö (1969) formuló un 
sistema para codificar las acciones faciales ${ }^{15}$, basándose en el estudio del movimiento de los músculos de la cara en cada acción. Este fue mejorado por Ekman, Friesen y Tomkins (1971), quienes finalmente publicaron este método para medir las expresiones faciales ${ }^{16}$, a partir del análisis de imágenes de rostros (Ekman y Friesen 1978). Dicho análisis partía de la división de la cara en 3 áreas: una conformada por los ojos, otra por la frente y las cejas, y la restante, por la nariz, las mejillas, la boca y el mentón; y luego, tejía relaciones entre los movimientos resultantes y las emociones básicas ${ }^{17}$ (Ekman, Friesen y Tomkins, 1971). De aquí que el movimiento de fruncir el ceño se vincule con el enojo o la tristeza, o bien que el movimiento de la boca y las comisuras hacia afuera con la felicidad, etc. Estas técnicas aún hoy siguen teniendo adeptos (ver por ejemplo Matsumoto et al. 2008). Sin embargo, su mayor desacierto radica en el modo en que conciben la emoción y finalmente, en cómo la vinculan con el movimiento. Esto se debe a que las emociones básicas se desprenden de la observación y clasificación de imágenes de individuos de distintas culturas y a que, lo que se tiene en cuenta a la hora de categorizar, es el movimiento de las diferentes áreas del rostro entre imagen e imagen. En este sentido las emociones son severamente encasilladas y el movimiento no existe como desarrollo en el tiempo sino como cambio entre dos elementos que se presentan estáticos, como sucede con las imágenes. De este modo la emoción es vista como algo simple, pues si un rostro presenta determinado movimiento en un área específica, por ejemplo en la nariz, las mejillas, el mentón y la boca, se considera que el individuo está demostrando felicidad. Sin embargo, desde otro marco teórico, esto no es necesariamente así. Aunque este concepto excede ampliamente la problemática tratada en esta Tesis, nos interesa aclarar brevemente que la emoción puede ser explicada como un reflejo afectivo de la psiquis, que es descripta en diversas culturas como algo que podemos manipular, disfrutar, sentir y disimular; y provocada por diferentes elementos, que van desde la obra más sublime hasta la más vulgar (Damasio, 1999).

Una teoría posterior que supera en parte las problemáticas que presentan estas técnicas fue formulada por McNeill (1992). A partir de observaciones detalladas, este autor explicó que gesto y habla aparecen sistemáticamente organizados y por ello, son co-expresivos y suceden de modo sincrónico. Además, indicó que el gesto es global, porque el todo determina el significado de las partes y sintético, porque un único gesto puede combinar muchos significados (McNeill 1992, 2000). Propuso entonces cinco categorías para el análisis de los gestos durante el habla: (i) gestos icónicos, para aquellos que establecen representaciones figurativas de objetos o acciones; (ii) gestos metafóricos, para los que intentan ilustrar una idea o concepto abstracto; (iii) gestos batidos, para los movimientos

\footnotetext{
${ }^{15}$ En el original, facial action coding system, reconocido por la sigla FACS.

${ }^{16}$ Este método fue denominado técnica de puntuación del afecto facial (en el original, facial affect scoring technique, FAST).
}

17 Felicidad, tristeza, sorpresa, enojo, disgusto y miedo son las emociones a las que se hace referencia cuando se habla de emociones básicas. 
que ajustan de modo sincrónico con la pulsación rítmica del discurso hablado; (iv) gestos cohesivos, cuando pretenden unir dos partes del discurso que están temáticamente relacionadas pero temporalmente separadas; y (v) gestos deícticos, para los gestos de señalamiento hacia objetos, lugares concretos e ideas abstractas (McNeill 1992). Si bien este autor se preocupa directamente por la función del gesto, dado que el contexto en que produce sus investigaciones pragmáticas es el de la conversación, esa función resulta ser básicamente comunicativa, con lo cual, las categorías se reducen a observar el modo en que se desarrolla la función específica como resultado de su vínculo exclusivo con el lenguaje. Por el contrario, en el marco de esta tesis, sugerimos que podrían existir relaciones directas entre las características del movimiento efectuado por el músico durante la improvisación y la música que está generando orientadas hacia el propio músico más allá de cualquier función comunicacional.

\section{GESTO, MOVIMIENTO Y EJECUCIÓN MUSICAL}

Uno de los autores más reconocidos en lo que refiere al análisis del movimiento en la ejecución musical, se ocupó de examinar los gestos realizados por el pianista Glenn Gould. Delalande (1988) propuso una categorización sintética que dividía los gestos de este pianista en: (i) efectores, cuando se considera a los gestos responsables directos de la producción sonora; (ii) acompañantes o no efectores, para aquellos que no son obligatorios en dicha producción, y (iii) figurativos, cuando se advierten únicamente a partir del sonido. No obstante, esta propuesta podría reducirse a dos tipos de gestos, los efectores, para designar a los que son productores de sonido y los no efectores, entre los que se encuentran los acompañantes y los figurativos, para referir a los accesorios. Muchas de las categorizaciones siguientes (ver por ejemplo Wanderley, 1999; Cadoz y Wanderley, 2000; López Cano, 2009; Mauléon, 2010) continuaron con esta separación, y ello les permitió hallar una cantidad importante de categorías que terminaron otorgándole mayor imprecisión y complejidad al asunto. Por ejemplo, Wanderley (1999) profundizó en el estudio de los tres gestos efectores que consideró más comunes entre los clarinetistas (soplar, presionar y articular con los labios), partiendo de una división entre gestos instrumentales y gestos ancillares, análoga a la de Delalande. En suma, los gestos ancillares que propone Wanderley (1999) son aquellos considerados acompañantes o no efectores por Delalande (1988). Posteriormente, Cadoz y Wanderley (2000) agregaron a estas categorías una sub-clasificación que atendía a los aspectos funcionales, donde fueron categorizados los gestos como de (i) excitación, instantánea o continua; (ii) modificación, paramétrica o estructural y de (iii) selección. En contraposición, algunos autores que se ocuparon más de categorizar los gestos no efectores. Tal es el caso de López Cano (2009), que propone que los gestos ancillares pueden ser (i) preparatorios, es decir, los gestos anteriores al efector; (ii) vinculados, cuando acompañan y determinan la calidad del sonido (serían los gestos instrumentales de modificación para Cadoz y Wanderley); e (iii) icónicos e indexicales, que designan aquellos gestos que aparecen profundamente conectados con el modo de producción sonora. Además, los gestos ancillares vinculados pueden considerarse supervisores (si controlan la evolución de los 
gestos efectores), auxiliares (si son dependientes de la técnica del ejecutante) y/o compensatorios (cuando ofrecen equilibrio al cuerpo alterado por la realización de gestos efectores). Por su parte, los gestos ancillares icónicos e indexicales, pueden clasificarse como traductores (si trasladan a otra semiosis aspectos musicales y por ello serían semejantes a los gestos ilustrativos de Ekman y Friesen), analíticos (si fuera posible visualizar a través de ellos el análisis previo de la obra) y/o interpretativos (cuando aparecen movimientos que no están en sincronía con la música). Al mismo tiempo, este autor presenta las categorías de gestos reguladores, adaptativos y de exhibición que tienen una estrecha vinculación con los planteos de los autores anteriores (particularmente Ekman y Friesen, 1969; McNeill, 1992; y Davidson, 2001), dado que son utilizadas para describir los movimientos que tienen una función que va más allá de lo instrumental y que compromete los aspectos emocionales involucrados en la actuación musical. Por su parte, Mauléon (2010) también incorpora varias de las categorías mencionadas (especialmente las de Delalande, 1988 y Cadoz y Wanderley, 2000) para el análisis de los gestos del cantante. Sin embargo, hay dos cuestiones relevantes que emergen de su propuesta. Una radica en la hipótesis de que el gesto puede ser funcionar como un vehículo de comunicación de la intención expresiva del ejecutante, y entonces, ella habla de una intencionalidad comunicativa, porque esos gestos tendrían la función de comunicar un mensaje; aunque no lo plantea como una hipótesis sino directamente como una categoría de análisis. La otra implica la definición del término gesto y su relación los conceptos de movimiento y acción. Para Mauléon (2010) el gesto "implica la transmisión de un significado, un sentimiento o una intención" (p. 98), y por ello puede ser tanto una acción que muestre un fin aparente o no, una postura corporal, una actitud corporal. Esta autora sostiene que para que estas acciones, posturas y actitudes puedan ser entendidas como gestos, debe haber un interlocutor que decodifique el significado en ese hecho comunicativo. Finalmente para delimitar el alcance, observa que movimiento y acción son elementos que constituyen al gesto, y que a su vez, pueden aparecer superpuestos. Por ello, "encontraremos gestos superpuestos a acciones que tienen otro fin específico distinto que el de comunicar; y encontraremos que algunos movimientos constituyen gestos per sé" (p. 98).

Las categorías que mencionábamos en la sección precedente vinculadas con el análisis del gesto durante el habla, han tenido un fuerte impacto en ámbito de los estudios en ejecución musical. Por ejemplo, con algunas modificaciones, varias de ellas fueron directamente aplicadas al análisis del movimiento en la interpretación vocal, en los estudios sobre el movimientos de los cantantes Annie Lennox y Robbie Williams (Davidson, 2001, 2006). Básicamente, estos trabajos consistieron en describir y categorizar los movimientos observados en la ejecución vocal, interpretando que pudieran ser movimientos que el músico realiza para regular emociones propias de la situación (ansiedad por ejemplo) o bien para comunicarse con la audiencia. Davidson completó el análisis de movimiento delimitándolo a un contexto intersubjetivo determinado, donde pudo visualizar funciones específicas de algunos movimientos y atender a las posibilidades de vinculación con el otro a través de ellos. En otros trabajos, esta autora analizó y 
comparó movimientos de diferentes instrumentistas (flautista, clarinetista, pianista), preocupándose por la relación entre movimientos faciales y corporales, el modo en estos pudieran vincularse con los aspectos expresivos de la performance y la manera en que están disponibles para la audiencia (Davidson, 2002, 2007, 2012). Inicialmente, se propuso (i) explorar si los movimientos de un pianista ofrecen información a los oyentes sobre sus intenciones expresivas de forma continua, o si esto sólo tiene lugar en determinados momentos de la performance, y (ii), si la parte superior del torso y las manos contribuyen igual a la manifestación física de la intención de la performance. Encontró que los movimientos más amplios fueron percibidos por los oyentes como los momentos más expresivos de la ejecución, que se originaron en 3 tipos de intenciones y que, en principio, es más factible detectar las intenciones expresivas de los músicos a través de los movimientos que realizan con la parte superior del torso. Sugirió que esto evidenciaría que la información expresiva está disponible en una variedad de formas en la performance, que interactúa teniendo su germen en los componentes corporales. Más recientemente indicó que, en un momento inicial, los movimientos corporales expresivos operan para generar en la música una propuesta inmediata, comunicativa entre performers; mientras que en un más largo plazo, ellos proveen a los co-performers de señales para la regulación del contenido musical expresivo en un contexto idiosincrático (Davidson, 2012).

También Jensenius et al (2010) atienden al modo en que los gestos funcionan en vinculación al sonido. Por esto, su clasificación propone gestos de control, para aquellos a través de los cuales se manipula el sonido; metafóricos, para los que parecieran explicar en términos cualitativos la música que está sonando; y comunicadores, cuando son gestos que forman parte de una especie de historia que se va transmitiendo como mensaje no verbal a partir de las acciones corporales.

Actualmente han comenzado a desarrollarse líneas de investigación que indagan la función de gestos y movimientos, ya no desde su categorización, sino valiéndose diferentes avances tecnológicos que permiten medir el movimiento humano y con ello, mayor precisión a la hora de describirlo (ver por ejemplo Camurri, 2004; Naveda, 2011; Naveda y Leman, 2013; Mota, Loureiro y Laboissière, 2013). Dada la complejidad, la cantidad y la singularidad de los datos que emergen de estas mediciones, es difícil todavía predecir el modo en que estos avances colaboraran con las explicaciones que se han conseguido hasta el momento sobre el tema; y/o fomentaran nuevos esclarecimientos al respecto. $\mathrm{Si}$ estas investigaciones llegaran a buen puerto, es probable que superen las técnicas de clasificación, en principio, porque tendrían mayor precisión para explicar el movimiento humano y más generalmente, porque ofrecerían diversas formas de explicarlo.

En síntesis, todas estas perspectivas han sido muy útiles para el análisis pormenorizado de los gestos que tienen en la performance musical, y también lo han sido las que describíamos en el apartado anterior para el análisis de aquellos gestos que suceden durante el habla. Sin embargo, observamos dos puntos de conflicto en los estudios que proponen el uso de distintas categorías. El primero, se reduce al solapamiento entre las 
categorías. Por ejemplo, un gesto puede ser efector y al mismo tiempo, emblemático, y este último, también ancillar. Pensemos por ejemplo en un pianista tocando una lenta balada clásica, en la que se articula un acorde por cada tiempo. El gesto efector que le permite articular el acorde también es emblemático, porque si se lo hace sin estar tocando el piano, probablemente sea fácil advertir a qué se está haciendo referencia. También podría ser clasificado como un gesto ancillar que precede al efector, o podríamos decir que contiene a un efector porque sin anticipación que permite ese movimiento, difícilmente haya gesto efector. Entonces, ¿en qué medida las categorías se ajustan a lo que sucede en la realidad? ¿Es verdaderamente posible indicar a qué categoría corresponde un gesto? Realmente, ¿puede un gesto pertenecer a una única categoría? 0 las categorías ¿se solapan?. Estas preguntas se vinculan directamente con el segundo punto de conflicto, que reside que estas categorías dan una explicación del movimiento basada en las diferentes partes que conformarían el procesamiento cognitivo. Entonces, si un gesto es efector, es responsable de la producción sonora; si es ancillar, antecede esta acción. En un sentido más funcionalista, un gesto podría ser considerado efector porque tiene la función de permitirle al sujeto tocar, o mejor dicho, de permitirle realizar el proceso cognitivo necesario que le permite tocar. Por su parte, el gesto ancillar, tendría la función de preparar, auxiliar y colaborar con el gesto efector, pero sin participar del proceso cognitivo, que estaría llevado a cabo solamente por el gesto efector. El problema aquí, es que el proceso de cognición es visto como la suma de cómputos obligados para una determinada tarea. El proceso cognitivo lo realiza el gesto efector y los movimientos restantes solo ayudan a resolver la tarea. La idea central de esta tesis es otra: aquí nos proponemos entender al movimiento como partícipe necesario, del mismo modo que son partícipes la mente y el entorno, en el proceso cognitivo, en este caso, de una ejecución improvisada. Por eso no nos detendremos en la problemática entre gesto y movimiento, apelando a algunos trabajos donde se trata gesto y movimiento indistintamente (ver por ejemplo Español, Martínez y Pattin, 2008) y prefiriendo mayormente el término movimiento por ser más abarcador y menos viable para la segmentación. Sin embargo, el concepto de gesto que más se acerca a lo que consideramos el movimiento corporal, aparece cuando se observan dos condiciones decisivas: la continuidad y la indivisibilidad. En este sentido, el gesto es un paradigma complejo cargado de relaciones intermodales (Naveda, 2011; p. 12). Particularmente, el gesto musical es llamado expresivo cuando es responsable de la comunicación de aquello que llamamos contenido expresivo (Camurri et al. 2004). Para estos autores, el contenido contiene aspectos relacionados con los sentimientos, estados de ánimo y afectos; en otras palabras, con la intensidad emocional de la experiencia.

Resumiendo, preferiremos el concepto de movimiento, que será tratado en estas páginas con un alcance que incumbe no sólo a la calidad de ese accionar, sino también al sonido y al significado que involucra; con lo cual el concepto de movimiento acarrea un complejo multimodal que tiene lugar durante la experiencia (que como veremos más adelante incluye interacciones mente-cuerpo-entorno) del músico y del oyente. 


\section{COGNICIÓN MUSICAL CORPOREIZADA}

\section{MENTE-CUERPO Y ENTORNO: INTERACCIÓN EN EL PROCESO COGNITIVO}

Desde la perspectiva de la ciencia cognitiva clásica, el cuerpo ha sido considerado como el encargado de proporcionar al individuo un conjunto de informaciones provenientes del entorno a través de los sentidos. Esto implica la reducción del cuerpo a un objeto que pareciera estar puesto al servicio del procesamiento mental. En definitiva, desde esta perspectiva, lo relevante es lo que la mente hace durante ese procesamiento y el cuerpo no tiene allí otra función que aportarle la información a la mente. De este modo, la mente tiene la supremacía de los procesos cognitivos, sin la que intervengan en ellos ni cuerpo ni del entorno. Las ciencias cognitivas de segunda generación aportan una mirada diferente del cuerpo y del entorno, al proponer que el conocimiento no es simplemente resultado de los cómputos que efectúa la mente sino que resulta de la interacción entre la mente, el cuerpo y el entorno (Varela, 1988; Clark, 1997; Johnson, 2007). Dicho de otro modo, el cuerpo y el entorno, también forma parte del proceso y cada uno de ellos tiene un rol fundamental en el entramado de los procesos cognitivos. Concretamente, a partir de la experiencia corporal se construye buena parte del conocimiento, que radica fundamentalmente, tal como veremos en el próximo apartado, en la elaboración del significado (Varela, Thompson y Rosch 1991; Gendlin, 1997; Johnson, 2007; Leman, 2008 y 2010). El cuerpo y su constante movimiento dan lugar a una acción corpórea que se desarrolla a diario y que regula nuestro comportamiento cotidiano. El enfoque enactivo propone que esa acción corpórea es una reflexión donde la mente y el cuerpo trabajan mancomunadamente, no es una reflexión posterior a la acción, sino que constituye una forma reflexiva de experiencia en sí misma (Varela, Thompson y Rosch, 1991). Durante esa experiencia nos vamos encontrando con un conjunto de posibilidades de acción, vamos probando, cambiando y eligiendo en función de lo que estas opciones nos permiten. Esto nos permite retomar el concepto de affordances que formuló Gibson (1979) para referirse a las distintas posibilidades de acción que un mismo objeto situado en un entorno determinado puede ofrecer a cada individuo, según este prefiera más algunas propiedades, tanto del objeto como del entorno, por sobre otras. Desde esta perspectiva, durante esa experiencia el entorno ofrece distintas posibilidades de acción al sujeto que obra, en función de las reflexiones que consigue a través del trabajo conjunto de la unidad mente-cuerpo. Es por eso que también el entorno tiene un papel determinante en la construcción del conocimiento que realiza el sujeto. Visto de este modo, tanto cuerpo como entorno adquieren otra dimensión en el desarrollo de los procesos cognitivos. Desde el enfoque enactivo, estos procesos tienen de base estructuras cognitivas que emergen de los sistemas sensorio-motores recurrentes, y ello, permite que sea la acción quién guía a la percepción. Sin embargo, las acciones que vamos realizando están influenciadas tanto por aquellos hechos que las anteceden como también por el objeto mismo y la historia particular de cada individuo. En este sentido, el concepto de affordances nos ayuda a aproximarnos al modo en que las acciones corporales, realizadas por el cuerpo en movimiento, van otorgándonos diferentes posibilidades de acción en la acción misma. 
Una de las formas de abordar el rol del cuerpo y las implicancias que tiene en estos procesos, nos lleva a estudiar el modo en que se comportan corporalmente los sujetos en la realización de una determinada tarea. Por ejemplo, cuando mantenemos una conversación con otra persona, los gestos espontáneos constituyen una parte importante del mensaje que estamos emitiendo, esto es, "conforman un mensaje corporal continuo que se extiende aún cuando callamos" (Español, Martínez y Pattin, 2008). Podríamos pensar entonces que la comprensión que la otra persona tiene del mensaje que le estamos intentando transmitir está influenciada también por el modo en que nos movemos mientras hablamos y los gestos particulares que utilizamos en cada parte del discurso. También que esos movimientos que suceden junto con el habla nos van dando la posibilidad de organizar y explicar nuestra idea. Nuestro discurso no contempla solo el diálogo, sino las palabras y los movimientos espontáneos que realizamos al hablar. En este sentido, el cuerpo tendría un rol en el proceso cognitivo que supone el habla, tanto para el emisor del mensaje, como para el receptor. Desde una perspectiva más amplia, los gestos no solamente tendrían un rol en la cognición, sino que también implican un "modo particular de sentir" (Shifres y Wagner, 2008; p.33). Gendlin (1997) sostiene que este modo es una significación sentida, esto es, una experiencia corporal que contiene en forma implícita el conocimiento sentido, experimentado, vivido, que tenemos sobre el mundo. En suma, el rol del movimiento corporal podría ser el de permitirnos acceder a ese modo particular de sentir, pues la esa experiencia corporal que vamos ganando a través del movimiento contiene en sí misma el significado, con el que finalmente logramos el conocimiento. Ahora, ¿qué es lo que hacemos cuando practicamos significado?.

\section{LA PRÁCTICA DE SIGNIFICADO MUSICAL}

Leman (2008) define a la práctica de significación musical como un proceso donde se amplía el nivel de vinculación corporal directo con la música por parte de los oyentes. En este proceso las interpretaciones de la música que hacen los oyentes pueden transformarse en descripciones verbales que los ayudan a contactarse con el significado musical. Leman (2008) sostiene que estas descripciones "revelan significados escondidos"(Leman, 2008; pág. 7), en el sentido de que poseen no sólo el contenido verbal, sino también el contenido vinvenciado a través del movimiento corporal durante la experiencia musical. Mas generalmente, plantea que

"la participación directa se basa en las energías físicas que tienen un impacto en el cuerpo y la mente humanas. Este enfoque basado en la acción explica las prácticas de significación por medio de las articulaciones corpóreas (gestos). (...) La música, en verdad, tiene un gran impacto en el comportamiento y la acción puede ser vista como el componente corpóreo que contribuye a la significación. Referirse a los componentes corpóreos, sin embargo, implica hablar de energías físicas. El estudio de la corporeidad requiere una comprensión de la relación entre mente, cuerpo y materia usando metodologías que se basan en la experimentación y el modelado por computadora (Leman, 2008; pág. 23). 
Ahora, si en el proceso de práctica de significado interviene el cuerpo, probablemente no lo haga despojado de sus emociones. Más allá de que el concepto de emoción exceda el marco de esta tesis, quisiéramos dedicarle unos párrafos con el objetivo de valorarla dentro de este proceso, para poder comprender mejor cómo actúa el cuerpo, cómo se relaciona con los conceptos hasta aquí tratados y en un futuro, plantear el estudio de estos procesos de modo más completo.

Desde el plano filosófico, la emoción es subjetiva porque permite experimentar sentimientos localizados dentro del sujeto. Cuando una persona experimenta una emoción, siente por ejemplo, la contracción de su frente, la tensión de sus músculos, la circulación sanguínea, es decir, lo que está pasando fisiológicamente en su cuerpo y las emociones que de ello derivan. Entonces, la subjetividad de la emoción se refleja en el modo en que cada persona interpreta, mediada por sus experiencias previas y el contexto al que pertenece, un mismo fenómeno fisiológico. Para Budd (1985) estas sensaciones de tensión y distensión reflejan nuestro pensamiento al experimentar las propiedades del fenómeno emocional y pueden vincularse con las características del mundo musical. Por eso, sostiene que podemos entender la música como agitada, anhelante, calma, seductiva, inquieta, pomposa, apasionada, sombría, triunfal, entre otras. Estas palabras que solemos usar estarían describiendo en realidad, no sólo cómo nos parece que es la música, sino cómo sentimos corporalmente esas características que la música presenta. En sintonía con este planteo, Johnson (2007) ofrece varios argumentos sobre los cuales comenzar en la explicación del proceso de elaboración de significado musical. Una de sus ideas centrales asume que la música tiene significado para nosotros porque presenta en formas corporeizadas lo que experimentamos al escucharla y ello, se condice con la manera en que la vivenciamos. En otras palabras, la música es significativa, porque presenta el flujo de la experiencia humana, el sentimiento y el pensamiento en formas corporeizadas, y este es el significado en su sentido más profundo (p. 236). De modo más general, este autor plantea que las estructuras corporeizadas son relevantes, aún cuando no son 'cognitivas' o 'conceptuales' en el sentido tradicional de estos términos, porque proveen de significados basados en el cuerpo que afectan nuestra comprensión, aún sin la mediación de una conceptualización de alto nivel y del razonamiento. Consecuentemente, plantea que el sistema sensoriomotor es responsable de nuestro entendimiento del mundo, dado que nos abastece de las estructuras no conceptuales y no proposicionales que empleamos en la producción del significado que hace posible este entendimiento. Resumiendo, el significado se basa en nuestra experiencia corporal, emerge, vive y crece en la profundidad de los procesos corporales y se traduce en el resultado de las interacciones y transacciones organismo-entorno que nuclean cerebro, cuerpo, entorno, interacciones sociales, instituciones y prácticas (p. 12). De este modo, cambia el concepto tradicional de razonamiento por una definición que lo abarca en términos de procesos corporales entrelazados, inseparables e inextricables, a la emoción. En palabras de Johnson, 
"La razón y la emoción están íntimamente entrelazadas: esta afirmación desafía directamente la creencia popular de que la razón y la emoción son capacidades diferentes, independientes, una incorpórea (la razón) y otra corporeizada (la emoción). La dicotomía de base es un dualismo metafísico que puede encontrarse en cualquier lugar y que tiene profundas consecuencias para nuestra visión del pensamiento y el conocimiento" (Johnson, 2007; p. $14^{18}$ ).

El significado surge a partir de una experiencia compleja que nuclea lo físico, lo social y lo cultural, y ello sucede a través de nuestros sentimientos, emociones y conceptos, durante nuestro encuentro corporeizado con ellos. Dicho de otro modo, el significado de una situación crece a medida que vamos hallando diferencias, similitudes, cambios y relaciones, haciendo finas discriminaciones en el flujo de la experiencia (Johnson, 2007; p. 101).

Para explicar la manera en la que son experimentados estos cambios, Stern (2010) presentó el concepto de forma de la vitalidad. La forma de la vitalidad es aquello que emerge como producto de la experiencia corporal en términos de tiempo, fuerza, espacio, dirección e intención: el encuentro de estos atributos conforman la cualidad sentida en la experiencia corporal y permiten que sea posible la distinción entre experiencias diversas. Este modo de vivir como seres corporeizados en el mundo aprendiendo a partir de la vivencia corporal, implica entender la cognición como un complejo en el que lo contextual y lo emotivo también adquieren relevancia. Así, el significado que se otorga a la música está delineado por el contexto cultural al que se pertenece (Leman, 2008). Consecuentemente, el significado corporeizado emerge de la estructura de las interacciones y transacciones organismo-entorno; se basa en la experiencia corporal que resulta de la combinación del cerebro, cuerpo, entorno, interacciones sociales, instituciones y prácticas; y se fundamenta en el sistema sensorio-motor y en las capacidades imaginativas para usar este sistema durante la cognición (Johnson, 2007). Ahora, ¿por qué somos capaces de entender en términos corporeizados la música?. Una respuesta posible ofrece Leman (2010), cuando afirma que a través de los gestos, la música puede ser experimentada como la acción de un organismo dinámico similar a un organismo humano (p. 126). En otras palabras, somos capaces de entender la música como movimiento por las analogías que establecemos con nuestro propio movimiento y con el de nuestros semejantes. Los gestos y movimientos, tanto los que realizamos como los que vemos que otros realizan, nos estarían sirviendo de base para el entendimiento en términos de movimiento que tenemos, en este caso, de la música. Ahora bien, también estos movimientos serían responsables de la práctica de significado musical, de modo directo, cuando la música es corporalmente experimentada e indirecto y mediado por el

18 En el original, "reason and emotion are inextricably interwined: this claim directly challenges the received wisdom that reason and emotion are separate, independent capacities, one disembodied (i. e. reason) and other embodied (i. e. emotion), The dichotomy is a basic a metaphysical dualism as you will find anywhere, and it has profound consequences four view of thought and knowledge". 
pensamiento, cuando la experiencia es entendida como una expresión de un comportamiento aristocrático prototípico o de una clase social en general (Leman, 2010; p. 126). Este autor propone que la formación de significado musical puede ser estudiada en un contexto científico simple, que incluya al menos un músico, un observador y un oyente. El músico transforma la energía biomecánica en energía sónica; el observador, tiene la tarea de estudiar los gestos como movimientos físicos y la práctica de significado; y el oyente, percibe la energía sónica y expresa su compromiso con la música a través de su cuerpo. Los movimientos que de allí resultan son llamados articulaciones corporales. Esas articulaciones corporales pueden dar lugar al sentimiento de agencia: ser movido, o activado por la música. La práctica de significado puede protagonizar desde el momento en que el oyente es capaz de interactuar con la música en términos de movimiento físico que parece tener este carácter de agencia (p.130). Veamos ahora como se relacionan estas ideas con el tema central de esta tesis, la improvisación musical.

\section{IMPROVISACIÓN MUSICAL: SONIDO, MOVIMIENTO CORPORAL Y PRÁCTICA}

\section{DE SIGNIFICADO}

Para definir la base de una perspectiva corporeizada de la improvisación, nos proponemos atender a cada uno de los apartados que fuimos desarrollando en el transcurso de este capítulo. Pero antes, es necesario redefinir el estatus de la improvisación con respecto a la ejecución de música leída. En esta última, la práctica de significado alcanza ciertas instancias que van más allá del alcance performativo. Esto significa que el músico que toca una obra leída pudo haber construido el significado no sólo a partir de las sensaciones sentidas que experimenta durante la ejecución sino también, por ejemplo, a través del análisis de la obra. En cambio en la improvisación, la práctica de significado pasaría por otros carriles. Al no haber obra escrita, el improvisador no puede valerse del análisis previo de la obra, aunque sí de las características y limitaciones que impone el contexto. Esta particularidad de la improvisación de no disponer de un a priori hace que se constituya en un modo de ejecución pertinente para observar el papel que desempeña el cuerpo en la práctica de significado musical, básicamente porque obliga al músico a improvisar para construir significado y porque por su naturaleza performativa, deja afuera otras variables que pudieran colaborar en la práctica de significado. Por ejemplo, en una obra leída, la práctica de significado puede estar influenciada por las etapas de ensayo previas a la ejecución en vivo de la obra, aunque lógicamente en esa situación también aparecen nuevas variables, tales como la presencia del público, la reubicación en función del nuevo espacio de los músicos, las dimensiones de la sala, entre otras; que también aparecen en la práctica de significado durante la improvisación. Sin embargo, la improvisación no puede valerse del ensayo previo, pues no lo tiene. Tomamos a la improvisación para estudiar el movimiento corporal que el improvisador allí realiza porque muchos de los estudios sobre la relación entre movimiento y performance han tendido a basarse en performances que tienen un plan previo, es decir, en ejecuciones de obras leídas. La idea de pensar en performances que no tienen plan previo (o que por lo menos 
tienen un plan previo mucho más reducido) como es una improvisación, permite encontrar relaciones que tienen mucha menor chance de ser el resultado de una elaboración 'coreográfica' digamos, y por lo tanto, se podría especular que permiten adentrarse mejor en el punto principal de la cognición corporeizada, en esta idea de que se piensa con el cuerpo. En este sentido, la práctica de significado en la improvisación, estaría regulada por la experiencia corporal sentida, posible a través del movimiento corporal; por los elementos que dispone el improvisador (la base de conocimiento, el referente y el instrumento en términos de objeto sonoro que permite posibilidades de acción); y por las variables que van surgiendo a medida que la situación va transcurriendo (el entorno). Nuestro alcance del término improvisación contempla los aspectos corporales suscitados durante la misma partiendo de que ellos son fruto de un proceso de interacción cuerpomente-entorno, que se desarrolla constantemente durante la experiencia musical. Pensemos por ejemplo en géneros como el jazz, el folclore argentino, el rock o la canción. Estos géneros se han desarrollado en contextos socio-culturales y musicales diversos. Sin embargo, es posible observar en la historia particular de cada uno de ellos la improvisación como factor común. Por ejemplo en el jazz, es a partir de una melodía (denominada estándar en ese contexto) y de su armonía subyacente, que el músico produce una ejecución constituida por una sección de melodía con acompañamiento, una de solo o improvisación y una repetición (probablemente con variaciones) de la primera. De ahí que los ejemplos clásicos del repertorio de jazz como "Autumn leaves", "Blue bossa", o "In a sentimental mood", por nombrar sólo algunos, sean piezas tripartitas (ABA, ó ABA'). Generalmente la sección improvisada se apoya en la armonía de la unidad precedente, aunque puede presentar mayor grado de variación en comparación con las restantes. Allí, el solista puede producir diferentes tipos de improvisación, comenzando por ornamentaciones de la melodía base hasta llegar a proponer una melodía diferente de la presentada en la sección anterior. Sea una variación o una melodía completamente distinta, subyace un concepto de improvisación que atañe a la utilización de materiales previamente aprendidos (actuales en la base de conocimiento del improvisador) que implican un grado de dominio instrumental y una adecuación al contexto musical. Este tipo de improvisación que se practica en el ámbito del jazz ha tenido fuerte impacto primeramente en el folclore argentino, gracias a los aportes de reconocidos músicos como Eduardo Lagos (1929-2009), Gustavo Leguizamón (1917-2000), Manolo Juárez (nacido en 1937) entre muchos otros, y posteriormente ha penetrado en el género de la canción, lo que es posible observar en intérpretes tales como Guillermo Vadalá (nac. 1968), Daniel Maza (nac. 1959), entre tantos otros. Del mismo modo ha tenido notable incidencia en la música de grupos de grupos de rock, que integran en sus canciones una sección de interludio donde el guitarrista (por ejemplo) realiza el solo. Actualmente, el folclore, el rock y la canción se constituyen en géneros que han sido conquistados por esta definición de improvisación vinculada al jazz descripta en el capítulo anterior, en los que la misma es ampliamente utilizada. Pero también este tipo de improvisación se manifiesta, aunque con menor frecuencia, en otros géneros. En el ámbito de la música occidental del romanticismo, las ejecuciones de Arcadi Volodos (nac. 1972) son muestra de ello. Sin 
embargo, adoptando un criterio etnomusicológico, se podría decir que la improvisación ha estado presente en cualquiera de estos géneros de modo activo y en cualquier práctica musical anterior al jazz, por el hecho de ser un componente más de la actuación musical. El jazz simplemente cobijó un alcance del término determinado. Estas afirmaciones se sustentan en un cúmulo importante de bibliografía, preferentemente de carácter etnomusicológico, donde numerosos análisis de músicas improvisadas en diversos contextos socio-culturales dan cuenta de las divergencias existentes en el alcance del concepto de acuerdo con cada contexto. Por supuesto que desde este marco, es imprescindible comprender la improvisación en un sentido amplio del término y entender que remite al conjunto de decisiones que el músico necesariamente toma en el transcurso de la ejecución (Anderson Sutton, 1998). De este modo, el concepto de improvisación resulta por demás elusivo, por lo cual, remitir al mismo lleva ineludiblemente a delimitar el contexto musical en el que se desarrolla. $Y$ aquí, un enfoque corporeizado de la improvisación podría aportar distintos puntos de apoyo para sustentar el estudio de improvisación como una ejecución que abarca la vinculación con el contexto, es más, que depende de ella para poder ser realmente definida, donde la práctica de significado también está sujeta al contexto, y por ello, entre otros factores, estos géneros son fácilmente diferenciables.

Una perspectiva corporeizada del estudio de la improvisación, nos invita a preguntarnos cómo, por qué y para qué se desarrollan distintos tipos de movimiento corporal en este modo de conocimiento, entendido como la resultante de un proceso interactivo mentecuerpo-entorno. También, que rol está cumpliendo el cuerpo en dicho proceso. A su vez, la perspectiva es enactiva, indicando con ello que el movimiento es más bien una acción corporal que tiene como objetivo guiar el modo en que vamos experimentando el mundo que nos rodea, en este caso, reducido a la experiencia musical presente. También, es definida como situada, y entonces, la pregunta gira en torno a un ámbito concreto de realización, por caso, la improvisación en folclore argentino. Y finalmente, es multimodal, porque como decíamos anteriormente (ver pág. 42), el movimiento aparece en medio de un complejo de relaciones intermodales que tienen lugar en la experiencia musical; junto con el sonido, la emoción y el significado.

Tomando a la improvisación desde la perspectiva que acabamos de presentar, se constituyen problemáticas de investigación algunos tópicos sobre los que aún no se ha ahondado demasiado. Una de estas líneas corresponde a los trabajos de Schögler (1999) y Schögler y Trevarthen (2008). Estos autores asumen que uno de los pilares de la comunicación radica en nuestra capacidad para compartir un tiempo en acción, que nos permite producir una coordinación temporal intersubjetiva. Esta es una capacidad que desarrollamos por nuestra propia naturaleza comunicadora y la vamos refinando, principalmente, a partir de diversas experiencias en distintos sistemas de comunicación e interacción. Para Schögler (1999), compartir un tiempo en acción conduce a una toma de conciencia sobre las otras personas, sus motivos, propósitos, intereses y las cualidades de su emoción. Buscando encontrar alguna evidencia empírica al respecto, este autor analiza 
el modo en que dos improvisadores se comunican durante una improvisación que ambos llevan a cabo, pero no en la misma escena, sino en habitaciones separadas. Básicamente, examina los componentes de la improvisación resultante (notas, sílabas, frases, melodías) en analogía con el lenguaje verbal y el comportamiento del pulso, calidad y narrativa, en términos de la teoría de la musicalidad comunicativa de Malloch (1999). Concluye que la conversación entre dos músicos que sucede por medio de la improvisación, constituye una interacción dinámica a partir de la cual nace una narrativa musical. $Y$ esto, es comparable con el modo en que se producen distintos tipos de interacciones adulto-infante (ver por ejemplo Español, 2007; Español, Martínez, y Pattin, 2008), con la diferencia de que aquí la interacción puede ser más fácilmente confinada a un canal de comunicación, que en la música. Otra línea muy interesante de trabajo, aparece con aquellos estudios que indagan el modo en que se produce las elecciones que involucra la improvisación. En este sentido, se la considera una habilidad que implica el conocimiento del saber cómo resolver un problema en un contexto determinado, a partir de la búsqueda y la consecuente toma de decisiones sobre posibles maneras de comportarse dentro de un marco reglado (Ross, 2010, 2011). En términos más generales, la improvisación puede ser vista como la negociación colaborativa dentro de las reglas estructuradas entre distintos agentes (Ross, 2011). Desde un punto de vista similar, se integra además el concepto de la creatividad, afirmando que puede participar de la toma de decisiones y que se produce como consecuencia de un proceso de emergencia colaborativa que se suscita, no sólo en un músico, sino entre los integrantes de la performance (Sawyer, 2006).Finalmente, el trabajo de Benson (2003) plantea el estudio de la improvisación desde una perspectiva fenomenológica y hermenéutica, explicando el modo en que se constituye la performance improvisada e interpretándolo en su contexto de origen. Si bien estos enfoques complementan nuestra estudio de la improvisación, exceden los objetivos de esta Tesis. Por esto, pasamos entonces a declarar nuestra definición de improvisación y a plantear los argumentos principales que sustentan la siguiente sección de este trabajo.

Como adelantábamos al inicio de este apartado, definimos a la improvisación musical como una ejecución que comprende la experiencia corporal sentida, los elementos previos que poseen los participantes y las variables que suceden 'momento a momento'; en la que el modo en que estos componentes van interactuando permiten al improvisador y al público la práctica de significado. La experiencia corporal sentida comprende el movimiento corporal, en términos de acciones que guían el comportamiento del músico y del los oyentes durante la improvisación. Los elementos previos son por un lado, aquellos con los que el improvisador ha podido tener un contacto anterior, que puede manejar con cierta soltura y que conoce por las sucesivas improvisaciones; como la base de conocimiento, los referentes, el instrumento que ejecuta y las posibilidades de acción que éste le ofrece; y por el otro, aquellos con los que los espectadores se han relacionado, por ejemplo, si escuchan habitualmente ese tipo de música, si tocan un instrumento de los que aparecen en escena, etc. Las variables 'momento a momento' están dadas por el entorno, por sus características y por el modo en que se van entrelazando durante la improvisación. En el caso del músico, estas variables pueden incluir el tipo de obra que está tocando, una 
falla técnica, la respuesta sonora que percibe (el retorno), la comunicación con los demás músicos y con la audiencia y las características del lugar donde se lleva a cabo la performance, entre otras. Para los espectadores, las variables pueden ser la familiarización con ese tipo de música, la posición en la sala, la sonoridad percibida, entre otras. Ahora, tanto la experiencia corporal, la preparación previa y las variables del entorno hacen posible la práctica de significado durante la improvisación musical. En suma, la improvisación puede ser entendida como una ejecución que involucra una práctica de significado mediada por las experiencias corporales de los individuos que intervienen, sean los músicos o los espectadores, su preparación y el modo en que manejan las variables que genera el entorno.

\section{PUNTOS DE PARTIDA}

La definición que presentamos es la que creemos más completa y acabada; sin embargo, damos cuenta de que es necesario tomar solo uno de los aspectos que plantea para que sea posible abordarlo en el marco de esta Tesis. Por eso, nos vamos a ocupar aquí del estudio del movimiento corporal en la improvisación, pero basándonos en esa definición, para que se advierta claramente porqué nos detenemos a estudiar el movimiento, y qué concepción tenemos del mismo. Volviendo a nuestra hipótesis inicial, el movimiento corporal no efector realizado por el improvisador se vincula con la configuración de la melodía que está improvisando. Recordemos que cuando decimos movimiento no efector nos referimos al movimiento corporal que no está vinculado, al menos directamente, con la demanda técnico instrumental que le requiere al músico tocar su instrumento. Del mismo modo que acotamos el objeto de estudio a una de las particularidades de nuestra definición, también delimitamos la improvisación al desarrollo de la configuración melódica, porque de otro modo sería inabarcable. En el estado del arte que elaboramos en el inicio de este capítulo notamos que uno de los problemas clave que presentan los estudios del gesto, tanto en el habla como en la ejecución musical, es la segmentación, es decir, la posibilidad de determinar la unidad gestual. Es por esto que, más recientemente, algunos estudios tienden a abandonar la metodología de observación y clasificación (a través de sistemas de categorías) para establecer relaciones (co-relaciones en realidad) continuas. Para eso se basan en tecnologías que permiten mediciones continuas (ver Camurri, 2004; Naveda, 2011; Naveda y Leman, 2013; Mota, Loureiro y Laboissière, 2013) o bien utilizan un sistema de categorías pero procurando una descripción más cualitativa de los movimientos observados (ver por ejemplo Español, Martínez y Pattin 2008; Español et al. 2011). Aquí vamos a retomar la tradición de los estudios clasificatorios desde un punto de vista más cualitativo en el capítulo 3 y vamos a encarar un intento de explicar la relación movimiento-estructura musical, a través de medidas contínuas, evitando el tema de la segmentación del gesto, en el capítulo 4. 


Segunda Parte

EVIDENCIA EMPÍRICA 


\section{CAPITULO 3}

\section{RASGOS DINÁMICOS DEL MOVIMIENTO CORPORAL EN LA IMPROVISACIÓN}

Fuerza y forma del movimiento.

\section{INTRODUCCIÓN}

Este capítulo nos proponemos estudiar en forma cualitativa cómo se desarrolla el movimiento corporal del músico durante la improvisación. Para ello, necesitamos primero definir en qué rasgos del movimiento vamos a centrarnos para poder estudiar su calidad. Por un lado, nos ocupamos de observar cómo se desarrolla la fuerza del movimiento, entendida como la energía que implica cada movimiento. Por el otro, examinamos la forma del movimiento, en términos de la trayectoria que genera una serie de movimientos determinados. Ambos rasgos están determinados concordando con la propuesta de Laban y Bartenieff (1980) que desarrollamos con mayor detalle en el próximo apartado. Para poder describir cualitativamente los rasgos de forma y fuerza del movimiento, en principio tuvimos que seleccionar un material que presente un conjunto de características determinadas. Seleccionamos entonces de un concierto completo del grupo Cuartoelemento $^{19}$ una obra compuesta el guitarrista del grupo llamada "Bahionga para Lydia". De esa obra, elegimos un solo improvisado, interpretado por el flautista del conjunto, por una serie de razones que enumeramos a continuación. En primer lugar, el músico realiza mientras improvisa el solo una cantidad importante de movimientos considerados innecesarios para la producción sonora. Por ejemplo, mueve la cabeza, el tronco, los pies; y esos movimientos no serían requerimientos, en términos técnicos, para tocar la flauta. Sin embargo, igual los realiza. En segundo lugar, en particular este solo presenta una buena cantidad de movimientos innecesarios para la producción sonora que fueron realizados durante todo el concierto (en este sentido, es una síntesis del mismo). En este sentido, la escena es representativa del concierto porque lo que ocurre en este solo también ocurre por ejemplo en el solo que improvisa en "Afiches" de Atilio Stampone y Homero Expósito, también cuando interpreta la melodía de Oblivión de Astor Piazzolla.

\footnotetext{
${ }^{19}$ Cuartoelemento está formado por Rubén "Mono" Izarrualde, en flautas y voz; Néstor Gómez, en guitarra y voz; Matías González, en bajo y voz; y Horacio López, en percusión y voz. "Cuartoelemento aborda un repertorio sin encasillamientos estilísticos, donde confluyen compositores tan disímiles como Yupanqui, Bill Evans, Joao Bosco, Antonio C. Jobim, entre otros o Néstor Gómez y Horacio López. Una propuesta que con lenguaje personal, improvisación colectiva y audacia artística, versiona temas tradicionales y propios, dentro de la estructura de la música de raíz folklórica" extraído de http://cuartoelementoweb.com.ar/grupo.htm
} 
En tercer lugar, los movimientos que realiza son a simple vista, cualitativamente distintos, y parecen estar relacionados con el sonido ejecutado. En cuarto lugar, el sólo contiene un momento donde el flautista cita un motivo antes usado por el guitarrista. Finalmente, porque antes de comenzar el tema el músico en una actitud muy graciosa, busca la partitura y inunca la encuentra! Y entonces, si tenía algo anotado para realizar su improvisación, puede que lo esté recordando pero no lo está leyendo en este caso. Por todo esto, el solo que elegimos constituye un material adecuado para indagar el modo en que forma y fuerza del movimiento corporal del ejecutante se producen en la improvisación, y permite describir cualitativamente forma y fuerza del movimiento atendiendo a la vinculación que pudieran tener con el sonido producido, bajo la hipótesis de que el movimiento del ejecutante privilegia alternadamente los rasgos de forma y fuerza del movimiento corporal.

\section{MÉTODO}

Para realizar el microanálisis del solo improvisamos acudimos a las categorías para el análisis del movimiento en la danza establecidas por Laban (1970) y ampliadas por Bartenieff y Lewis (1980). Estas categorías se denominan dimensión, flujo, cuerpo, esfuerzo y forma. Dimensión, refiere a la esfera donde el cuerpo puede moverse, que está limitada por la extensión máxima de las extremidades, y que se denomina kinesfera. Flujo, refiere al modo en que se desarrolla el movimiento en el tiempo, en términos de tensión y distensión. Cuerpo, se utiliza para designar a las partes del cuerpo que realizan el movimiento. Esfuerzo, remite a la energía desplegada en cada movimiento. Forma, indica los cambios constantes de la forma del cuerpo durante el movimiento. Además de ser utilizadas en el campo de la danza, estas categorías también se han empleado para el análisis del movimiento en distintos ámbitos de investigación (véase por ejemplo Español 2007 y Español et al. 2007 y 2011, en psicología del desarrollo; Lourens, Van Berkel y Barakova 2010 en inteligencia artificial; y Wanderley 2000, Wanderley et al 2005 y Campbell, Chagnon y Wanderley 2005 en ejecución musical; por mencionar sólo algunos). De estas categorías, seleccionamos cuerpo, esfuerzo y forma, por ser las que consideramos que nos podrían brindar información sobre la cualidad del movimiento. No es que las categorías restantes no la aporten, sino que la taxonomía esfuerzo tiene un amplio alcance, dado que se configura a partir de la conjunción de factores diversos, y ellos nos aportarían datos suficientes para describir cualitativamente el movimiento. La categoría esfuerzo queda determinada por el modo en que se comportan durante un movimiento 4 factores: peso, espacio, tiempo y flujo. Cada uno de estos factores contribuye a la descripción de la cualidad del movimiento, apelando a una simple dicotomía. Así, cuando se refiere al peso, se considera pesado o liviano; al tiempo, súbito o sostenido; al espacio, directo o indirecto y al flujo, libre o conducido. Cabe destacar que considerar al movimiento directo en el espacio significa que el movimiento del cuerpo se dirige a un punto determinado en el espacio, en tanto que se lo califica indirecto cuando se desplaza sin encaminarse a una dirección fija. Por su parte, el flujo del un movimiento es libre cuando presenta menor grado de tensión, y en el caso de que esa tensión crezca 
entonces se convierte en conducido. Para poder llevar a cabo el análisis de acuerdo con las categorías de cuerpo, fuerza y forma, en primer lugar observamos detenidamente el solo seleccionado y definimos 12 segmentos, atendiendo por un lado a la trama narrativa que se va desarrollando y por el otro, a la conformación de pequeñas frases o motivos musicales. Cada uno de los segmentos que establecimos fue analizado siguiendo los pasos que se detallan a continuación: (i) descripción general del movimiento y del sonido de cada segmento; (ii), extracción de fotogramas de cada segmento; (iii) selección de los fotogramas: se eligieron 5 fotogramas, el primero, el último y 3 fotogramas intermedios donde se alcanzan los puntos extremos de cada movimiento, intentando con ello explicitar la forma del movimiento; (iv) análisis de cada movimiento de acuerdo con las categorías Laban-Bartenieff e (v) interrelación movimiento-sonido-tiempo. Es preciso mencionar que para explicitar la forma del movimiento se trazó un segmento tomando como punto fijo entre fotogramas la frente del músico, porque representa un lugar del cuerpo que no está comprometido con los aspectos técnicos que implica la ejecución de la flauta. Para este análisis se usó la filmación de la cámara de frente. Sin embargo, se utilizó también el registro de la cámara de perfil, principalmente, para observar la amplitud del movimiento. En otras palabras, la toma de perfil se usó para completar lo que se observa en el plano de frente, ayudando así a completar la descripción cualitativa. Dicho esto, pasamos entonces a la descripción general del solo.

\section{INTERPRETACIÓN Y DISCUSIÓN DE RESULTADOS}

Como anticipamos en la introducción, la escena que analizamos corresponde a un solo improvisado por el flautista Rubén Izarrualde. El solo dura 1'25" y posee un carácter agitado, que no está dado únicamente por cómo está interpretado, sino también por el modo en que los músicos del grupo lo acompañan. Para que el análisis sea factible, el solo fue dividido en fragmentos breves, atendiendo en primer lugar a la trama narrativa y en segundo lugar, al contenido sonoro en términos de la conformación de un tema. De este modo, el solo presenta una introducción, una sección de desarrollo, que comprende primera y segunda parte, y una sección final. A su vez, la introducción está formada por 2 segmentos breves; el desarrollo 1, por 4 segmentos; el desarrollo 2, por otros 4 segmentos y la sección final por 2 segmentos más; quedando entonces dividido el solo en 12 segmentos breves.

Dentro de la introducción, el segmento 1 posee aproximadamente 11" de duración. En cuanto al sonido, encontramos que el flautista ejecuta 3 diseños melódicos que ascienden de modo cromático, sincopados, y luego, un descenso que presenta saltos y repeticiones de alturas, y con ello mayor densidad cronométrica. Con respecto al movimiento, se observa que el músico mueve el torso, los hombros y la cabeza de modo sutil y breve, aunque tenso. Hacia el final, comienza a mover las piernas de modo similar. En términos de esfuerzo, los movimientos son livianos, directos y conducidos. Sin embargo, cuando describimos los movimientos en el tiempo encontramos que si se trata del torso, el movimiento en el tiempo es sostenido. En cambio, cuando el movimiento es realizado por las piernas el factor tiempo se caracteriza como súbito. En la figura 1 podemos observar 
los fotogramas seleccionados (con su correspondiente número indicado arriba), las partes del cuerpo que realizan el movimiento y la clasificación de los factores que intervienen en la fuerza de ese movimiento (peso, espacio, tiempo y flujo), una línea de tiempo (en segundos) y la transcripción de la melodía que improvisa el flautista en el segmento 1. Además, sobre los fotogramas aparece una línea amarilla para describir la forma del movimiento (sobre la frente) y flechas en rojo para indicar el movimiento del torso y en verde, para el movimiento de las piernas.

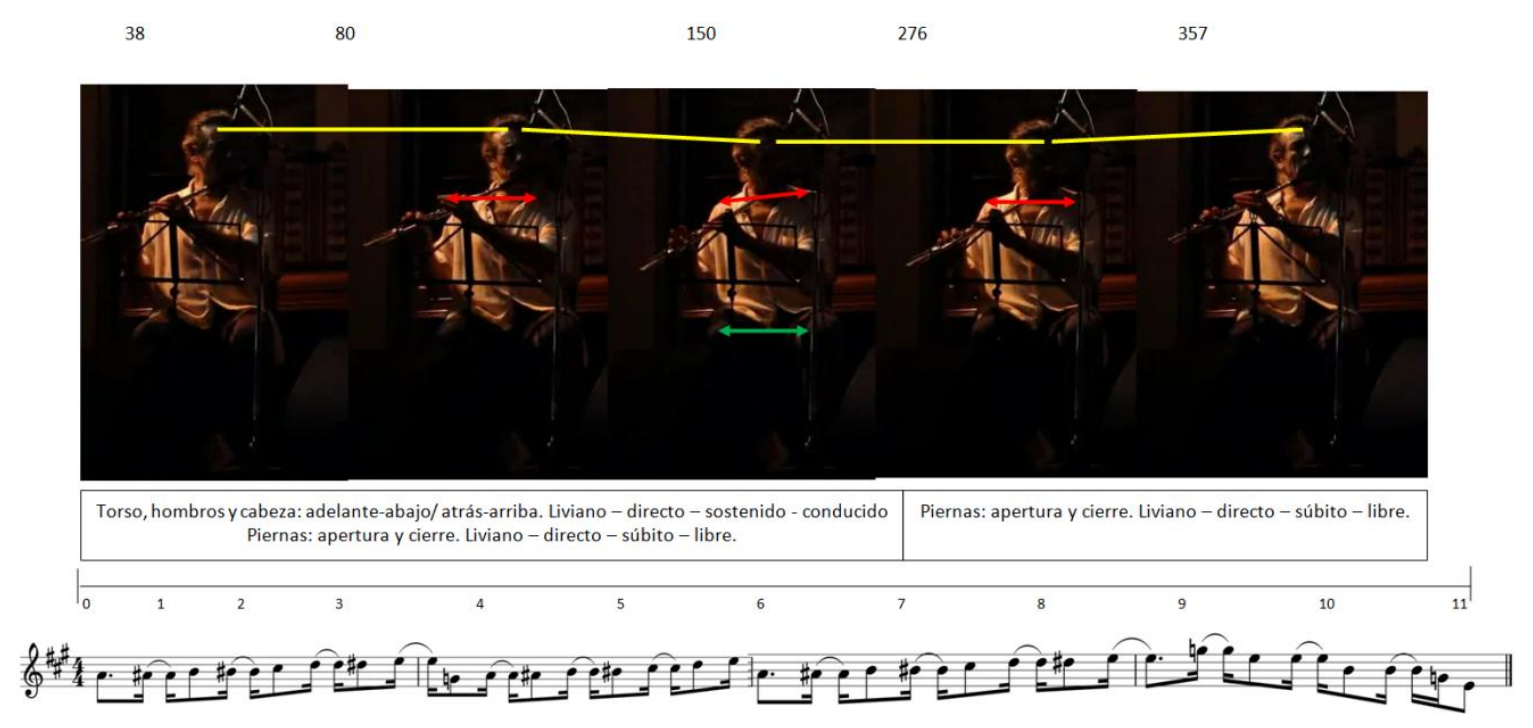

Figura 1: fotogramas, caracterización e improvisación del segmento 1.

Las líneas en amarillo muestran que el movimiento que el músico realiza con el torso es en un comienzo recto, luego presenta un descenso (fotograma 150), que se mantiene (fotograma 276) y finalmente un ascenso (fotograma 357). La forma presenta mayor oscilación hacia el final, y ello podría estar vinculado con que luego del descenso, el movimiento de las piernas está más presente. La forma podría estar mapeando la melodía en términos de cambio: a medida que el cambio melódico que se desarrolla sobre el final se acerca, la forma va mostrando mayor variabilidad con respecto al comienzo. En cuanto al esfuerzo, los movimientos difieren en cómo se comporta el factor tiempo (en el torso los hombros y la cabeza es sostenido, mientras que en las piernas súbito). Esto podría indicar que aunque la forma del cuerpo muestre una trayectoria determinada, las extremidades por ejemplo pueden, al mismo tiempo, estar realizando movimientos que impliquen otros grados de esfuerzo y con ello, mapear otros elementos de la configuración melódica. En este caso, el movimiento de las piernas parecería estar más vinculado al ritmo de la melodía, dado que las características del comportamiento que presentan los factores de peso, espacio, tiempo y flujo en el desarrollo de ese movimiento conforman una serie de impulsos sobre que el músico va improvisando más rítmicamente la melodía.

Finalizando la introducción, aparece el segmento 2, que tiene una duración de 5 ". En este segmento el flautista realiza 7 diseños melódicos que descienden por saltos, empleando 
en algunos casos alturas que provienen de un acorde disminuido. Al mismo tiempo, realiza un movimiento por cada diseño (hasta el quinto diseño) hacia adelante-abajo 'dirigido' por la cabeza. Hacia el final, desplaza la cabeza y el torso hacia arriba-atrás. En la figura 2 exhibimos el movimiento corporal (sintetizado por los fotogramas seleccionados), la clasificación y la improvisación del segmento 2 .

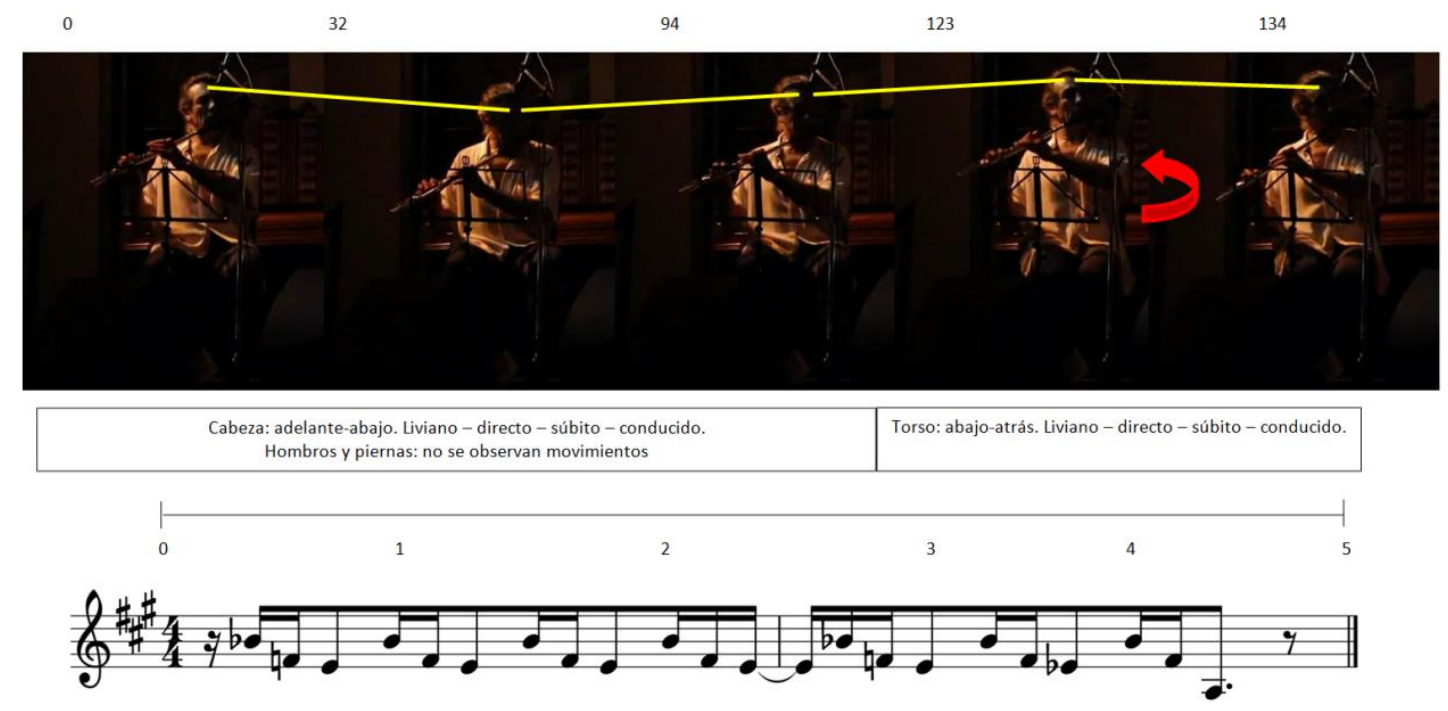

Figura 2: fotogramas, caracterización e improvisación del segmento 2.

En este caso, se observa un descenso y un acenso, ambos graduales, evidenciados por la línea que trazamos para describir la forma. Durante el descenso, la forma del movimiento se asemeja al contorno melódico. En cambio, en el ascenso se invierte la relación entre forma del movimiento y contorno melódico. Quizás, porque ese ascenso funciona como preparación para el próximo diseño melódico. Si esto fuera así, entonces en algunos momentos la forma del movimiento estaría mapeando la direccionalidad de la melodía y en otros, podría ser la resultante de un proceso de anticipación y por eso, no necesariamente se condiga con el tipo de contorno melódico que se ese ejecuta en ese momento. En términos de fuerza, los movimientos presentan comportamientos similares en los factores de peso, espacio, tiempo y flujo. Esta similitud indicaría que los movimientos realizados con la cabeza y con el torso son parte de un mismo movimiento. Dada la cercanía entre ellos, serían menos probable que cada uno realice movimientos que difieran en la fuerza. Con respecto a los hombros y las piernas, no encontramos movimientos salientes. La fuerza del movimiento de la cabeza y el tronco podría mapear la improvisación de la melodía sobre un nivel de agrupación menor, en este caso, sobre cada diseño melódico; ya que a cada uno le corresponde un comportamiento específico de la fuerza.

Luego, comenzando la primera sección de desarrollo, encontramos el segmento 3 que posee 6" de duración. El mismo se inicia con un ascenso cromático rápido que desemboca en un motivo más cantable, empleando también el silencio como recurso, a partir del cual, el diseño melódico puede explicarse en función de de dos pequeñas partes, aunque de mayor duración y mayor densidad cronométrica la primera con respecto a la segunda. 
Mientras improvisa este segmento, el flautista levanta los hombros, principalmente el hombro derecho, y luego, desplaza bruscamente el torso hacia adelante-abajo. Al mismo tiempo, desplaza la cabeza en idéntica dirección, pero además girándola hacia la izquierda. Participan también las piernas de este desplazamiento. En la figura 3 mostramos la síntesis del movimiento corporal, su clasificación y la partitura de la improvisación que suena en el segmento 3 .

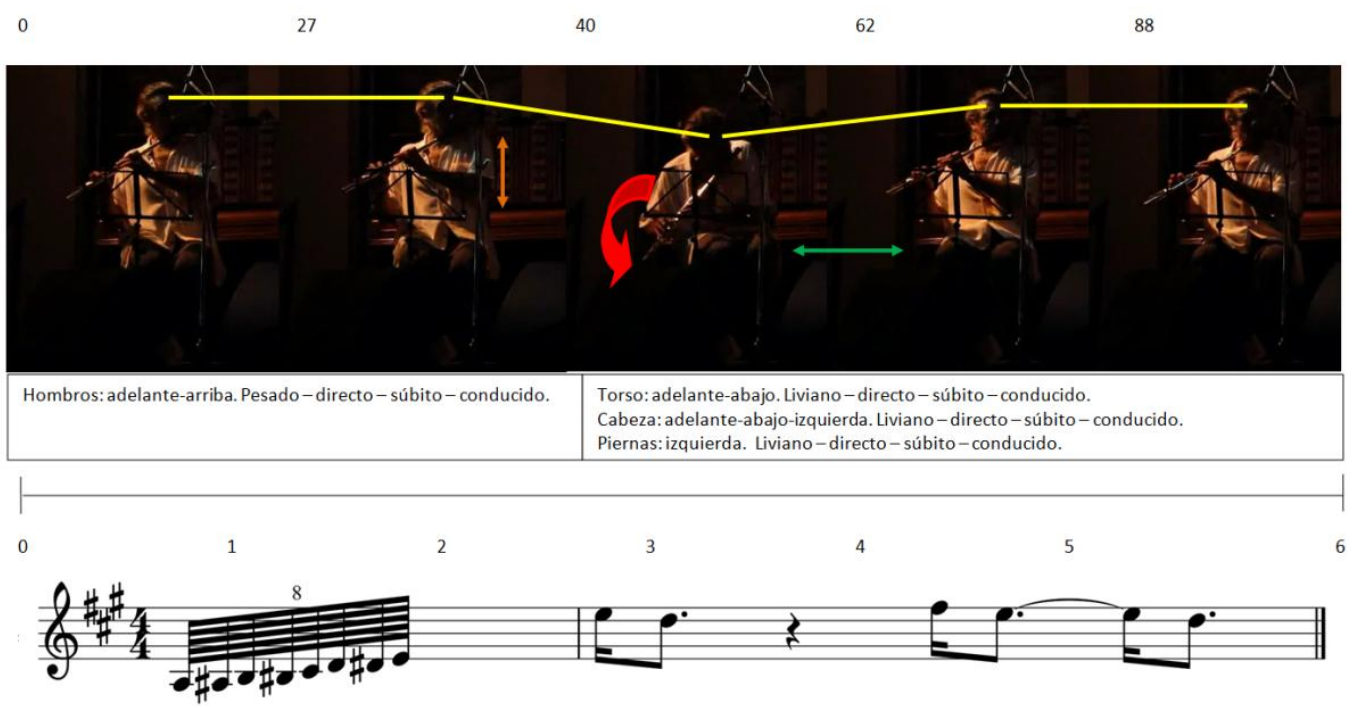

Figura 3: fotogramas, caracterización e improvisación del segmento 3.

La forma resultante es simétrica, ya que se suceden un descenso y un ascenso de similar duración. Hay un punto de llegada que a su vez es punto de partida (fotograma 40) en el movimiento del torso, la cabeza y las piernas, que coincide con la articulación de la nota re (precedida por una apoyatura). Justamente, esa altura conforma la tónica de ese fragmento. Entonces, la forma del movimiento de caída con el torso y la cabeza, principalmente, estaría mapeando la llegada a la tónica. En términos de esfuerzo, los movimientos producidos por las diferentes partes del cuerpo son semejantes, a excepción de lo que sucede con el peso del movimiento de los hombros, que es mayor que el peso de los movimientos restantes. Esto podría estar relacionado con el peso en términos de tensión, generada por el ascenso cromático de valores irregulares que el flautista improvisa al comienzo del segmento. Por su parte, el esfuerzo que implica la caída que producen la cabeza y el torso, con la participación de las piernas (fotograma 40) se caracteriza como liviano, directo, súbito y conducido y ello, estaría implicando una estrecha vinculación con el contenido melódico en términos de tensión y distensión melódica. En otras palabras, el movimiento corporal se encarga aquí de mapear el movimiento melódico.

Continúa el desarrollo el segmento 4, de 8" de duración. El flautista utiliza para improvisar su melodía un ascenso y un descenso cromático y luego un diseño por saltos que va acrecentando la tensión, tanto por las alturas que posee como por la zona donde suceden 
(emplea saltos disonantes y está sobre el final de una vuelta). En cuanto al movimiento corporal, inclina torso y cabeza hacia adelante-abajo, levanta los hombros y finalmente, realiza 3 giros con el torso y la cabeza, que se evidencian en la trayectoria que realiza la flauta. Por su parte, las extremidades inferiores se encuentran más estáticas. En la figura 4 podemos apreciar el movimiento corporal, su clasificación y la improvisación del segmento 4.

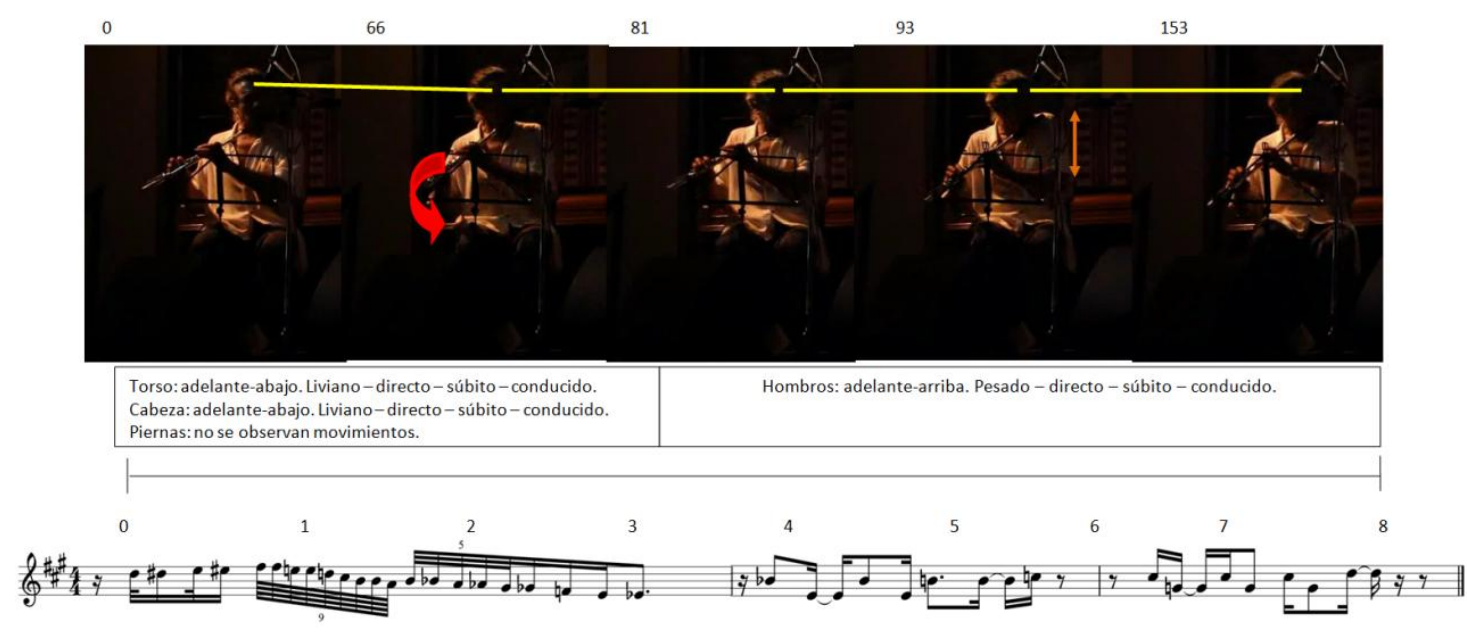

Figura 4: fotogramas, caracterización e improvisación del segmento 4.

La forma del movimiento muestra un movimiento descendente muy sutil (entre los fotogramas 0 y 66) y luego se mantiene recta. En comparación con el segmento anterior, aquí la amplitud de ese descenso es visiblemente más pequeña. Sin embargo, se produce cuando el músico está empleando en su improvisación un cromatismo descendente. En este sentido, el movimiento corporal estaría mapeando el movimiento melódico. En cuanto a la fuerza, los movimientos del torso y la cabeza son similares, lo que indicaría que una de las dos partes dirige el movimiento y la otra queda subordinada. Por su parte, los hombros mantienen el esfuerzo de los demás movimientos, pero cambian en cómo se comportan respecto del peso. Que la calidad del peso sea mayor en los hombros podría estar avalando a la hipótesis de que el movimiento corporal mapea el movimiento melódico en términos de tensión, ya que el músico improvisa allí un pasaje extremadamente tenso, que conforma el final de una frase melódica armonizada por un acorde dominante.

Comienza luego el segmento 5, que tiene una duración de 6". El inicio comprende un motivo cantable, que emplea algunas alturas cromáticas y presenta una densidad cronométrica menor a la que se usa en la mayor parte del solo. Luego, aparece un diseño descendente cromático y la densidad cronométrica es mayor. Mientras improvisa estas melodías, el flautista mueve las piernas en dirección derecha-izquierda-derecha, coincidiendo ese movimiento con el nivel de pulsación del tiempo de la obra. Luego, mueve sutilmente la cabeza y el torso, haciendo unos pequeños rebotes abajo arriba, para terminar en una postura más erguida. Los hombros permanecen quietos. En la figura 5 
exhibimos el movimiento corporal, la clasificación y la partitura de la improvisación en el segmento 5 .

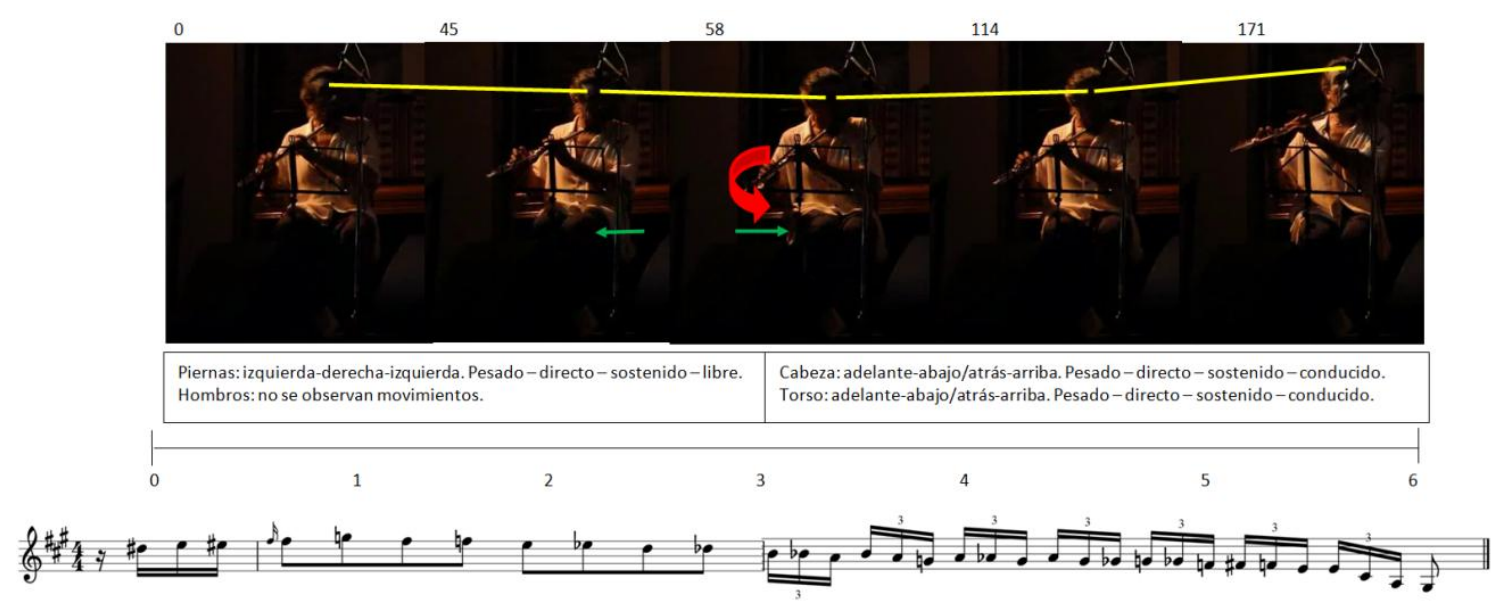

Figura 5: fotogramas, caracterización e improvisación del segmento 5.

La forma del movimiento muestra un descenso prolongado (hasta el fotograma 114) y un ascenso súbito (fotograma 171). Si observamos detenidamente la partitura vamos a notar que el movimiento melódico, si bien presenta un rápido ascenso al comienzo y algunas bordaduras en el segundo compás, se configura en forma descendente. En este sentido, la forma del movimiento corporal estaría mapeando el movimiento melódico. Con respecto al esfuerzo, los movimientos son similares, salvo en la conducta que presentan en el factor flujo. El torso y la cabeza se mueven con un flujo conducido, esto es, el flujo de ese movimiento posee mayor tensión. En cambio, el flujo del movimiento de las piernas es libre porque denota menor tensión en el movimiento que producen (recordemos que realizan un vaivén que parece articular con el nivel del tiempo musical). Esto revelaría que la fuerza del movimiento de la cabeza y del torso se encuentra más estrechamente vinculada con el movimiento melódico, en tanto que las extremidades inferiores se relacionan más con los aspectos métricos de la pieza; al menos en algunas secciones de la pieza.

El segmento 6, de 9" de duración, finaliza la primera sección de desarrollo. El flautista improvisa primero una melodía cantable, con figuras de valores más largos que los que habitualmente utiliza. Luego, un diseño eminentemente descendente, cromático, que alterna figuras de escasa duración y valores irregulares. Con respecto al movimiento, se suceden distintos movimientos, que involucran desplazamiento de los hombros hacia arriba, el torso y la cabeza hacia adelante marcando pequeños giros, las piernas hacia abajo y luego, se retoma el movimiento circular del torso y la cabeza pero en trayectorias más largas (que se evidencia además en la distancia que recorre la flauta). Hacia el final del segmento los hombros y las piernas no expresan movimiento. En la figura 6 reunimos el movimiento corporal, la caracterización y la improvisación del segmento 6 , en dos partes debido a la longitud del segmento. 


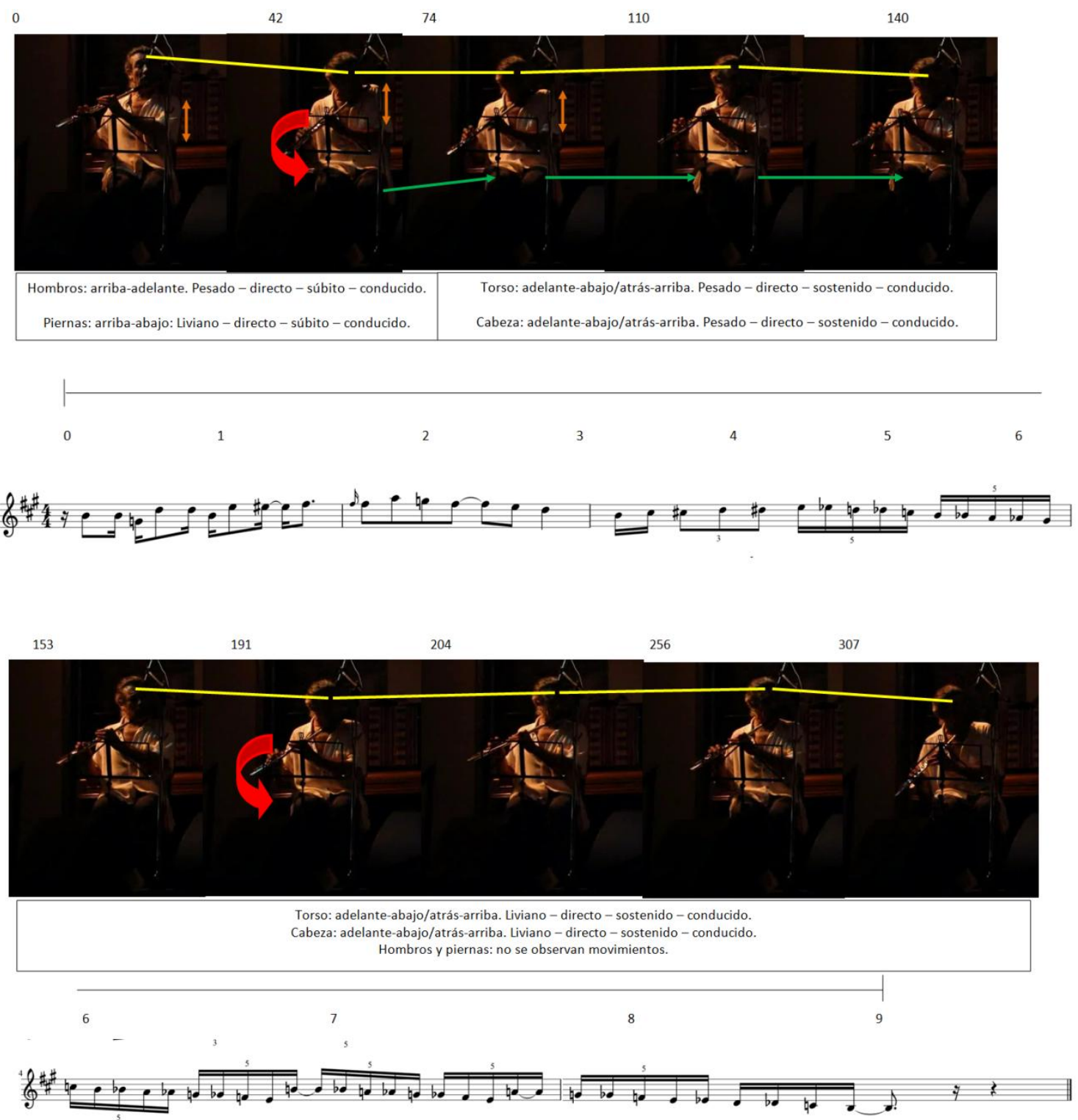

Figura 6: fotogramas, caracterización e improvisación del segmento 6.

La forma del movimiento alterna ligeros ascensos y descensos. En la primera parte del segmento (fotogramas 0 a 140) a grandes rasgos, esto se corresponde con el movimiento melódico. En la segunda (fotogramas 153 a 307) esto no parece ser tan directo. En este caso, si bien habría secciones donde la forma del movimiento corporal mapea el movimiento melódico, también sería posible que dicha forma mapee otros aspectos. Por ejemplo, esta segunda parte se compone de un descenso articulado de modo cuasi cromático con valores irregulares y su forma sigue siendo semejante a la de la primera parte. Sin embargo, la fuerza no es la misma. Y en ese sentido, podríamos decir que puede haber elementos inherentes a la melodía (por ejemplo los valores irregulares que presenta) que no alcancen para configurar un cambio en la forma general del movimiento, pero sí en la fuerza que implica el movimiento. Probablemente, si fraccionáramos en partes más pequeñas este segmento nos encontraríamos una nueva forma resultante y con ello, la posibilidad de explicar más parcialmente cómo se produce el desarrollo de la 
forma en el tiempo. Con respecto a la fuerza, en la primera parte el movimiento de los hombros, el torso y la cabeza se caracteriza de la misma manera, aunque posean distinta direccionalidad. Por su parte, la fuerza del movimiento de las piernas sólo difiere del torso, los hombros y la cabeza en el que el peso es menor. Esto implicaría, como ya hemos dicho anteriormente, que las extremidades inferiores podrían ser capaces de realizar un movimiento que implique una fuerza diferente a la que es llevada a cabo por el movimiento de la parte superior del cuerpo (excluyendo las extremidades superiores). Esto implicaría que mientras la cabeza y el torso mapean un aspecto de la melodía, las extremidades inferiores pueden al mismo tiempo mapear otros elementos que conforman la melodía. En la segunda parte, mientras los hombros y las piernas entran en una zona de reposo, la cabeza y el torso se mueven en forma unánime, cambiando con respecto a la parte anterior el peso. Ahora, se mueven de manera liviana. Quizás, esto podría vincularse particularmente con la utilización del valor irregular, dado que el cambio del esfuerzo empieza ya hacia el final de la primera parte (fotograma 140).

Con el segmento 7, de 4" de duración, comienza la segunda sección de desarrollo. En este segmento, el músico improvisa un diseño melódico por saltos, que se repite. El diseño es muy cantable, y quizás provenga de alguna pieza conocida dentro del campo de la música popular. Es interesante destacar que el guitarrista había tocado en su solo (que es antecede al del flautista) un motivo similar, porque ello abona a una de las particularidades de la improvisación como modo de conocimiento musical. En cuanto al movimiento, aquí ocurren 3 movimientos marcados con la cabeza y el torso: primero hacia adelante-derecha-abajo, luego, con pequeños rebotes abajo-arriba; y por último, en un desplazamiento derecha-atrás. Los hombros y las piernas se encuentran en una zona de reposo. En la figura 7 mostramos movimiento corporal, características y partitura de la melodía improvisada en el segmento 7.

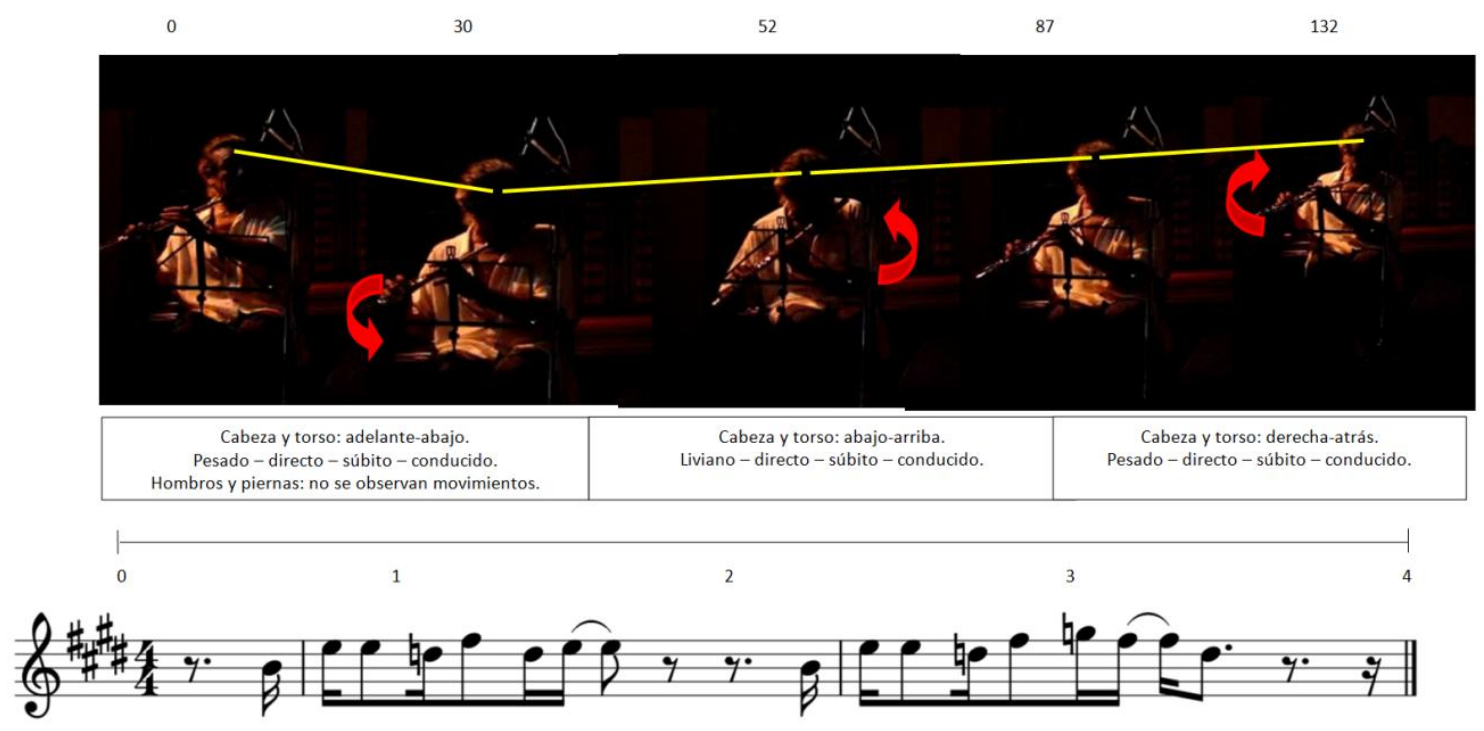

Figura 7: fotogramas, caracterización e improvisación del segmento 7. 
La forma del movimiento implica un brusco descenso y un ascenso paulatino. El punto extremo del descenso (fotograma 30 ) se da casi sobre el final de lo que constituye el primer motivo de la improvisación e inmediatamente comienza el ascenso casi sobre el segundo motivo. Esto podría indicar que la forma del movimiento condice en esta ocasión con la estructura morfológica del fragmento. Con respecto al esfuerzo, se clasifica de manera similar los movimientos del torso y cabeza adelante-atrás y derecha-atrás, salvo en lo que refiere al peso (primero y tercer recuadro de la figura 7). En cambio, cuando el movimiento es abajo-arriba, es liviano. Una de las razones por las que podría cambiar el peso entre estos movimientos puede ser el comportamiento del factor tiempo durante el transcurrir de los mismos. En este caso, pasar del movimiento abajo-arriba al movimiento derecha-atrás, estaría regulado por la estructura morfológica que mapea la forma del movimiento. Esto es, para pasar de un movimiento a otro, no sólo no hay demasiado tiempo, sino que ese tiempo está limitado por esa estructura. Es por eso que el peso estaría cambiando, volviéndose liviano, para poder continuar rápidamente. La fuerza del movimiento parecería ser copartícipe en el mapeo de la estructura morfológica.

Continuando, en los 4" de duración que presenta el segmento 8, el flautista improvisa un diseño melódico cromático descendente compuesto por 4 alturas y luego, un salto ascendente a partir del cual genera una secuencia. Mientras tanto, realiza una serie de movimientos circulares con la cabeza y el torso que finalizan en una agitación breve. Las piernas y los hombros continúan en reposo. En la figura 8 desplegamos la forma del movimiento, las particularidades y el contenido improvisado del segmento 8.

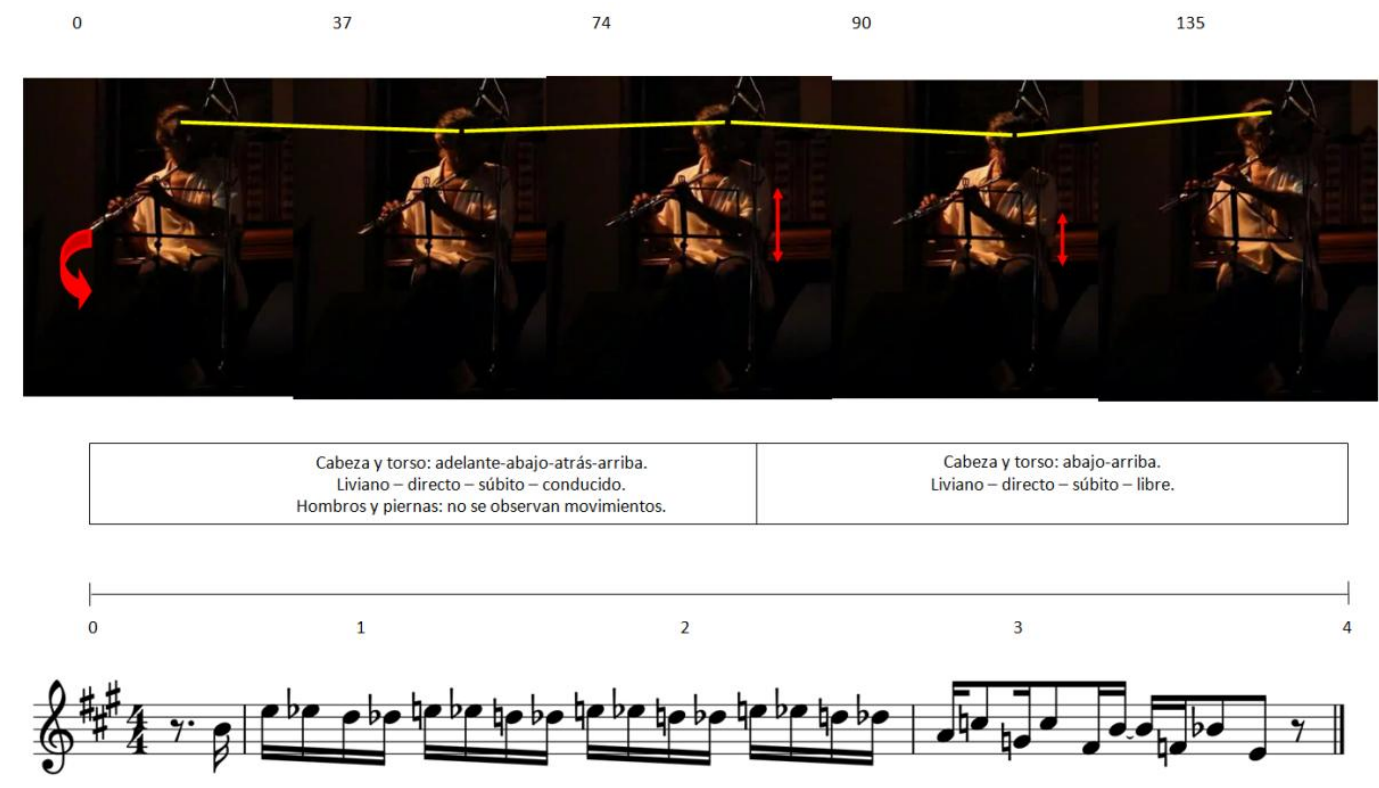

Figura 8: fotogramas, caracterización e improvisación del segmento 8.

La forma del movimiento estaría concordando con el contorno melódico dado que en el comienzo se sucede un tenue descenso y ascenso (fotogramas 0 a 74) y sobre el final un descenso y ascenso más marcado (fotogramas 90 a 135) y esas características ocurren también en la improvisación (el primer compás implica descenso y ascenso sutil, mientras que el segundo es más grosero). En cuanto a la fuerza, el cambio está en el 
comportamiento del flujo. Al principio es conducido, es decir, que implica mayor tensión y hacia el final es libre, y entonces la tensión va decayendo. Quizás el modo en que se comporta el flujo de la fuerza del movimiento podría relacionarse con la tensión sonora que implica la melodía que está improvisando, que luego se relaja a medida que se alcanza un determinado grado de resolución. Asimismo, esta libertad del flujo podría estar indicando una anticipación a la frase musical siguiente, porque ello en sí mismo también es un modo de resolución.

Por su parte, el segmento 9 dura 6" y allí el improvisador toca un motivo melódico breve, que luego repite en forma de secuencia y cada repetición la separa empleando silencios. Hacia el final, el motivo adquiere mayor densidad cronométrica dada por la repetición de alguna de las alturas que lo componen. Se observa un movimiento de marcación con la cabeza y el torso, a veces hacia la derecha, otras hacia la izquierda, que contrasta con zonas de escaso movimiento. Hacia el final, las marcaciones se transforman en un vaivén que denota mayor continuidad y velocidad. Por su parte, hombros y piernas prolongan el reposo. En la figura 9 exhibimos el movimiento corporal, sus características y la melodía improvisada del segmento 9.

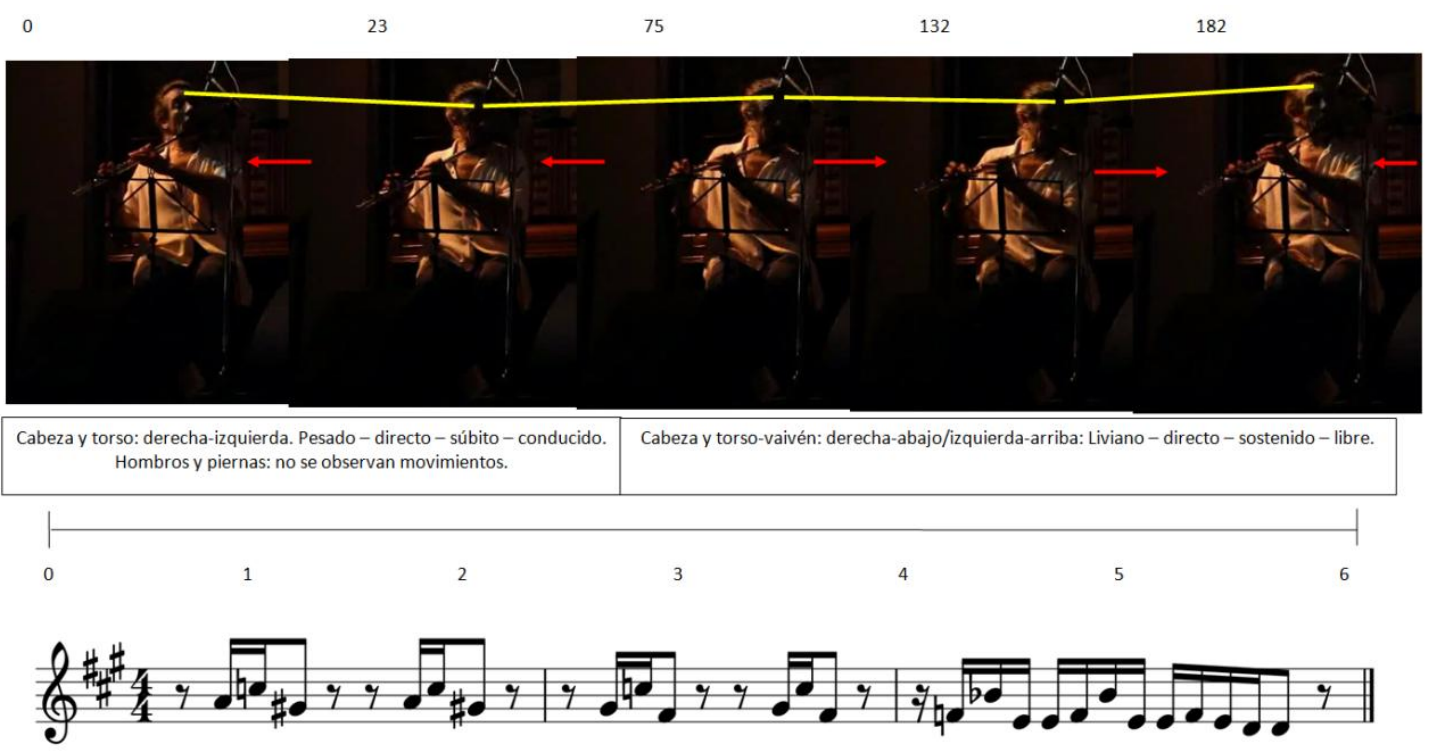

Figura 9: fotogramas, caracterización e improvisación del segmento 9.

La forma del movimiento muestra una alternancia entre leves ascensos y descensos, excepto hacia el final. En un sentido general, esta forma se correspondería con el contorno melódico. En cuanto al esfuerzo, el primer movimiento implica mayor peso, velocidad y tensión que el segundo (ver recuadros figura 9). Sin embargo, el espacio es el mismo. Esto implicaría que cuando la fuerza del movimiento ocurre junto a un evento que se encuentra separado en el tiempo (en este caso cada patrón del primer y del segundo compás están separados por silencios), el comportamiento de los factores peso, tiempo y flujo tienen la posibilidad de inclinarse hacia el extremo mayor: mayor peso, mayor velocidad, mayor tensión. En cambio, cuando esa fuerza sucede junto con eventos iguales (sobre el final, donde se ejecutan figuras de igual duración sin separaciones) parecería que estos factores 
requieren de otro comportamiento, que implica menor peso, velocidad y tensión. En este sentido, la fuerza del movimiento corporal manifiesto en la cabeza y el torso podría estar mapeando la articulación del ritmo de la melodía.

El segmento 10, de 9" de duración, configura el final de la segunda parte del desarrollo. En términos de sonido, ocurre un ascenso cromático hasta una altura aguda (casi sobre el extremo del registro) que se ejecuta con un valor largo; luego, un descenso cromático hasta una altura grave (también cercana al extremo) y finalmente, un diseño por saltos que va alcanzando cada vez más tensión, dada por la intensidad y por las alturas que en él se emplean. En cuanto al movimiento, el flautista levanta los hombros; comprime el torso dirigido por la cabeza mientras mueve rápidamente las piernas; y retoma el vaivén derecha-izquierda anteriormente efectuado. En la figura 10 exponemos el movimiento, la caracterización y la improvisación realizados en el segmento 10.

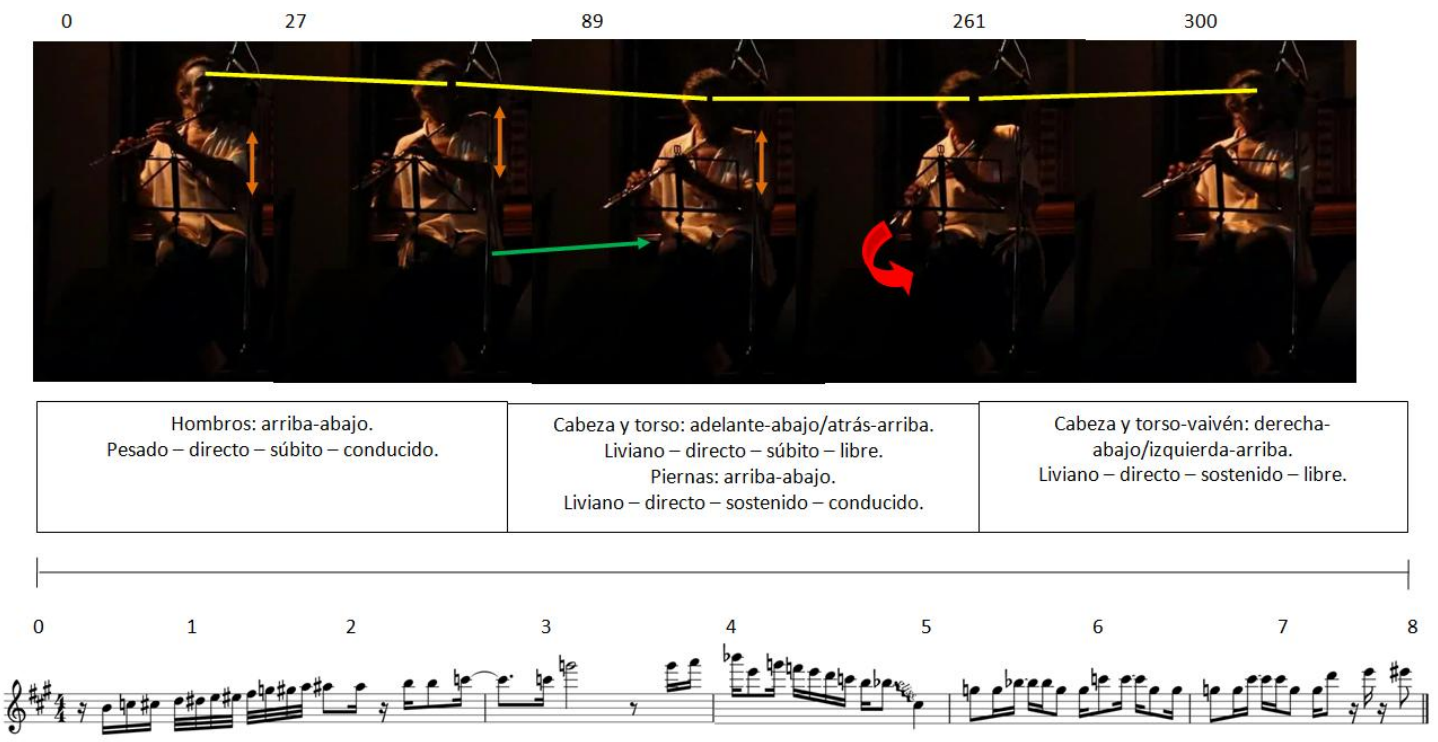

Figura 10: fotogramas, caracterización e improvisación del segmento 10.

La forma del movimiento está determinada por un descenso que se prolonga hasta la mitad del segmento (fotogramas 0 a 89), un mantenimiento (fotograma 261) y un ascenso gradual en el final (fotograma 300). Los puntos extremos están dados en el medio y hacia el final del segmento (fotogramas 89 y 261). La forma entre ellos se mantiene y luego continúa en un ascenso. La forma podría corresponderse con lo que ocurre en términos de dinamismo del movimiento melódico: el ascenso inicial implica la llegada a un sonido más largo que tiene un peso mayor que las restantes (la nota sol en el segundo compás); luego una zona de mantenimiento, que se debe a que ninguna de las alturas tiene un peso mayor (compás 3 ) y finalmente, el ascenso gradual hacia la meta próxima (primera altura del segmento siguiente). Por su parte, la fuerza del movimiento de los hombros también estaría mapeando la dinámica del movimiento melódico. Primero, en términos de la creciente tensión que implica el ascenso inicial. Luego, las piernas continúan con esa fuerza pero cambiando el peso (ver recuadros de la figura 10), probablemente porque 
podrían desvincularse de las características que presentan los movimientos efectuados por la parte superior del cuerpo. El torso y la cabeza prolongan el comportamiento del peso y el espacio, pero varían la conducta del tiempo y del flujo (ver recuadros de la figura 10). Esto implicaría que algunos movimientos implican comportamientos comunes de ciertos factores, mientras que la marcha de otros factores puede variar. En otras palabras, mover la cabeza y el torso adelante-abajo/atrás-arriba supone un esfuerzo liviano, directo, súbito y libre, mientras que mover las piernas implica un esfuerzo liviano y directa, pero sostenido y conducido en este caso; y ambos movimientos pueden darse en simultáneo, compartiendo el comportamiento de algunos factores (peso y espacio en este caso) y difiriendo en otros (tiempo y flujo).

La sección final del solo está compuesta por dos segmentos. En primer lugar, el segmento 11, que posee 6" de duración, donde el músico realiza un diseño por saltos, en su mayoría descendentes. Es el único segmento en el que la melodía se articula en el nivel del tiempo casi en su totalidad, y ello otorga cierta oxigenación al solo. Mientras realiza esta improvisación, el flautista realiza una contracción con el torso guiada por la cabeza casi coincidiendo con la articulación de cada altura y por momentos, ocurre junto a esa contracción la apertura y el cierre de las piernas. Los hombros vuelven al estado de reposo. En la figura 11 mostramos el movimiento corporal, la clasificación y la melodía improvisada en el segmento 11.

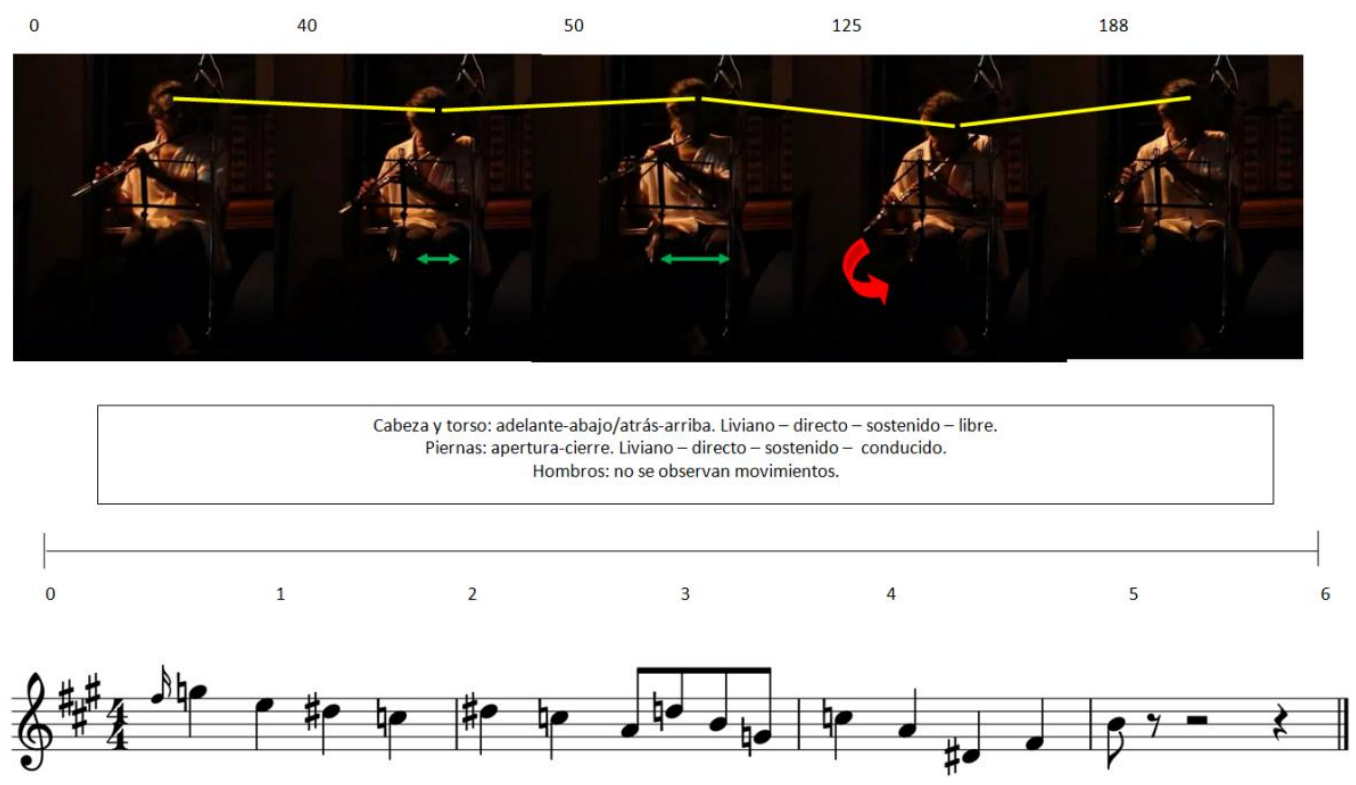

Figura 11: fotogramas, caracterización e improvisación del segmento 11.

La forma del movimiento implica dos diseños que alternan descenso y ascenso, el primero más sutil y el segundo más grosero. Eso se condice con lo que ocurre en términos de direccionalidad melódica en la improvisación. En este caso, la forma del movimiento estaría mapeando el contorno melódico. Los factores que determinan la fuerza se comportan de manera similar, a excepción del flujo. Como ya lo hemos observado en otros 
segmentos, esto implicaría un nivel de asociación y otro de disociación entre la fuerza que involucra el movimiento de distintas partes del cuerpo. La fuerza del movimiento del torso se correspondería aquí con la articulación del ritmo de la melodía, alternándose con la fuerza del movimiento de las piernas, que se ocupa más del mapeo de las articulaciones de los valores más cortos de la melodía.

Por último, el segmento 12, de 10" de duración configura el final del solo. En este cierre el flautista combina todo lo que fue saliendo durante el solo: emplea en primer lugar un ascenso que fusiona saltos y un rápido cromatismo, luego una variación de la melodía del segmento anterior y finalmente, un descenso cromático que se resuelve empleando nuevamente los saltos. En cuanto al movimiento, también parece haber claramente 3 partes: una inicial, donde abre y cierra rápidamente las piernas; otra, donde mueve la cadera levantándose de la silla, gira la cabeza y el torso para dirigir la mirada a los músicos restantes y luego mueve ambas partes casi señalando la articulación de cada nota; y la última, donde desliza sutilmente cabeza y torso hacia la derecha y luego hacia adelante, como indicando que ahora es el turno de otro músico. Los hombros continúan en reposo. En la figura 12 podemos observar el movimiento corporal, las particularidades y la partitura de la improvisación efectuada por el flautista como cierre de su solo improvisado.

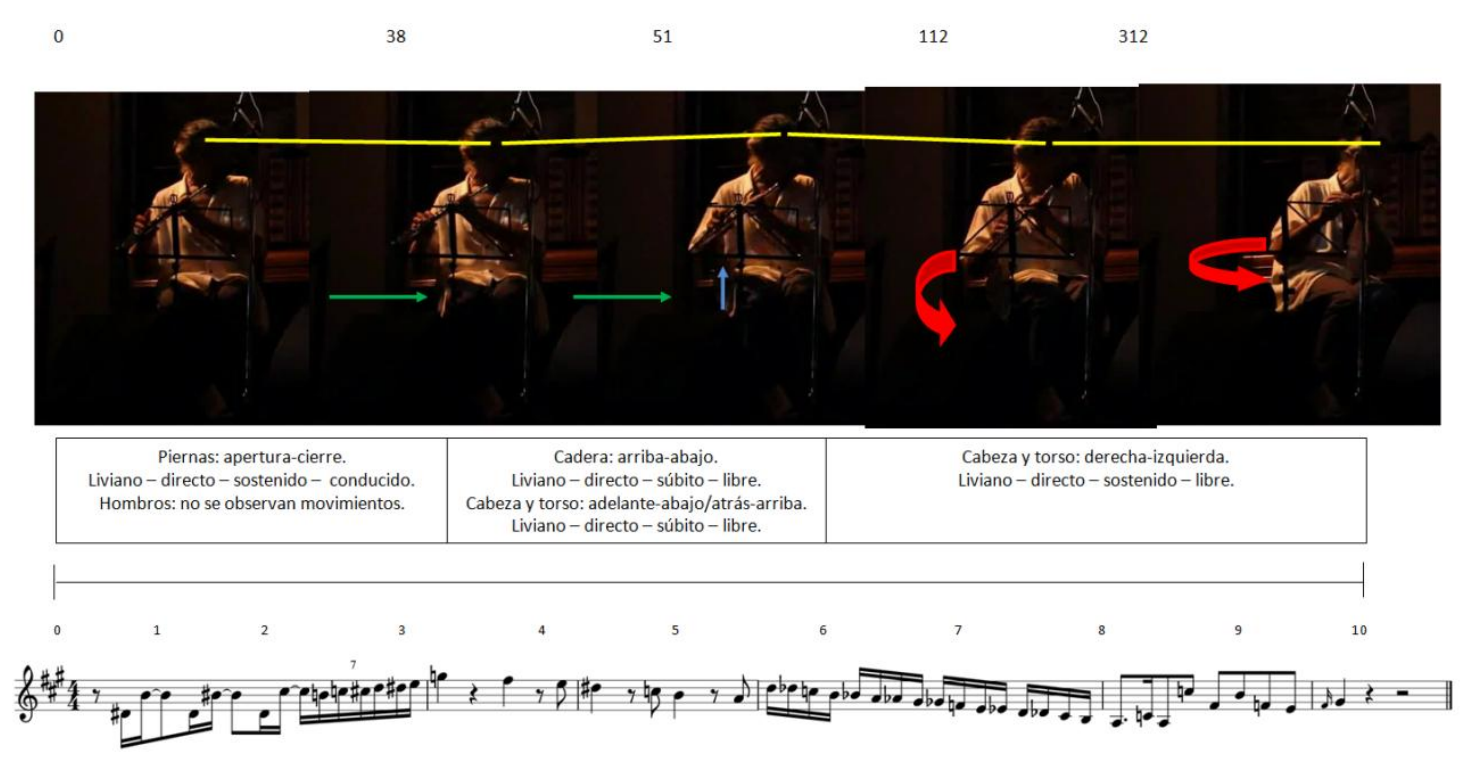

Figura 12: fotogramas, caracterización e improvisación del segmento 12.

La forma del movimiento queda esquematizada en un mantenimiento (fotogramas 0-38), un ascenso sutil (fotogramas 38-51), un descenso (fotogramas 51-112) y un mantenimiento hacia el final (fotogramas 112-312). En líneas generales, el diseño de la forma se correspondería con la dinámica del movimiento melódico. En primer lugar, el mantenimiento implica que entre las alturas ejecutadas durante el primer y el segundo compás no hay una que concentre una energía mayor. Luego, el ascenso se condice con la creciente tensión hasta alcanzar la meta en el tercer compás (la nota si constituye este punto de mayor energía). En tercer lugar, el descenso concuerda con la disolución de la 
tensión luego de la meta y finalmente, el mantenimiento conserva el nivel de tensión logrado. Con respecto a la fuerza, las piernas comparten con las partes del cuerpo restantes el comportamiento de los factores de peso y espacio, en tanto que difieren en tiempo y flujo (ver recuadros de la figura 12). Como habíamos supuesto anteriormente, aquí también los movimientos suponen tanto comportamientos compartidos como disímiles. Novedosamente, aparece el movimiento de la cadera y sus características son iguales a las del movimiento del torso y la cabeza. En este sentido, podríamos sugerir que la cadera también (además del torso y la cabeza) constituye otra de las partes del cuerpo que es dirigida, eventualmente por el torso. Por último, cambia la fuerza del movimiento de la cabeza y el torso en los factores de tiempo y flujo (ver recuadros de la figura 12). Esto podría deberse a que, dada la cercanía con el final de la frase, la tensión se disuelve. Con todo, la fuerza del movimiento también estaría sujeta a lo que sucede con respecto al dinamismo de la melodía.

\section{SUMARIO}

A lo largo de este capítulo hemos observado que la forma del movimiento corporal efectuado por la cabeza y el torso podría estar mapeando distintos aspectos de la configuración melódica: algunas veces la dinámica del movimiento, en términos de la tensión y la distensión sonora que se produce en el devenir melódico; otras veces, el contorno melódico; en otros momentos la articulación del el ritmo y en otros, la estructura morfológica de la melodía en cuestión. De aquí que la forma podría entonces mapear en algunos sitios aspectos más abarcadores, como la dinámica y la estructura morfológica, y en otros, aspectos más puntuales, como la articulación tanto del ritmo como del contorno de la melodía. Por otra parte, la forma del movimiento podría ser entendida como la resultante del desarrollo del movimiento en cada segmento que permitiría conocer el recorrido que posee cada movimiento, mostrando sintéticamente como el cuerpo va adoptando distintas posturas a través del movimiento y con ello, el transcurrir del movimiento corporal en el espacio.

En cambio, la fuerza del movimiento se ocuparía más del mapeo de los aspectos generales, ya que en la mayoría de los segmentos observamos un mapeo del desarrollo dinámico del la melodía. Sin embargo, también encontramos en algunos segmentos (por ejemplo en el 6 y en el 11) que el modo en que la fuerza se comporta podría evidenciar un mapeo del ritmo de la melodía. Además, otros segmentos (ver por ejemplo los segmentos 1 y 4) advertimos que la fuerza del movimiento de las extremidades inferiores puede tener características diferentes a la fuerza del movimiento de la parte superior del cuerpo. En otras palabras, estas partes del cuerpo pueden mostrar cierto grado de disociación en el desarrollo de la fuerza del movimiento que realizan. Esto podría deberse a que los movimientos sean visiblemente distintos, pero también, a que los movimientos sean similares en apariencia pero impliquen comportamientos distintos de cada uno de los factores que intervienen en él. A pesar de esto, con mayor frecuencia la fuerza del movimiento podría ser copartícipe, junto con la forma, en el mapeo del dinamismo 
melódico. Finalmente, retomando el planteo sobre el comportamiento de los factores que intervienen en la fuerza, encontramos que las actitudes de entrega o resistencia durante el movimiento de los factores peso, espacio y tiempo), posibilitan generan 8 tipos básicos de movimientos. A continuación los mencionamos e indicamos también cómo se clasifican respecto de su actitud. Por ejemplo, presionar, implica un movimiento en que cual la comportamiento de los factores de peso, espacio y tiempo puede describirse como pesado, directo y sostenido. En cambio, el movimiento de retorcer, es pesado, indirecto y sostenido. Siguiendo, deslizar, es liviano, directo y sostenido; flotar, es liviano, indirecto, sostenido; golpear con un puño, es pesado, directo y súbito; arremeter es pesado, indirecto y súbito; dar toques ligeros es liviano, directo y súbito y dar latigazos ligeros, liviano, indirecto y súbito (Español 2007). Algunos de los movimientos que realiza el flautista tendrían correspondencias con la fuerza que implican estos movimientos. Por ejemplo; el modo en que los factores que involucra la fuerza del movimiento se comportan cuando el flautista mueve la cabeza y el tronco hacia adelante (ver comienzos de los segmentos 7 y 9), podría ser equiparable al movimiento de golpear con un puño. En estos movimientos los factores de peso, espacio y tiempo se estarían comportando de la misma manera. En algunos casos, también el movimiento de los hombros responde a este mismo comportamiento (por ejemplo, como sucede en el segmento 10). También con el movimiento de deslizar, cuyo comportamiento de los factores es liviano, directo y sostenido; encontramos algunas correspondencias. Por ejemplo, el movimiento de apertura y cierre de piernas se caracterizaría del mismo modo que el movimiento de deslizar (ver segmentos 10, 11 y 12). Sin embargo, en algún caso, cuando el torso y la cabeza realizan un movimiento de vaivén (ver por ejemplo la 2da parte del segmento 9) también se puede caracterizar de acuerdo con el movimiento de deslizar. Por su parte, el movimiento de dar toques ligeros, cuyo comportamiento es liviano, directo y súbito, podría ser equivalente al movimiento de las piernas (apretura y cierre en el segmento 1; arriba y abajo en el segmento 6); del torso y la cabeza (en los segmentos 2,8 y 10 ) y de la cadera (en el segmento 12). En este sentido, este capítulo implica un pequeño avance en la descripción del movimiento corporal del ejecutante, a través de la caracterización de la forma y la fuerza que el movimiento conlleva en comparación con otros movimientos corporales más concretos, relativos a la vida diaria; ofreciendo así un punto de partida para continuar en la indagación del movimiento corporal en la improvisación musical. 



\section{EL MOVIMIENTO CORPORAL DEL MÚSICO Y EL ASPECTO MELÓDICO}

\section{INTRODUCCIÓN}

Aquí nos proponemos definir el rol del movimiento corporal del ejecutante en la improvisación musical. Para eso, retomamos el solo presentado en el capitulo anterior y la segmentación allí propuesta pero ahora nos dedicamos al análisis descriptivo basado en algunos datos cuantitativos (ver pág. 57). En primer lugar, describimos el movimiento corporal y la improvisación que cada segmento presenta. Luego, analizamos dos mediciones efectuadas sobre el movimiento realizado por la cabeza del ejecutante, porque en base a otras investigaciones, consideramos que esa parte del cuerpo podría ser entendida como la que sintetiza el movimiento general del cuerpo (Assinnato y Pérez 2011b y 2013, Assinnato, Shifres y Pereira Ghiena 2013). Finalmente, vinculamos las mediciones obtenidas con una partitura que realizamos intentando observar el modo en que se vinculan las mediciones con la improvisación resultante en cada segmento. En suma, este capítulo tiene como objetivo principal indagar el modo en que podría vincularse el movimiento de la cabeza del ejecutante y la melodía que mientras realiza ese movimiento improvisa, bajo la hipótesis de que el movimiento de la cabeza del músico mapea la configuración melódico-rítmica de la improvisación.

\section{METODOLOGÍA}

El método comprende 3 pasos: (i) descripción general, (ii) medición de la velocidad y de la cantidad de movimiento y (iii) vinculación con la melodía. En (i) se explica cómo se desarrollan en el tiempo y qué características presentan los movimientos y cómo se conforma y qué particularidades posee la melodía improvisada. En (ii) se realizan dos mediciones con el software VideoAnalysis sobre el movimiento de la cabeza, la velocidad absoluta (a partir de aquí, VA) y la cantidad de movimiento (desde ahora, QoM). La medida VA es la velocidad con la que se desplaza el centro de gravedad de la imagen del video. El programa calcula la posición del centro de gravedad de cada cuadro y lo compara con la posición del centro de gravedad del siguiente cuadro. De ahí se deriva la velocidad de desplazamiento sobre cada eje, sobre la que se calcula la velocidad absoluta del desplazamiento del centro de gravedad. De este modo es posible obtener una medida confiable de la velocidad del movimiento observado dentro del área seleccionada. La medida de Cantidad de Movimiento (QoM) compara de manera similar el cambio de pixeles entre cuadros determinando una cantidad de esos cambios. De este modo pondera la cantidad de cambios en la imagen que se registran entre un cuadro y el siguiente. Aquí no importa la distancia recorrida por el punto sino la cantidad de puntos que cambiaron. En (iii) se establecen relaciones entre estas medidas y la improvisación que se realiza en 
cada segmento, a partir de flechas, líneas y recuadros que permiten seguir mejor la interpretación de los gráficos. Entre las medidas que se pueden extraer de los segmentos con este software elegimos la QoM y la VA porque ya han sido bastante utilizadas para el análisis del movimiento corporal del músico (ver por ejemplo Friberg 2004, Camurri, Mazzarino, y Volpe 2004, Castellano et al 2008) y porque estas medidas podrían ofrecernos valiosos datos para caracterizar aspectos que aparecen en forma recurrente durante el movimiento y que podrían hallarse más cercanos al componente melódico de la música. Como decíamos en la introducción, para este análisis utilizamos los segmentos establecidos en el capítulo 3. Sin embargo, aquí tomamos los fragmentos provenientes de la toma de perfil porque esa toma nos permite realizar mejor las mediciones (en términos técnicos, porque no interfieren micrófonos ni atriles entonces el programa puede realizar las mediciones sin inconvenientes) y conocer mejor la amplitud del movimiento.

\section{INTERPRETACIÓN Y DISCUSIÓN DE RESULTADOS}

En el segmento 1, el flautista mueve el torso realizando pequeñas marcaciones hacia adelante con el torso y la cabeza y produce una apertura y cierre de las piernas; ambos movimientos en forma tensa. Como mencionamos en la introducción, aquí nos vamos a ocupar sólo del movimiento de la cabeza. Teniendo en cuenta los resultados del capítulo anterior, el movimiento del torso del músico está estrechamente vinculado con el movimiento de la cabeza. Es decir que cuando mencionemos la cabeza, estamos planteando un movimiento corporal más abarcador, que incluye también al torso. Ahora, mientras el flautista realiza esos movimientos con la cabeza, improvisa una melodía que consiste en la repetición de un patrón ritmico 4 veces (señalado con corchetes sobre la melodía). De esas 4 repeticiones, la primera y la tercera son iguales, mientras que la segunda presenta una sutil variación al comienzo (se inicia en la nota sol) y la cuarta cambia por completo el diseño melódico. Al observar la figura 1, podemos notar como la QoM (señalada con recuadros en color verde) es mayor en cuatro sitios con respecto a la melodía: en el final del primer y del segundo compás y sobre el $2^{\text {do }}$ y el $4^{\text {to }}$ tiempo del compás final, es decir, en la cuarta repetición. En líneas generales, la QoM es mayor cuando finalizan las repeticiones del patrón rítmico (excepto la tercera repetición). Que el movimiento se incremente sobre el final podría indicar que con él se está mapeando la estructura de la melodía al nivel del motivo, porque la mayor cantidad de movimiento se concentra antes de comenzar una nueva repetición o antes de pasar a un nuevo motivo, como sucede al final del segmento. 


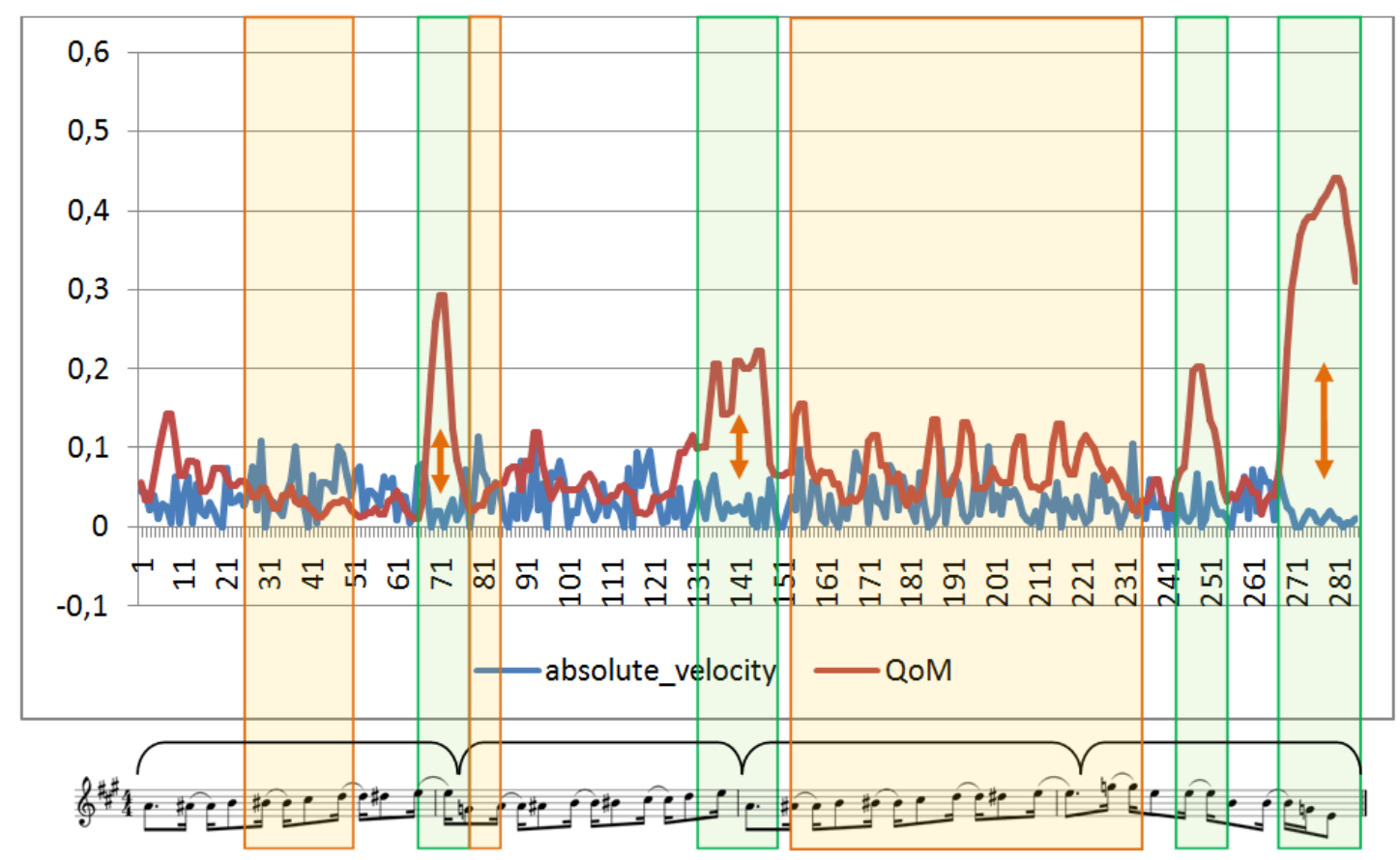

Figura 1: QoM y VA del segmento 1. El eje X indica el número de fotograma a lo largo del video, mientras que el eje Y utiliza números arábigos para ofrecer la medida.

Por otra parte, en la figura 1 observamos que la VA es más constante en las zonas donde la QoM es menor (en comparación con sus picos), esto es, donde habría menor movimiento (indicadas con recuadros en naranja) y menos constante cuando la QoM es mayor, es decir, en las zonas de mayor movimiento (ejemplificada con flechas en naranja). Más sintéticamente, cuando la cantidad de movimiento es mayor, la velocidad es menos estable. Esta estabilidad en la velocidad abarca el $2^{\text {do }}$ y el $3^{\text {er }}$ tiempo del primer compás; el $1^{\text {er }}$ tiempo del segundo compás; casi la totalidad del tercer compás y el $1^{\text {er }}$ tiempo del último compás. Ello indicaría que la VA podría estar maperando aspectos vinculados con la estructura métrica, ya que los sitios de mayor constancia se dan sobre el $1^{\mathrm{er}}$ y el $3^{\mathrm{er}}$ tiempo del compás, en este caso, los beats más fuertes del compás. Por otra parte, la VA presenta tres desaceleraciones que anteceden zonas de mayor constancia y coinciden dos de los picos de la QoM sobre los finales del primero, del segundo y del cuarto compás, respectivamente. Quizás esto sea una necesidad del ejecutante para poder retomar las zonas de VA constante.

Continuando, en el segmento 2, el flautista improvisa 7 motivos melódicos que descienden por saltos, empleando en algunos casos alturas que provienen de un acorde disminuido (señalados por corchetes y una letra arriba de la partitura). De estos 7 motivos, los motivos $a, b, c, d y$ e son iguales mientras que los restantes varían en una altura. Mientras improvisa este segmento, el músico realiza un movimiento hacia adelante-abajo con el torso y la cabeza y sobre el final, cambia por un desplazamiento hacia arriba-atrás con las mismas partes del cuerpo. En la figura 2 apreciamos que la QoM presenta picos durante toso el segmento (resaltados con recuadros en verde). Sin embargo, el pico inicial y los picos finales son los que alcanzan mayor altura. Esto podría indicar que el mapeo que 
realiza el movimiento corporal se relaciona con un nivel superior al del motivo, por caso, la frase, ya que estos picos parecerían marcan el comienzo y el final de una unidad de sentido. No obstante, si comparamos la cantidad de picos que señalamos en el gráfico con la cantidad de motivos que muestra la partitura, encontramos que hay mayor cantidad de picos que de motivos (9 picos) y esto, podría estar aludiendo a un mapeo menor al del motivo, por ejemplo, al nivel de la nota.

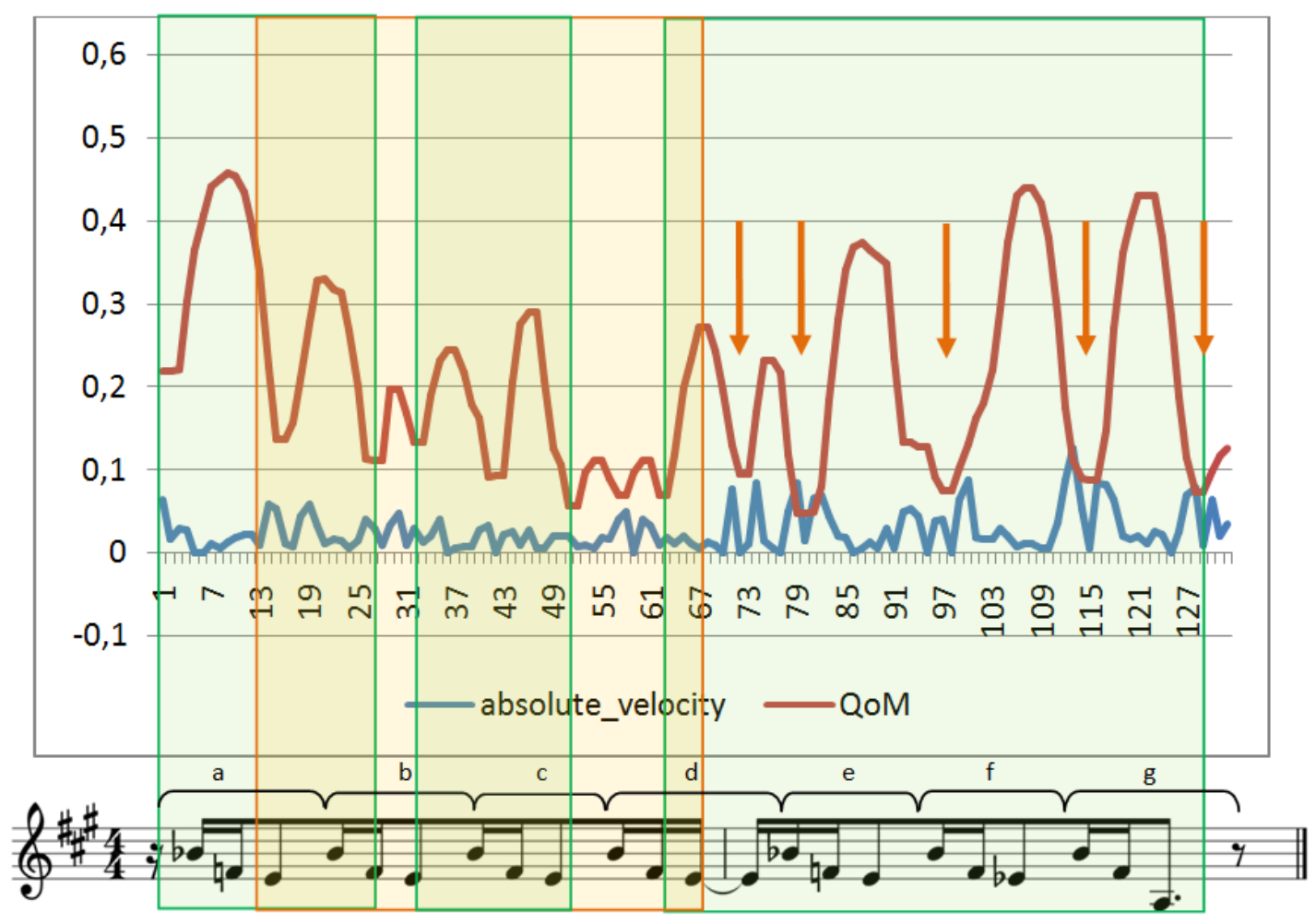

Figura 2: QoM y VA del segmento 2.

Por su parte, la VA presenta cierta regularidad cuando el flautista ejecuta los motivos b, c y $d$ (señalada con un recuadro naranja); se acelera luego del motivo $d$ y antes del g; y se desacelera durante los motivos a y e (indicado con flechas en naranja). Durante el b, c y d la VA es más regular, la QoM es menor y no hay variabilidad melódica. Esto podría indicar que la VA del movimiento corporal se encarga de mapear el nivel del motivo, expresamente la repetición motívica. Sin embargo, esto no es constante en los motivos restantes. Por el contrario encontramos que la VA es más irregular, incluso en lugares donde la QoM es mayor. Entonces, podría ser que la VA esté por momentos acelerándose, justo cuando la QoM es mayor (como sucede hacia el final); y que en otros momentos, la VA este desacelerándose (como sucede al comienzo); y que ello implique que estas dos medidas que extrajimos del movimiento puedan trabajar en conjunto. Esto significa que una no solapa a la otra, sino que el mapeo puede ser conjunto. No es que la QoM se encarga de una cosa y la VA de otra, sino que podría ser también que ambas mapeen en algunos momentos, como sucedería en este caso, el nivel del motivo (dado por la repetición motívica al comienzo) y en otros, un nivel de superficie de la estructura melódica (denotado por la variabilidad melódica al final). 
El segmento 3 comienza con un ascenso cromático rápido que desemboca en un motivo más cantable. Aparece aquí el por primera vez el silencio como recurso, a partir del cual, el motivo puede ser dividido en dos pequeños motivos. La primera de esas partes es de mayor duración y mayor densidad cronométrica en comparación con la segunda, que emplea también por primera vez una melodía cantable. Al mismo tiempo, el músico desplaza bruscamente la cabeza y el torso hacia adelante-abajo, inclinándola hacia la izquierda. En la figura 3 observamos que durante el primer motivo, la QoM tiene un comportamiento irregular, siendo en parte menor que la VA (indicado en el recuadro naranja); mientras que en el segundo motivo, la QoM es mayor e incluso más regular. Esto parecería reflejar que la mayor cantidad de movimiento se produce cuando la melodía plantea un cambio con respecto a lo anterior. Dada la regularidad, se podría pensar que el mapeo es ahora al nivel del motivo melódico. Sin embargo, también podría ser posible que exista un mapeo del ritmo de la melodía, porque cuando no hay sonido articulado (durante el silencio de negra que separa los motivos) la QoM se mantiene.

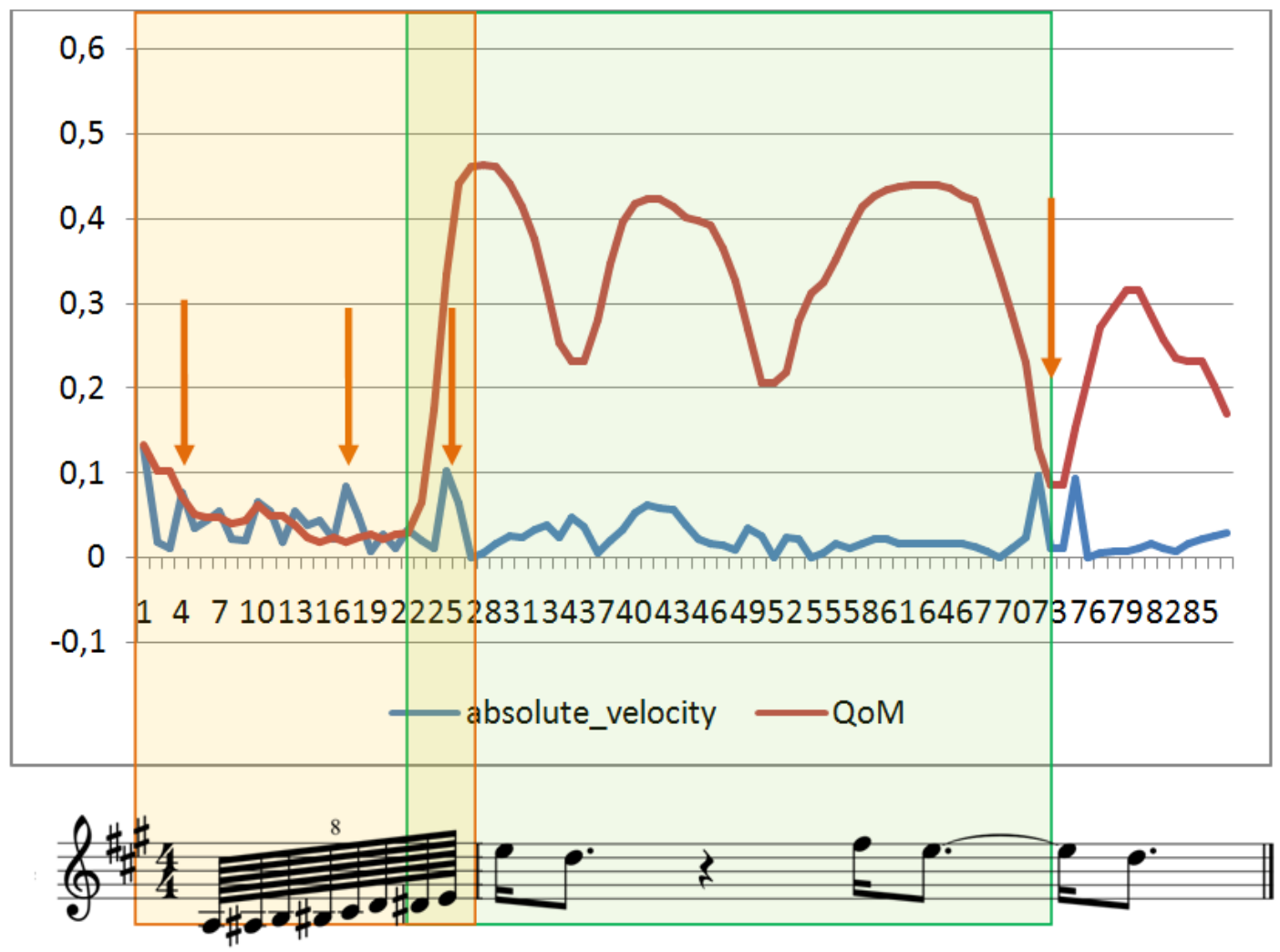

Figura 3: QoM y VA del segmento 3.

Por su parte, la VA muestra sobre la anacrusa al primer motivo una zona de mayor aceleración que posee 3 picos más marcados (señalados con flechas y un recuadro naranja respectivamente), luego una zona de aceleraciones más sutiles (fotograma 28 al 70) y sobre el final, dos nuevos picos (señalados con la última flecha naranja). Que la VA se acelere sobre la anacrusa podría indicar que en las zonas de mayor densidad cronométrica se producen aceleraciones que están más vinculadas con el nivel de superficie (dada la cantidad de picos internos que en esta zona se observan). También, estas aceleraciones 
podrían ser interpretadas como impulsos hacia zonas de mayor movimiento, de acuerdo con lo que ocurre después. Lo que ocurre con la VA podría exteriorizar que ella está mapeando un nivel jerárquico mayor, por caso el de la frase, ya que los picos se encuentran más concentrados al principio y al final y en la zona media no se alcanzan a establecer picos mayores.

Continuando, en el segmento 4 el flautista improvisa una melodía que contiene un breve ascenso y un descenso de mayor longitud, ambos cromáticos; y un diseño por saltos que va acrecentando la tensión, tanto por las alturas que utiliza como por el lugar donde se encuentra (emplea saltos disonantes y está sobre el final de una vuelta). En cuanto al movimiento corporal, primero, el músico inclina la cabeza y el torso hacia adelante-abajo, luego levanta los hombros y por último, efectúa 3 giros con la cabeza y el torso. La inclinación del torso y la cabeza y el levantamiento de los hombros suceden mientras transcurre el primer compás, en tanto que los giros se desarrollan en el segundo y el tercer compás. En la figura 4 observamos como la QoM muestra un diseño que indica menor movimiento al comienzo y un acrecentamiento paulatino de la cantidad de movimiento hacia el final. Esto podría indicar el movimiento corporal puede mapear la estructura morfológica de la música, porque a medida que se acerca el final de la frase, el movimiento es mayor (del mismos modo sucede en el segmento 2). Asimismo, el movimiento corporal podría mapear la dinámica del movimiento melódico, porque el acrecentamiento del movimiento se corresponde con el acrecentamiento de la tensión. Por su parte, los picos de la QoM coinciden con los tiempos débiles del compás (señalados con recuadros en verde), lo que indicaría que también puede haber por momentos un mapeo del ritmo de la melodía. Por ejemplo, el primer pico de la QoM que tiene lugar en el primer compás, ocurre cuando la melodía presenta un cambio rítmico, porque pasa de un valor irregular a un valor regular, y melódicamente continúa con la misma lógica que venía desarrollando. Luego, en el segundo compás, aparece junto con la prolongación de una de las figuras (sobre la segunda nota del compás). Por último, sobre el final del segundo compás y el inicio del tercero, ambos, lugares que implican mayormente silencios. Es decir, los picos de la QoM tienen lugar en 3 sectores donde el ritmo cambia en comparación con lo que venía sonando y en este sentido, podrían producirse por el mapeo del ritmo que en algunos momentos realiza el movimiento corporal. 


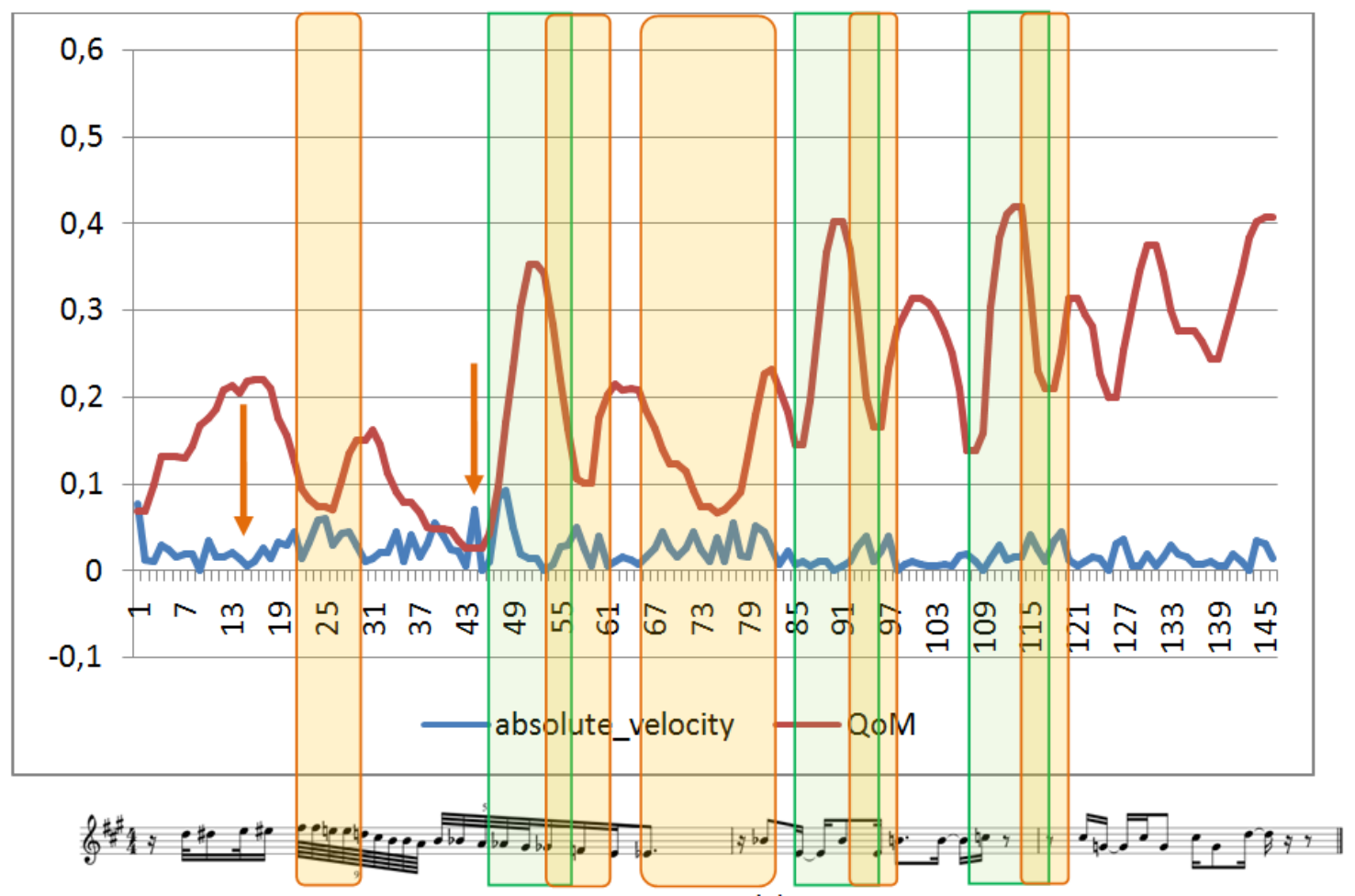

Figura 4: QoM y VA del segmento 4.

Por su parte, la VA exhibe una línea que presenta zonas más regulares (indicadas con recuadros en naranja) y zonas más irregulares (señaladas con flechas naranjas). Las zonas de mayor regularidad indican una constante en la velocidad que coincide con el $2^{\text {do }}$ y el $4^{\text {to }}$ tiempo del primer compás, con el $1^{\mathrm{er}}$ y el $2^{\text {do }}$ tiempo del segundo compás y con el $1^{\text {er }}$ tiempo del último compás de la melodía. Esto reflejaría que la VA está mapeando el ritmo de la melodía, tanto en la ejecución propiamente dicha (como sucede en el primer compás) como en los impulsos de los comienzos acéfalos (como muestra el segundo y el tercer compás). También la aceleración se produce cuando la densidad cronométrica es mayor, es por eso que allí la VA se encargaría de mapear el nivel de superficie de la melodía, particularmente el ritmo.

El segmento 5, comienza por un cromatismo ascendente que desemboca en un diseño también cromático, pero descendente y con figuras de valores más largos (anacrusa y primer compás). Continúa con un recorrido cromático, cuasi descendente, que emplea valores irregulares. Durante la improvisación de este segmento el músico comienza con un desplazamiento del torso y la cabeza hacia adelante. Luego, mueve las piernas desde la derecha, hacia la izquierda y nuevamente hacia la derecha, marcando con ese movimiento el tiempo de la obra. Hacia el final, mueve la cabeza y el torso, haciendo unos pequeños rebotes abajo arriba y alcanza una postura más erguida que lo hace estirarse hacia adelante, dejando apoyada en las dos patas delanteras la silla en la que está sentado. En la figura 5 apreciamos que los picos de la QoM (señalados por los recuadros en verde) se encuentran al comienzo y al final del primer compás y sobre el $3^{\text {er }}$ y el $4^{\text {to }}$ tiempo del segundo compás. Los primeros dos picos anticipan el cambio rítmico, y en este sentido 
podríamos decir que estarían mapeándolo. El tercer pico, dada su ubicación, estaría mapeando un nivel de la melodía más abarcador, por ejemplo, el nivel de la semifrase.

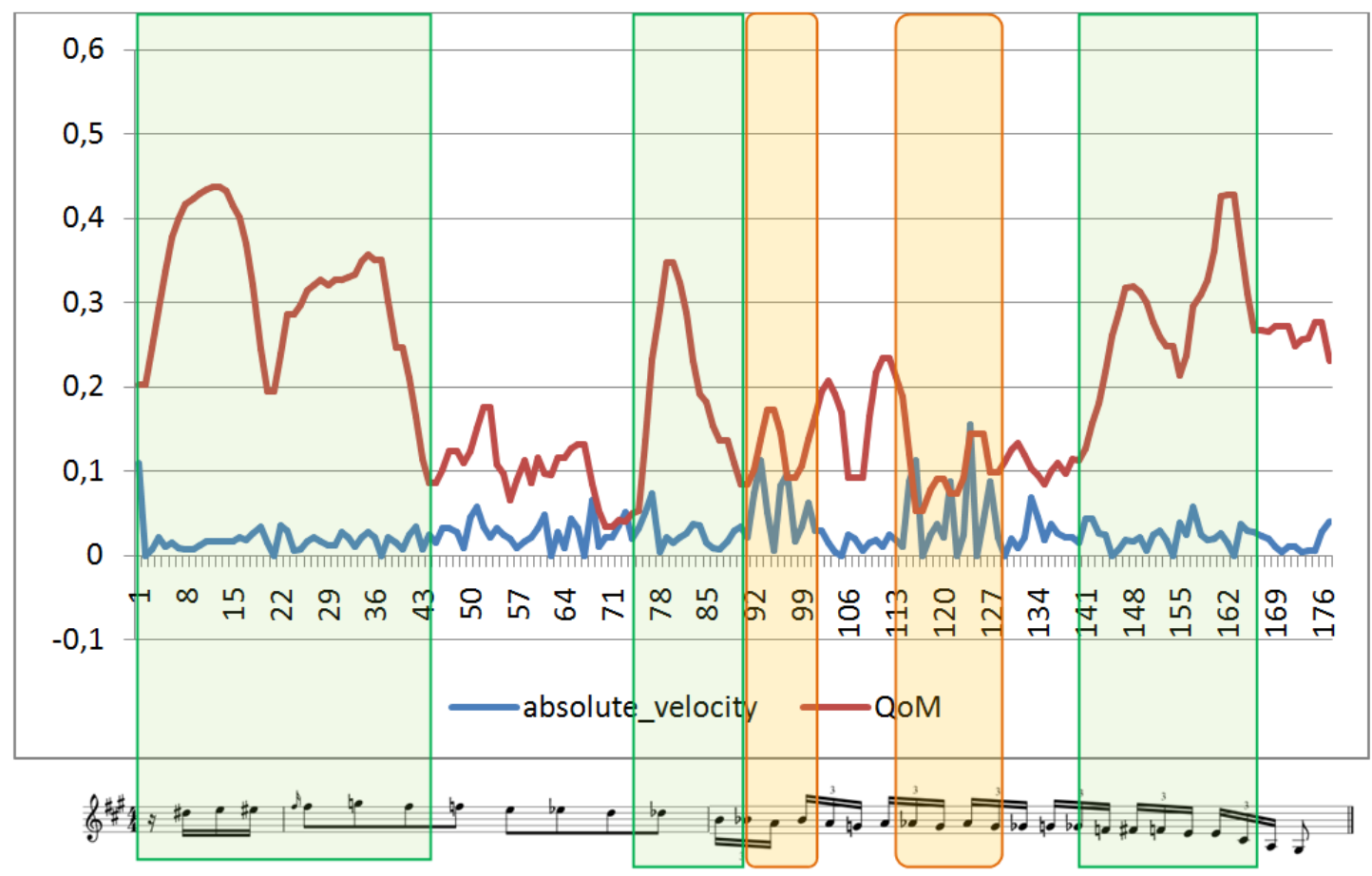

Figura 5: QoM y VA del segmento 5.

Por su parte, la VA posee dos zonas donde se observan aceleraciones, sobre el $1^{\text {er }}$ y el $2^{\text {do }}$ tiempo del segundo compás (indicadas por recuadros en naranja), lo que indicaría un mapeo del ritmo de la melodía, dado que se produce en una zona de cambio en comparación con la anterior.

En el segmento 6 el flautista realiza un diseño melódico que primero emplea un motivo con repeticiones y saltos que desemboca en una melodía cromática cuasi descendente de valores más largos que el motivo anterior, y luego, un descenso cromático realizado eminentemente sobre valores irregulares. Se observa en durante la improvisación de este segmento una sucesión de movimientos corporales que implican (i) el desplazamiento de los hombros hacia arriba y (ii) la realización de pequeños giros con el torso y la cabeza, (iii) la producción de un movimiento de marcación hacia abajo con las piernas y (iv) nuevamente la realización de giros con el torso y la cabeza efectuando un recorrido más amplio que en los giros de (ii). Esta sucesión da como resultado una línea de QoM con un alto grado de variabilidad. En otras palabras, que el cuerpo produzca toda esta secuencia de movimientos podría estar influyendo en el movimiento que realiza la cabeza, implicando con ello mayor cantidad. En la figura 6 observamos que la cantidad de picos dispersos por todo el segmento que presenta la QoM (señalados con flechas en color verde). También, que los picos de mayor altura (esto es, que superan el valor 0,4 ) ocurren al comienzo y al final; que hay dos picos que gozan de una altura considerable (entre los 
fotogramas 101 y 151) y que el resto de los picos presenta una altura intermedia (cuyo promedio aproximado es 0,28 ). Que los picos de mayor altura se encuentren al principio y al final del segmento podría evidenciar que el mapeo del movimiento corporal se produce al nivel de la frase. En cambio, los picos de altura considerable que se observan hacia la mitad del segmento, ocurren cuando en la melodía están comenzando a ser utilizados los valores irregulares y por ello, podríamos pensar que aquí el movimiento se ocupa de mapear el ritmo.

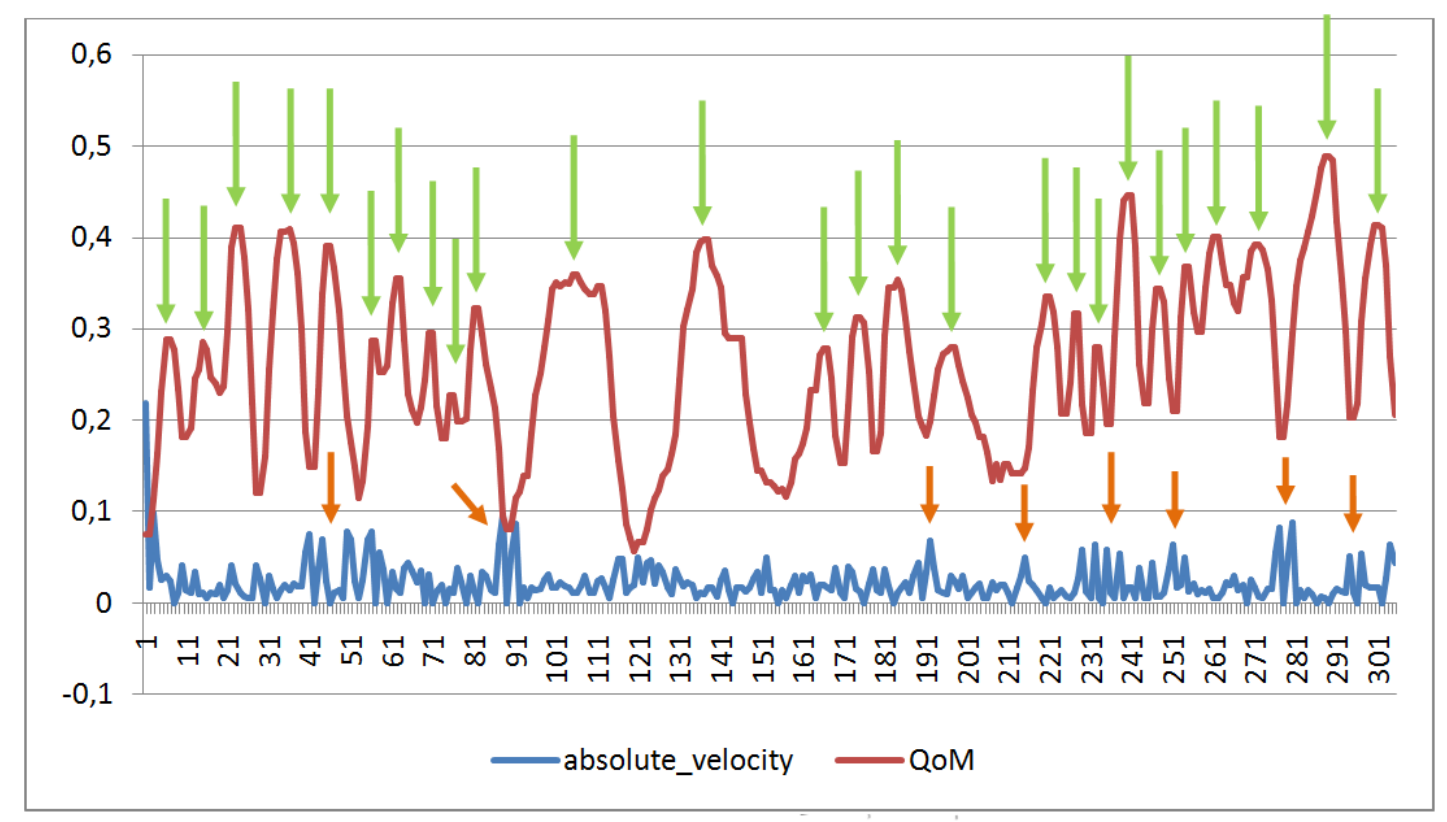

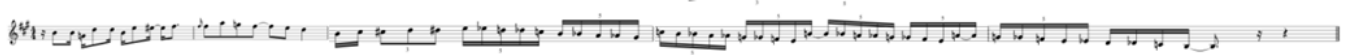

Figura 6: QoM y VA del segmento 6.

Por su parte, la curva de la VA muestra varios sectores donde se producen aceleraciones (indicados con flechas en naranja). El primero de estos sectores se desarrolla cuando la melodía posee los valores más largos del segmento, mientras que los restantes, se suceden sobre el tresillo de corcheas del tercer compás y sobre algunos de los quintillos del cuarto y del quinto compás. Estas aceleraciones podrían deberse al mapeo del ritmo que realiza el movimiento corporal, dado que se producen en momentos donde el cambio mayor se da a nivel rítmico (sobre los valores más largos en contraposición a los utilizados al inicio y luego, sobre las ligaduras que se realizan hacia el final).

En el segmento 7 el músico improvisa un diseño melódico constituido mayormente por saltos, que luego repite con una mínima variación. De este modo, encontramos dos motivos melódicos que alternan saltos y ascensos por grado conjunto. Al mismo tiempo que improvisa estos motivos, el músico realiza una serie de movimientos con la cabeza y el torso hacia adelante-derecha-abajo, produciendo pequeños rebotes abajo-arriba $y$ finalmente, un desplazamiento derecha-atrás. En la figura 7 advertimos que los picos de la QoM durante esos movimientos se producen sobre el inicio, sobre el final del primer motivo y sobre final del segmento (indicados con recuadros en verde). En otras palabras, la 
resultante de la QoM expresa una curva en la que los momentos de mayor altura coinciden con el modo en que configuramos la estructura de la melodía improvisada. En este sentido, el movimiento corporal estaría mapeando el nivel del motivo dentro de la melodía.

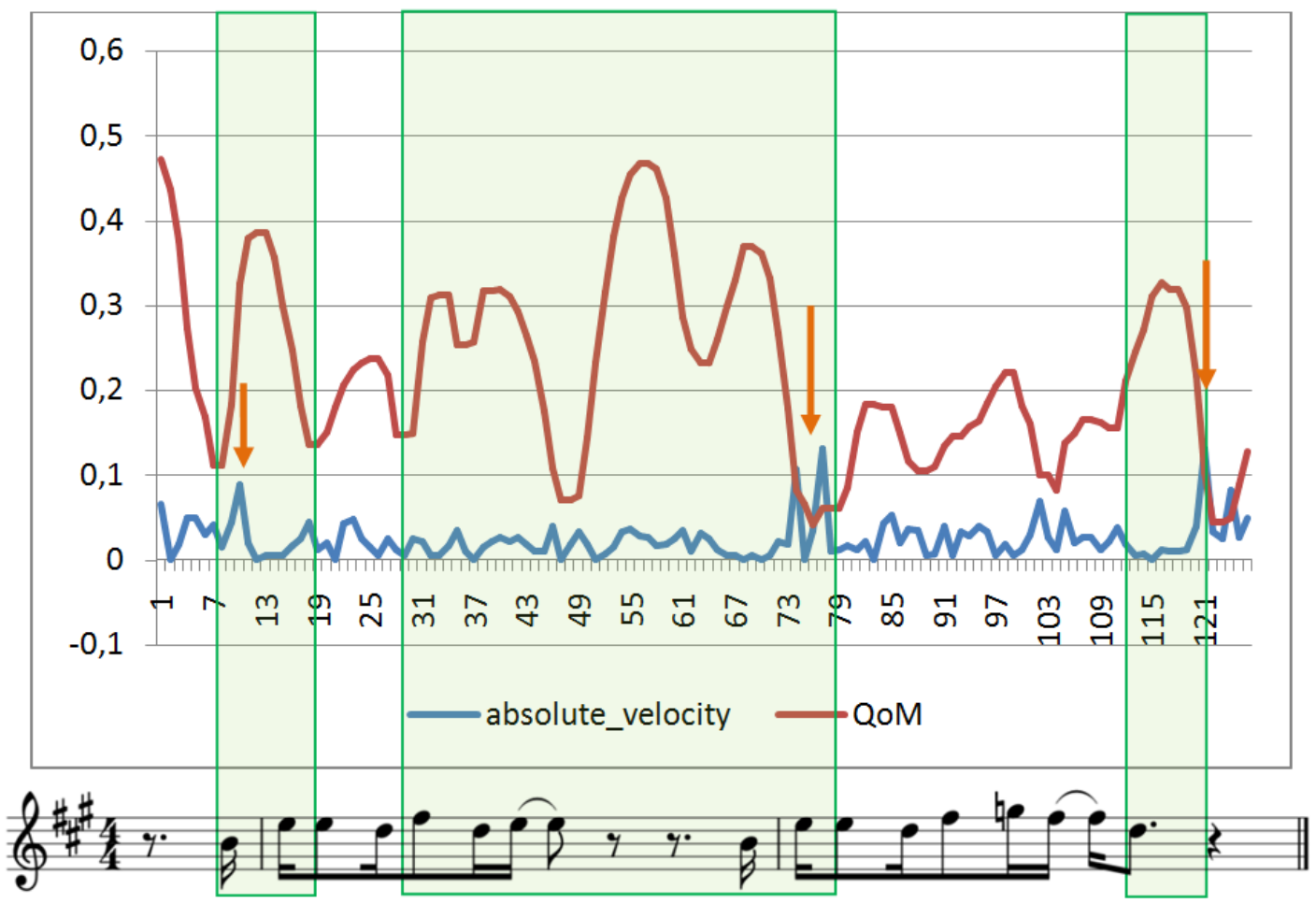

Figura 7: QoM y VA del segmento 7.

Continuando, la curva de la VA muestra 3 aceleraciones considerables (señaladas con flechas en naranja). La primera, ocurre sobre el inicio del segmento; la segunda, sobre el comienzo del segundo motivo y la última, sobre el final. Es por esto que podríamos pensar que la VA estaría reforzando el mapeo de la estructura melódica al nivel del motivo, porque como sugeríamos en el párrafo anterior también sería realizado por la QoM.

En el segmento 8 el músico propone una improvisación que contiene en primer lugar, un descenso cromático compuesto por 4 alturas y luego, un diseño compuesto por un salto ascendente que reúne dos alturas. Tanto el descenso cromático como el diseño por salto se repiten 4 veces, pero, este último varía en cada repetición la altura de la que parte, la altura a la que llega, o ambas. Por todo esto podemos interpretar que la melodía improvisada contiene dos motivos. Cuando el flautista improvisa en este segmento realiza una serie de sutiles movimientos circulares con la cabeza y el torso que en un elevamiento del torso hacia arriba-adelante. En la figura 8 notamos como la QoM crece hacia el final del segmento, donde la melodía presenta mayor variabilidad, en el sentido de que ya no es una repetición literal como es el primer motivo. Esto nos hace pensar que aquí el movimiento corporal estaría mapeando el nivel de la nota dentro de la melodía, ya que la 
mayor cantidad de movimiento aparece cuando la melodía presenta cambios mayores en este nivel.

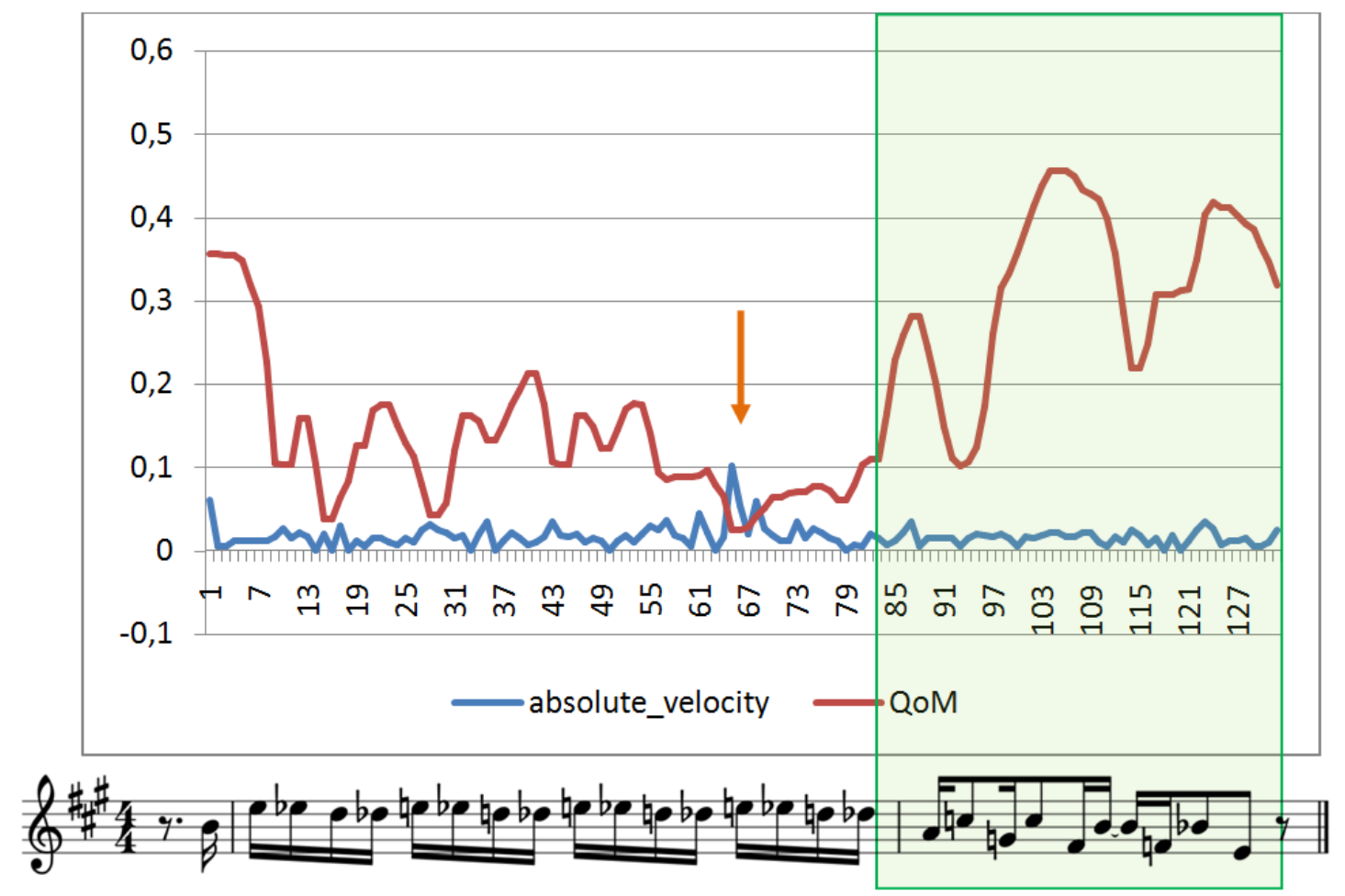

Figura 8: QoM y VA del segmento 8.

En contraposición, la curva de la VA sólo posee una aceleración notoria casi sobre el final de lo que configura el primer motivo de esta melodía, esto es, sobre la última repetición del diseño descendente cromático. Podríamos pensar que esta aceleración está anticipando el cambio que implica el pasaje de un patrón repetido a otro variado y con ello, reforzando la división del segmento en dos partes. Si así fuera, entonces la VA estaría mapeando la melodía en términos de su organización motívica.

Siguiendo, en el segmento 9 el improvisador toca en primer lugar un motivo melódico muy breve que luego repite secuenciado y en cada repetición, interpone un silencio. En segundo lugar, un motivo de mayor continuidad, donde emplea saltos, repeticiones de alturas y grados conjuntos como elementos generadores. Sobre la primera parte del segmento el músico realiza un movimiento de marcación con la cabeza y el torso hacia la derecha y hacia la izquierda, que alterna con zonas donde permanece más quieto. Dicho de otro modo, parece detenerse luego de cada marcación. Hacia el final del segmento, aparece un movimiento de vaivén con el torso y la cabeza más continuo y veloz que los movimientos anteriores. En la figura 9 distinguimos la cantidad de los picos que presenta la QoM, la variabilidad que presentan y cómo se ubican temporalmente en comparación con la melodía (señalados con flechas en verde). Se puede apreciar que en la primera parte los picos ocupan un rango de valores mayor que la segunda parte. En este sentido, en cada sección de la melodía están pasando cosas distintas, cuando el diseño melódico 
cambia, la cantidad de movimiento parece también alterarse. Podríamos sugerir que el movimiento aquí está realizando un doble mapeo. Por un lado, que la QoM pueda interpretarse a partir de la división en dos zonas de acuerdo con el rango que ocupan los picos, indicaría que existe un mapeo del nivel del motivo dentro de la melodía. Por el otro, que la cantidad de picos sea elevada en cada zona, implicaría un mapeo al nivel de la nota dentro de la melodía. Al observar detenidamente la figura 8 vemos que en la primera parte hay 8 picos y esto coincide con la cantidad de silencios que presenta la partitura. En este sentido podríamos hipotetizar que habría también un mapeo al nivel de la nota, particularmente del ritmo de cada evento.
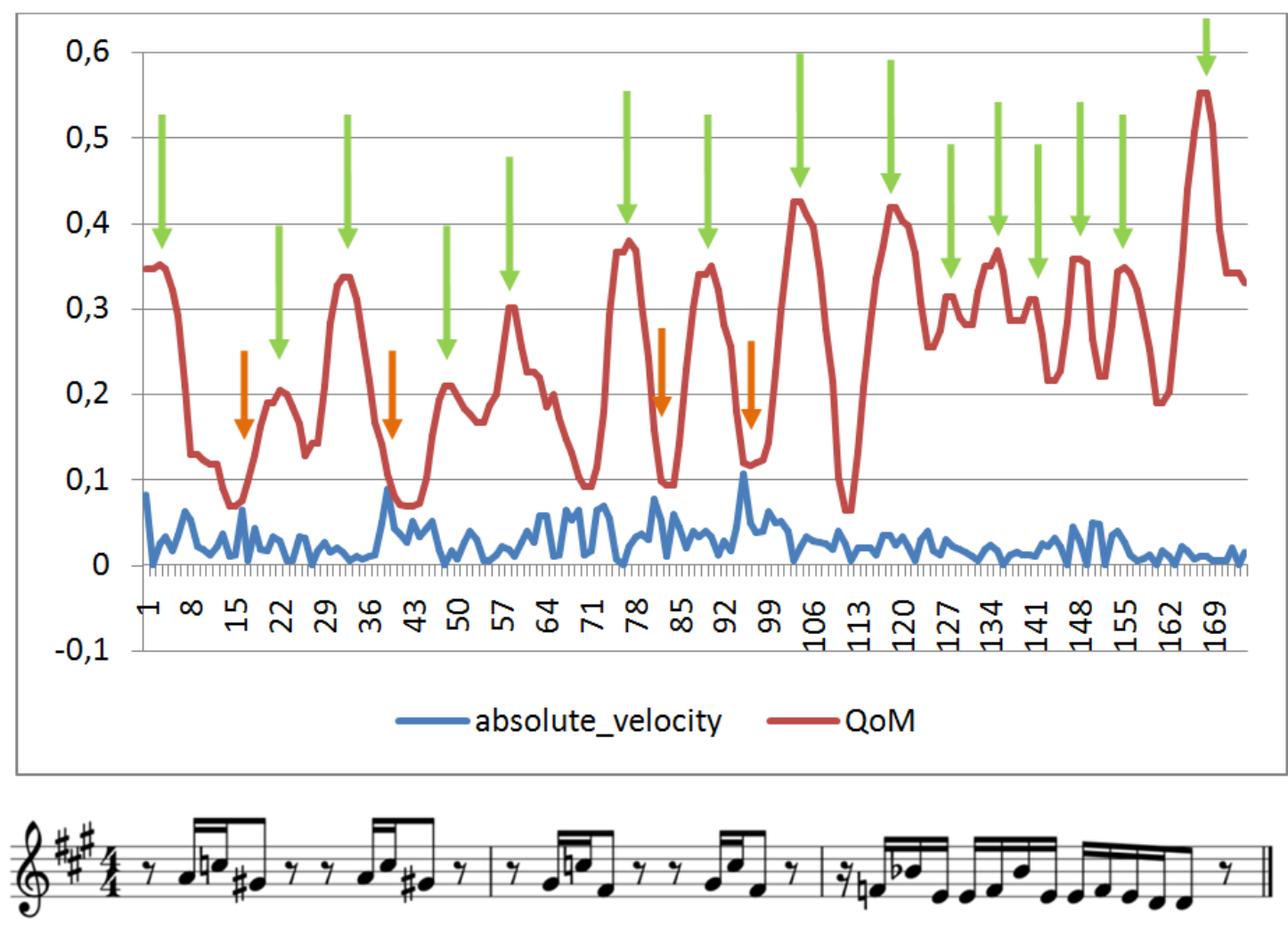

Figura 9: QoM y VA del segmento 9.

La curva de la VA muestra que las aceleraciones se dan sobre la primera parte del segmento (indicadas con flechas en naranja). Esto implicaría el mapeo de la melodía al nivel del motivo, dado que en su mayoría, las aceleraciones ocurren encima de cada motivo.

El segmento 10, el músico improvisa una melodía que presenta primero un ascenso cromático (que coincide con el primer compás); segundo, un diseño por saltos que emplea valores más largos y el extremo agudo del registro (segundo compás); tercero, un descenso cromático (anacrusa y tercer compás), y por último, un diseño melódico que emplea repetición de altura y saltos como elementos generadores (cuarto y quinto compás). En cuanto al movimiento, el flautista desplaza la cabeza y el torso hacia adelante- 
abajo, regresa luego al centro erguido y sobre el final, retoma el vaivén derecha-izquierda rápido y continuo, similar al efectuado sobre el final del segmento anterior. En la figura 10 es posible notar que las zonas donde la QoM presenta los picos mayores tienen lugar sobre la primera parte del segmento, en el $1^{\text {er }}, 2^{\text {do }}$ y $4^{\text {to }}$ tiempo del primer compás y $1^{\text {er }}$ tiempo del segundo compás; sobre el $2^{\text {do }}$ tiempo del tercer compás y prácticamente, sobre los dos compases finales (marcados con recuadros en verde). Los picos que se dan sobre el primer, el segundo y el tercer compás podrían estar aludiendo a un mapeo de la melodía en el nivel de la nota, particularmente del aspecto rítmico, porque estos picos anteceden y/o suceden cambios donde lo más saliente parece ser el ritmo. En cambio, los picos que acontecen en los últimos compases podrían vincularse con un nivel mayor de la melodía que el de la nota, por caso, el de la semifrase. En este sentido, mapearían la configuración melódica al nivel de la semifrase, atendiendo también al movimiento dinámico que presenta la melodía, que va creciendo gradualmente del mismo modo que lo hace la QoM, acrecentándose en este sector.

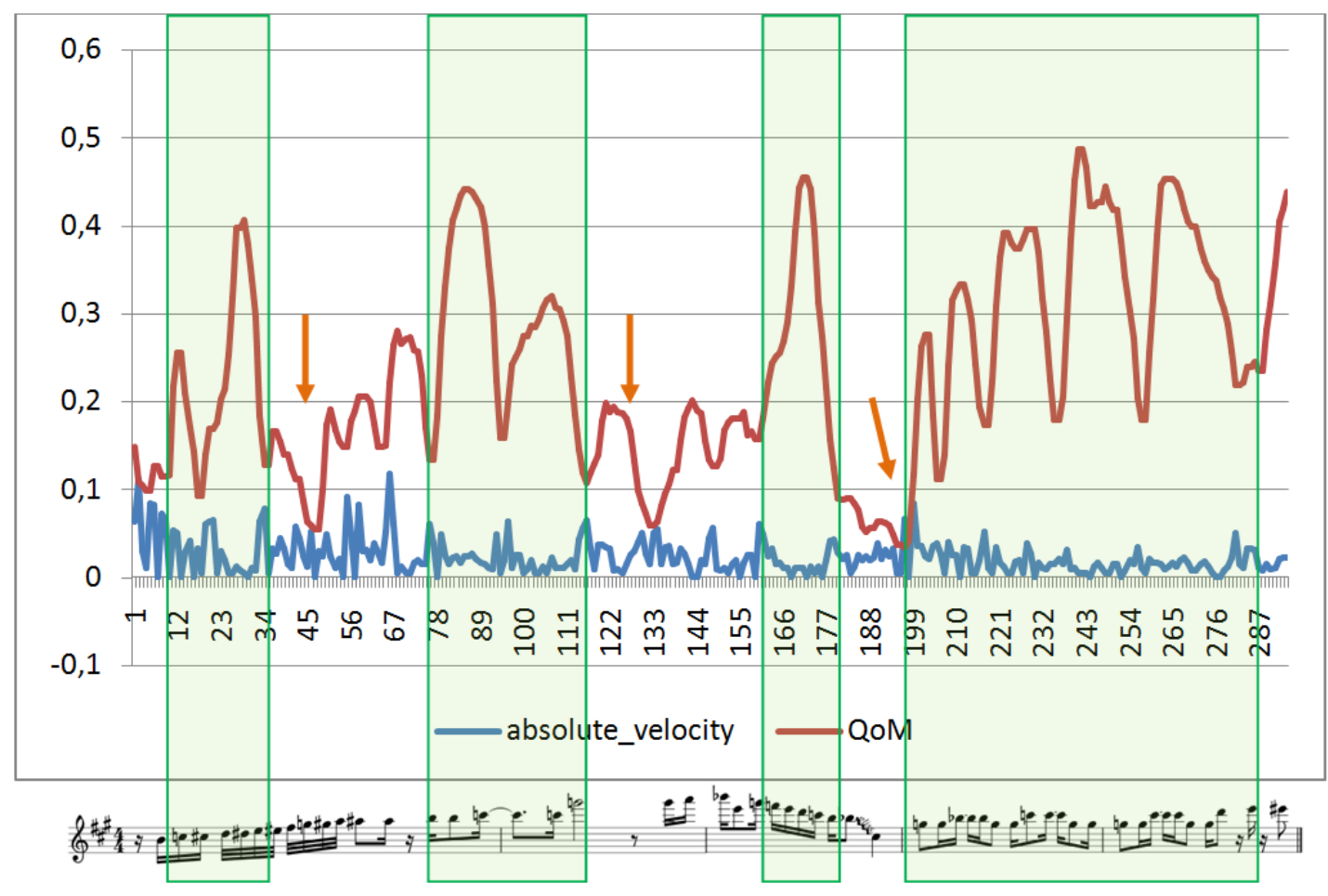

Figura 10: QoM y VA del segmento 10.

La VA presenta aceleraciones durante el primer, el segundo y el final del tercer compás (señaladas con flechas en naranja). Es interesante destacar que la aceleración que sucede sobre el segundo compás coincide en parte con el mantenimiento de la altura que allí se está ejecutando y luego, con otro tipo de valores. Esto indicaría que el mapeo estaría presente a un nivel mayor que el de la nota, por caso el nivel de la semifrase, porque de lo contrario debería haber exteriorizado algún cambio. Del mismo modo, la aceleración que se advierte al comienzo del cuarto compás sería indicio del mapeo a un nivel mayor que el de la nota. 
Casi sobre el final del solo, el flautista improvisa durante el segmento 11 una melodía mayormente constituida por un descenso cromático por saltos, hasta el final, donde cambia por un ascenso. Esta melodía está compuesta casi por completo con valores más largos que los frecuentemente utilizados en el solo y presenta 3 motivos asimétricos: el primero, de mayor longitud, abarca las primeras 6 alturas ejecutadas (desde el primer compás hasta la mitad del segundo compás); el segundo, es el más breve y comprende la articulación de las figuras que están agrupadas (sobre el final del segundo compás), y el tercero, contiene 5 alturas (sobre el tercer y el cuarto compás). Con respecto al movimiento, el músico pasa de una posición erguida a una serie de 6 movimientos del torso y la cabeza abajo-arriba, que parecen tener una vinculación directa con el aspecto métrico de la improvisación. En la figura 11 advertimos que los picos de la QoM se dispersan por todo el segmento, aunque que en el comienzo se colocan en un rango menor de valores con respecto a lo que ocurre con los picos en el resto del segmento (señalados con flechas en color verde).Al ver que la cantidad de picos de la QoM es similar a la cantidad de ataques (alturas ejecutadas) en la melodía, podríamos pensar que el mapeo que realiza el movimiento corporal en este segmento se vincula con el nivel de la nota. Sin embargo, si trazamos una línea de altura promedio entre los picos que se desarrollan en un rango de valores similares, encontramos que se diferencian 3 zonas (indicadas con las líneas en amarillo). Estas tres zonas se corresponden con el modo en interpretamos la estructura morfológica de este segmento y por ello, podríamos sugerir que el movimiento corporal estaría mapeando aquí la configuración melódica, al nivel del motivo. 


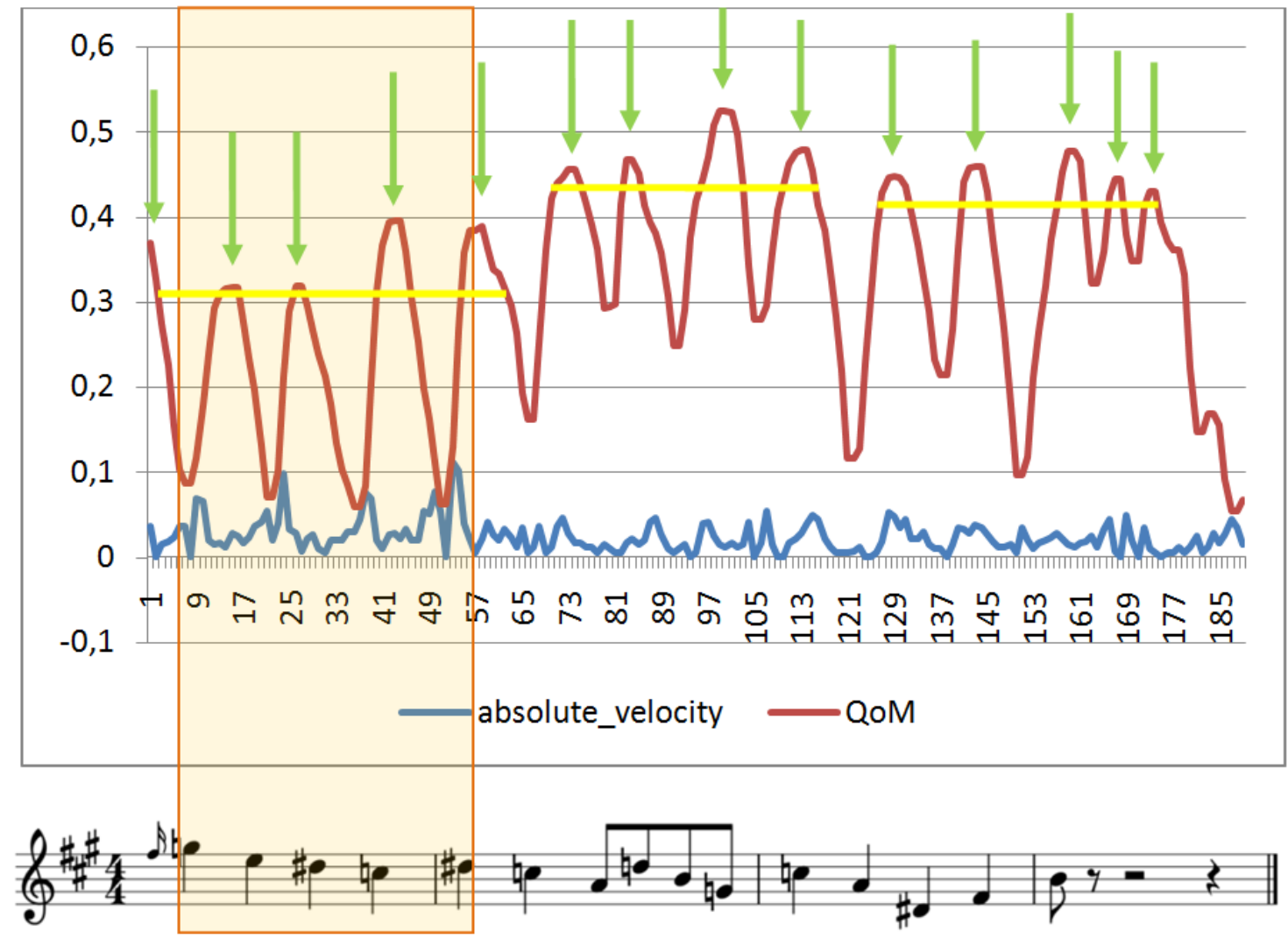

Figura 11: QoM y VA del segmento 11.

Con respecto a la VA, notamos que durante el inicio se produce una zona de aceleraciones (marcada con un recuadro naranja) y que luego, el segmento continúa con mayor estabilidad en términos de velocidad. Esto podría deberse a que el músico requiera, al menos al comienzo, de un mapeo que podría estar realizando la VA sobre el ritmo de la melodía, ya que encontramos casi tantas aceleraciones como articulaciones de altura.

Finalizando, el segmento 12 contiene una improvisación donde el flautista ejecuta primero un ascenso que incluye saltos y un cromatismo súbito; luego, una variante de la melodía improvisada en el segmento anterior; y para terminar, un descenso cromático que encuentra en una serie de saltos su resolución. Mientras cierra su solo con la improvisación de este segmento, el músico realiza en primer lugar un movimiento con la cadera, el torso y la cabeza hacia arriba-abajo, como un impulso brusco que lo obliga a despegarse por un momento de la silla en la que está sentado. En segundo lugar, consuma un desplazamiento de la cabeza y el torso hacia la izquierda que regresa rápidamente al centro y prosigue con pequeñas marcaciones que parecen coincidir con la articulación de los valores más largos. En tercer lugar, practica nuevamente ese desplazamiento hacia la izquierda, pero ahora enfatizándolo con una inclinación leve del torso y la cabeza hacia adelante-abajo. En la figura 12 encontramos que los 3 picos relevantes que posee la QoM (señalados con recuadros en verde) suceden sobre el final del primer compás, sobre el tercer compás y el $1^{\text {er }}$ tiempo del cuarto compás, y sobre el final del segmento, en este 
caso, del solo. El primero de estos picos podría interpretarse como una anticipación del movimiento que produce con la cadera, el torso y la cabeza, porque al observar el video de este segmento dicho movimiento se percibe sobre la primera altura del segundo compás (sobre la nota sol). Si funcionara así, el mapeo se daría en el nivel del motivo, y particularmente en la direccionalidad que el mismo presenta. El segundo pico, parecería estar más vinculado con el desplazamiento hacia la izquierda que retorna al centro. Dado el sitio donde acontece, este pico indicaría un mapeo de la estructura morfológica al nivel de la semifrase: de acuerdo con este pico, la frase que presenta este segmento puede ser dividida en dos partes. El tercer pico se relaciona con el desplazamiento y la posterior inclinación del torso y la cabeza hacia adelante, y coincide con la marcación del final de la frase. En este sentido, el movimiento corporal actuaría como mapeo a nivel de la frase.

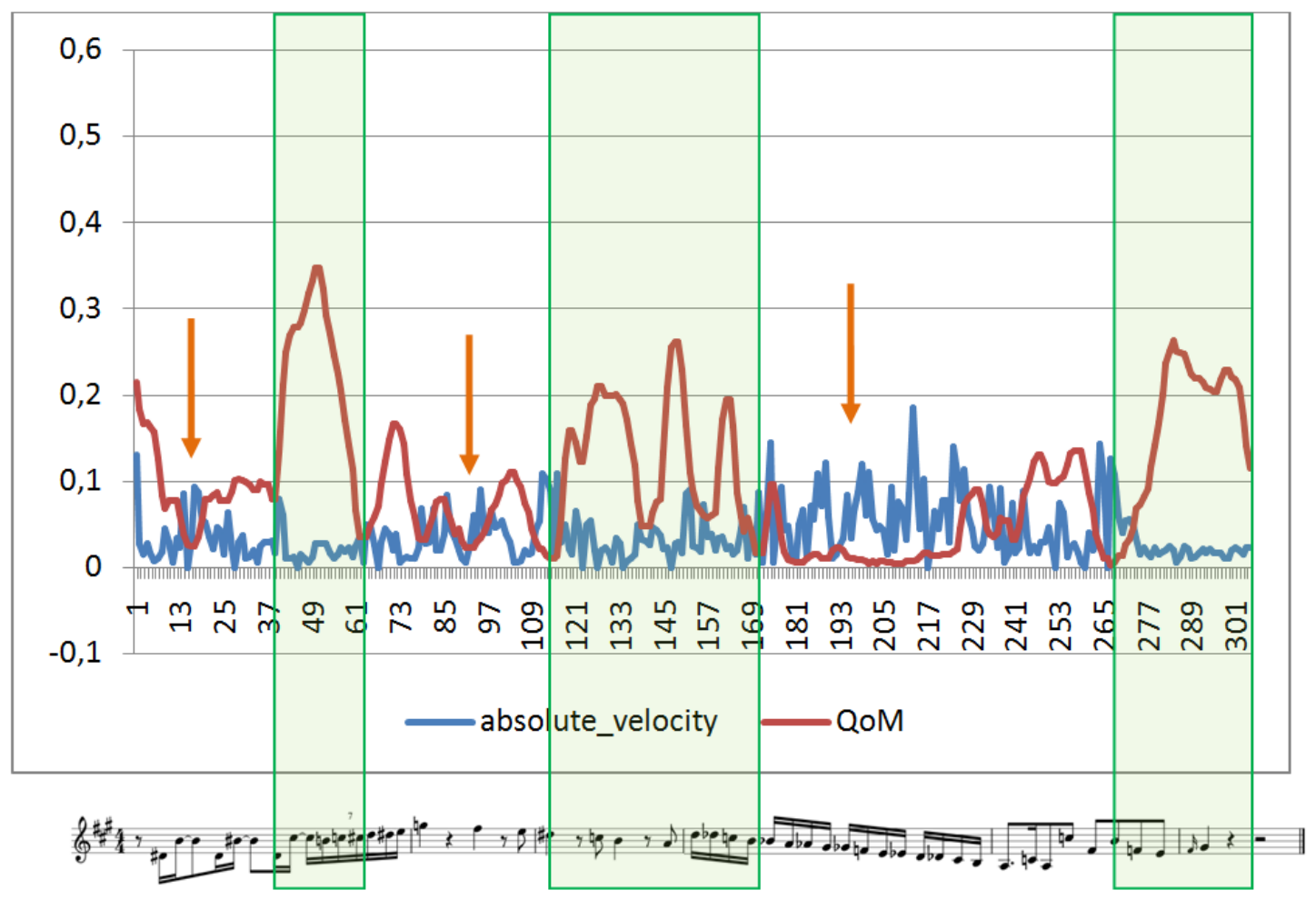

Figura 12: QoM y VA del segmento 12.

Por su parte, en la curva de la VA notamos que se suceden tres zonas de aceleraciones (señaladas con flechas en naranja). Sendas zonas ocurren cuando la QoM es menor, se encuentran a 'contratiempo' de la QoM. Podríamos pensar que la VA se estaría encargando en estos sitios determinados del mapeo a nivel de la nota; y que ese mapeo es circunstancialmente alterado por la QoM, cuando el mapeo de ésta prevalece.

\section{A MODO DE CIERRE}

A lo largo de este capítulo hemos visto que las medidas de QoM y de VA podrían vincularse con la configuración melódica, concretamente, con algún aspecto por sobre otro, o en un nivel específico de la organización de la melodía. Esto se evidencia en que en 
algunos segmentos la QoM se encarga de mapear la dinámica del movimiento melódico (por ejemplo en el segmento. 4), mientras que en otros se ocupa particularmente del ritmo (segmento 6 y 9). También la VA está con frecuencia relacionada al mapeo del ritmo (segmentos $4,5,6,11$ y 12 ) y de la estructura métrica (segmento 1 ). Sin embargo, se ha observado que en otras ocasiones ambas medidas estarían realizando el mapeo de la estructura que posee la melodía que está siendo improvisada. Ahora bien, ese mapeo no siempre se establece sobre el mismo nivel de la estructura, sino que por el contrario, lo hace sobre distintos niveles jerárquicos de la organización melódica. Es por esto que, en algunos casos, el movimiento corporal se estaría encargando del mapeo de la melodía al nivel de la frase melódica, denotando allí características motrices más abarcadoras (como sucede en los segmentos 2, 3 y 12). En otros casos, el mapeo se daría a un nivel jerárquico menor como es el de la semifrase (segmentos 5, 10 y 12); en otros al nivel del motivo (segmentos $2,7,8,9,10$ y 11 ) y finalmente, al nivel de superficie, esto es nota a nota, con énfasis en las alturas, en el ritmo, o en ambos (segmentos 4, 5, 6, 9, 10, 11 y 12). Por otra parte, encontramos que estas medidas pueden trabajar asociadas (segmento 2, 6 y 7), es decir que se encarguen de mapear en conjunto algún aspecto de la organización melódica, o bien que cada una se ocupe de mapear un aspecto particular (como sucede en la mayoría de los segmentos). Por último, en algunos sitios, el movimiento comienza mapeando un aspecto que durante el transcurso del segmento cambia por otro. Esto implicaría que no necesariamente debe haber una continuidad del mapeo, sino más bien, que el movimiento corporal va mapeando algún aspecto que quizás demanda la improvisación en ese momento y luego, al cambiar los requerimientos del entorno musical, se adapta y por ello comienza a realizar un nuevo mapeo. Sería necesario para complementar estos análisis la palabra del músico, para observar lo que implica, en $1^{\text {era }}$ persona, el movimiento corporal durante la improvisación musical. También, indagar más en las medidas que pudieran ofrecernos el software aquí utilizado y otros del estilo, para poder ganar otros recursos que aporten mayor información sobre cómo se produce el desarrollo del movimiento corporal en la performance improvisada. 



\section{CONCLUSIONES}

Esta Tesis se propuso describir y analizar el movimiento corporal suscitado en la performance improvisada, que muchos músicos llevan a cabo, pero que no están vinculados con las demandas técnico-instrumentales requeridas para esa ejecución. El trabajo se centró en un solo improvisado por el flautista argentino Rubén Izarrualde, en el que se observaron los movimientos corporales realizados por la cabeza, los hombros, el torso, la cadera y las piernas, entendiendo que los movimientos provenientes de estas partes del cuerpo son independientes de los movimientos ineludibles para la ejecución de la flauta. Por eso por ejemplo, no se tuvieron en cuenta los movimientos de los brazos y de la cara, porque conforman las partes del cuerpo que están más comprometidas con la ejecución del instrumento. Una vez efectuadas las tareas de descripción y análisis, se observó el modo en que los movimientos corporales se relacionaban con el contenido sonoro de la improvisación que el flautista realizaba mientras movía esas partes del cuerpo. Ello implicó por un lado, la segmentación del solo en unidades menores susceptibles de ser analizadas y por el otro, la escritura de cada segmento del solo de acuerdo con el código convencional de escritura musical. Finalmente, una unificación para regresar al punto de partida, que era el solo completo.

La descripción y el análisis del movimiento corporal efectuado por las partes del cuerpo que no están comprometidas con la demanda técnico-instrumental se realizó bajo la hipótesis de que tales movimientos se vinculan con lo que el músico improvisa en ese momento. Específicamente, se consideró en el marco de la presente Tesis que estos movimientos se relacionan con la configuración melódica de la improvisación de dos maneras. Una, alude a una relación en términos dinámicos, esto es, las cualidades de fuerza y forma del movimiento corporal se vinculan con la dinámica de la configuración melódica. La otra, refiere a una relación entre el movimiento corporal y la organización de la melodía improvisada.

Para comprobar estas hipótesis en primer lugar se consideró el alcance del concepto de improvisación musical. Allí observamos en primer lugar, que el alcance de la improvisación puede ser definido en función de su contexto de pertenecía. Las teorías provenientes del ámbito de la etnomusicología (ver por ejemplo Bailey 1992, Nettl y Russell 1998, Solis y Nettl 2009) muestran que si tratamos el concepto de improvisación en la música hindú, encontramos procedimientos distintos de aquellos que se utilizan en el ámbito del jazz; por mencionar sólo una de las comparaciones posibles. Por consiguiente, las ejecuciones que surgen bajo cada concepción de improvisación son substancialmente diferentes. Mientras que una ejecución se configura a partir de la presentación de un conjunto de patrones específicos que pueden ser mínimamente variados (por caso la obra proveniente del contexto hindú), otra se configura a partir de la variación a un tema y la interpretación de un solo que goza de mayor libertad a la hora de realizar variaciones (pensemos en un estándar de jazz por ejemplo). Por otra parte, notamos que el concepto de improvisación ha sido tratado por una variedad de ámbitos. La filosofía, se ocupa de analizar las fuentes, la obra, los obstáculos y aperturas, y los frutos que implican la realización de una práctica 
improvisada; y de observar el modo lúdico en que la misma se lleva a cabo. Además, agrega a la definición los conceptos de creatividad, espontaneidad y libertad. Sin embargo, apelando al ámbito de las teorías psicológicas, registramos que, si bien estos conceptos han sido frecuentemente asociados a la improvisación, no están invariablemente presentes en todas las concepciones de improvisación. Asimismo, en este campo encontramos numerosas explicaciones sobre el tema con particular énfasis en el proceso psicológico que subyace a la improvisación. Por ejemplo, Pressing (1998) sostiene que la improvisación pone en juego el concepto destreza, en términos del entrenamiento, la práctica y la adaptación que implica su práctica. Además, que en ella intervienen la base de conocimiento, que nuclea los diferentes tipos de materiales que pueden ser empleados a través de variados procedimientos y el referente, que se conforma por los elementos provenientes del contexto. Por su parte, Johnson-Laird (1991) sugiere que el proceso psicológico al que asisten los improvisadores tiene su origen en la selección, la combinación y la variación de materiales previos en acuerdo con los criterios que aplican al improvisar. Continuando, acudimos también a la pedagogía, la neurociencia y la pragmática, encontrando en ellas la posibilidad de estudiar meticulosamente uno de los conceptos troncales de esta Tesis. Como corolario notamos que todas estas teorías, si bien son valiosísimos aportes para el estudio de la improvisación, dejan de lado un sinnúmero de acontecimientos que forman parte de la performance improvisada: por ejemplo, los estados de flujo que atraviesan los improvisadores(Csikszentmihalyi 1988, Kenny y Gellrich 2002), la comunicación entre ellos y entre ellos y audiencia (Schögler 1999) y en términos más generales, el proceso de práctica de significado musical al que asisten los individuos que experimentan la música (Leman 2008). Concretamente, las teorías que planteamos en el capítulo 1 configuran marcos teóricos que explican el fenómeno de la improvisación basándose en una perspectiva clásica de la cognición humana.

Entonces, en segundo lugar, revisamos en el capítulo 2 el estado del arte de la cognición corporeizada de la música y encontramos en ese campo, entre otras cosas, que el movimiento corporal del músico puede ser entendido como mediador entre el entorno y la mente (Leman 2008) y que en esta línea, muchos autores se han ocupado de estudiar el movimiento corporal del ejecutante (ver por ejemplo Wanderley 1999, Cadoz y Wanderley 2000, Martínez y Epele 2008, Shifres y Wagner 2008, Martínez y Pereira Ghiena 2011). Además, pudimos ver con claridad que el movimiento como constituyente de distintos tipos de performance ha tenido también un desarrollo teórico y experimental en distintos ámbitos (como precursores en el ámbito de la danza, los trabajos de Laban 1970 y Bartenieff y Lewis 1980; y en psicología del desarrollo ver por ejemplo Español 2007; Español, Martínez y Pattin 2008; Español et al. 2011). En consecuencia, empezamos a observar que la improvisación musical también podía constituir un escenario donde el movimiento corporal del ejecutante sea partícipe de la práctica de significado que tiene lugar en la performance. Sin embargo, para ello primero era necesario elaborar la base de una perspectiva corporeizada de la improvisación que nos permitiera llevar a cabo, o al menos, iniciar el estudio del movimiento corporal del músico durante la improvisación, describiéndolo, analizándolo y vinculándolo con el acontecer sonoro de la performance. 
Por ello, en tercer lugar propusimos que un enfoque más amplio de la improvisación, en comparación con los planteos teóricos propuestos en el capítulo 1, debería ser corporeizado, porque nos permite indagar en cómo, por y para qué se despliegan diferentes movimientos corporales en la improvisación; enactivo, definiendo así que dichos movimientos bien pueden ser acciones corporales que guían nuestra experiencia durante la improvisación; situado, y con ello se delimita el ámbito concreto de trabajo, en el caso de esta Tesis, música de fusión argentina; y multimodal, porque el movimiento aparece entrelazado en la experiencia musical junto con el sonido, la emoción y el significado.

Partiendo entonces de una perspectiva ampliada de la improvisación, comenzamos a describir el movimiento corporal observado en la performance que no forma parte de aquellos movimientos instrumentales, vinculados con los requerimientos técnicos. Esta descripción alcanzaba también a los eventos sonoros que se desarrollaban simultáneamente con los movimientos y a la vinculación que pudiera haber entre ambos. En el capítulo 3 encontramos algunas evidencias de que la forma y la fuerza del movimiento corporal podrían tener un correlato con la melodía improvisada, particularmente con sus rasgos dinámicos y morfológicos. En el capítulo 4, profundizamos el estudio del movimiento corporal y tomamos la cantidad de movimiento (QoM) y la velocidad absoluta (VA) como dos medidas del movimiento que nos ofrecerían datos más certeros para poder caracterizarlo y posteriormente, vincularlo a lo sonoro. Nos topamos con que la QoM podría mapear en diferentes sitios o bien la dinámica del movimiento melódico, el ritmo o la organización de la melodía. Por su parte, la VA se encargaría en partes de mapear o el ritmo, la estructura métrica o la morfológica. Es interesante remarcar que en algunos casos, ambas medidas trabajan en conjunto, realizando un mapeo simultáneo de la estructura de la melodía que se está improvisando en ese momento. También, que aunque no tomamos estas medidas para el análisis del capítulo 3, tendrían una incidencia, en términos generales, en la caracterización de la forma y la fuerza del movimiento que allí realizamos, porque a través de la observación directa es posible agudizar la percepción de los distintos aspectos que conforman el movimiento. En este sentido, podríamos pensar que el movimiento sería el resultado de las relaciones que se tejen entre sus aspectos más globales y menos mensurables, por caso la forma y la fuerza, y los aspectos más puntuales y más fácilmente medibles, como la QoM y la VA. Siguiendo, la relación que pudimos establecer entre el movimiento corporal y la configuración melódica es en algunos casos cuasi sincrónica, en otros anticipada y en otros, demorada. Esto implicaría que el músico no tiene la necesidad de que el movimiento se produzca en sincronía con el sonido, porque que eso no garantizaría un mapeo directo del movimiento al sonido. Ahora, sí parecería que es necesario para el músico que el movimiento sea parte de su improvisación, no importa si en forma anticipada y demorada con respecto al sonido, sino que esté ahí, de algún modo, formando parte de ese escenario y de esa práctica de significado 'on-line', con adelantos y retrasos que ella implica, pero que igualmente permiten practicarla. 
Finalmente, los resultados obtenidos en esta tesis sustentan la idea de que la improvisación pueda ser comprendida como una ejecución en la que no se trata sólo de aplicar procedimientos y recursos compositivos en tiempo real, sino que también implica vivenciar una serie de procesos que se vinculan con el modo en que se comunican los músicos durante la performance, con el estado de flujo que allí experimentan y con la práctica de significado a la que esa performance da lugar. En este sentido, movimiento corporal y sonido producido por el improvisador conforman una unidad de sentido a través de la cual, tanto el músico como la audiencia, podrían experimentar el significado durante la performance improvisada. 



\section{REFERENCIAS}

Anderson Sutton, R. (1998). ¿Improvisan realmente los músicos del gámelan javanés?. En B. Nettl y M. Russell (eds.) In the course of the performance. [En el transcurso de la interpretación. Estudios sobre el mundo de la improvisación musical. (B. Zitman, traductor) Madrid: Akal 2004] Chicago: The university of Chicago Press, pp. 71-92.

Assinnato, M. (2009). El rol de la improvisación en la habilidad de transcribir melodías. En P. Asís y S. Dutto (Comp.) La Experiencia Artística y la Cognición Musical. Buenos Aires. SACCoM, $\mathrm{s} / \mathrm{p}$.

Assinnato, M. (2010). Improvisación experta y su relación con la audición: un estudio basado en entrevistas. En L. Fillotrani y P. Mansilla (eds.) Tradición y diversidad en los aspectos psicológicos, socioculturales y musicológicos de la formación musical. Buenos Aires: SACCoM, pp.296-305.

Assinnato, M. (2011a). Expectativa melódica en la improvisación de música tonal. En A. Pereira Ghiena, P. Jacquier, M. Valles y M. Martínez (eds.) Musicalidad humana: debates actuales en evolución, desarrollo y cognición e implicancias socio-culturales. Buenos Aires: SACCoM, pp. 627-634.

Assinnato, M. y Pérez, J. (2011b). El gesto en la improvisación. Movimiento corporal, acción epistémica y significación musical. En A. Pereira Ghiena, P. Jacquier, M. Valles y M. Martínez (Eds.) Musicalidad humana: debates actuales en evolución, desarrollo y cognición $e$ implicancias socio-culturales. Buenos Aires: SACCoM, pp. 31-47.

Assinnato, M. y Pérez, J. (2011b). El gesto en la improvisación. Movimiento corporal, acción epistémica y significación musical. En A. Pereira Ghiena, P. Jacquier, M. Valles y M. Martínez (Editores). Musicalidad Humana: Debates actuales en evolución, desarrollo y cognición e implicancias socio-culturales. Buenos Aires: SACCoM, pp. 31-47.

Assinnato, M. y Pérez, J. (2013). Improvisación musical y corporeidad. Acción epistémica y significado corporeizado. Epistemus, I, pp. 89-122.

Assinnato, M. y Silva, V. (2010a). La incidencia de la ejecución vocal leída e improvisada en la transcripción melódica ligada a la audición. En L. Fillotrani y P. Mansilla (eds.) Tradición y diversidad en los aspectos psicológicos, socioculturales y musicológicos de la formación musical. Buenos Aires: SACCoM, pp.2-7.

Assinnato, M. y Silva, V. (2010b). Reflexiones sobre diferentes habilidades de ejecución y su incidencia en la transcripción de melodías. En F. Shifres (ed.) II Jornada de desarrollo auditivo en la formación del músico profesional. Buenos Aires: SACCoM, pp. 8-19.

Assinnato, M.; Pereira Ghiena, A. y Shifres, F. Movimiento corporal y construcción de la ejecución musical en vivo. Nuestro Cuerpo en Nuestra Música, (1) 2, pp.521 - 528.

Bailey, D. (1992). Improvisation: is nature and practice in music. New York: Da Capo Press. 
Bartenieff, I. y Lewis, D. (1980) Body Movement: Coping with the Environment. New York. Gordon and Breach Science Publishers.

Benson, B. (2003). The Improvisation of Musical Dialogue: A Phenomenology of Music. Cambridge: Cambridge University Press.

Berkowitz, A. y Ansari, D. (2008). Generation of novel motor sequences: the neural correlates of musical improvisation. Neurolmage, 41, 535-543.

Cadoz, C. y Wanderley, M. (2000), Gesture - Music. M. Wanderley y M. Battier (Eds.) Trends in Gestural Control of Music. Paris: IRCAM - Centre Pompidou, pp. 71-94.

Campbell, L.; Chagnon, M.-J y Wanderley, M. M. (2005) On the use of Laban-Bartenieff techniques to describe ancillary gestures of clarinetists. Research Report. Input Devices and Music Interaction Laboratory . Copyright: McGill University.

Campbell, P. (2009). Learning to improvise music, improvising to learn music. En G. Solís y B. Nettl (eds.) Musical improvisation: Art, education and society. Urbana and Chicago: Universitiy of Illinois Press, pp. 119-142.

Camurri, A.; Mazzarino, B. y Volpe, G. (2004). Analysis of expressive gesture: the eyes web expressive gesture processing library. Proceedings of the XIV Colloquium on Musical Informatics, pp. 460-467.

Camurri, A.; Mazzarino, B.; Ricchetti, M.; Timmers, R. y Volpe, G. (2004). Multimodal analysis of expressive gesture in music and dance performances. A. Camurri y G. Volpe (eds.) 5th International gesture workshop. Genova. Springer, pp. 20-39.

Castellano, G.; Mortillaro, M.; Camurri, A.; Volpe, G. y Scherer, K. (2008). Automated analysis of body movement in emotionally expressive piano performances. Music Perception 26, 2, pp. 103-120.

Chan, S. (1998). Explotando el abdomen: la improvisación en la ópera cantonesa. En B. Nettl y M. Russell (eds.) In the course of the performance. [En el transcurso de la interpretación. Estudios sobre el mundo de la improvisación musical. (B. Zitman, traductor) Madrid: Akal 2004] Chicago: The university of Chicago Press, pp. 193-210.

Clark, A. (1999). Estar ahí. Cerebro, Cuerpo y Mundo en la Nueva Ciencia Cognitiva. Barcelona: Paidós.

Csíkszentmihályi, M. y Csíkszentmihályi, I. (1988). Optimal experience. England: Cambridge University Press.

Dalh, S. y Friberg, A. (2005). Visual perception if expressiveness in musician's body movements. Disponible en http://www.speech.kth.se/ sofiadah/pdf/paper4-expression.pdf (página consultada el 25/08/2013).

Damasio, A. (1999). The Feeling of What Happens: Body and Emotion in the Making of Consciousness. San Diego: Harcourt. 
Davidson, J. (2001). The role of the body in the production and perception of solo vocal performance: A case study of Annie Lennox. Musicae Scientiae 2 (5), pp. 235-256.

Davidson, J. (2002). Understanding the expressive movements of a solo pianist. Musikpsychologie 16: 9-31.

Davidson, J. (2006). 'She's the one': Multiple functions of body movement in a stage performance by Robbie Williams. In A. Gritten \& E. King (Eds.) Music and gesture. Aldershot: Ashgate, pp. 208-226.

Davidson, J. (2007). Qualitative insights into the use of expressive body movement in solo piano performance: A case study approach. Psychology of Music, 35 (3), pp. 381-401.

Davidson, J. (2012). Bodily movement and facial actions in expressive musical performance by solo and duo instrumentalists: Two distinctive case studies. Psychology of Music 40(5), pp. 595-633.

Delalande, F. (1988). La gestique de Gould; éléments pour une sémiologie du geste musical, in G. Guertin (ed) Glenn Gould pluriel. Montréal: Louise Courteau Editora, pp. 83-111.

Diccionario de la Lengua Española, (2001). Real Academia Española. Diccionario de la Lengua Española. Vigésima segunda edición. Disponible en www.rae.es/rae.html (página visitada el 12/03/2013).

Ekman, P. y Friesen, W. (1978). Facial action coding system. Palo Alto: Consulting Psychology Press.

Ekman, P. y Friesen, W. V. (1969). The repertoire of nonverbal behavioral categories: origins, usage, and coding. Semiótica, (1) 1, pp. 49-98.

Ekman, P., Friesen, W. y Tomkins, S. (1971). Facial affect scoring technique: a first validity study. Semiótica (3), 1, pp. 37-58.

Español, S. (2007). La elaboración del movimiento entre el bebé y el adulto. En M. de la P. Jacquier y A. Pereira Ghiena (eds) Música y Bienestar Humano. Buenos Aires: SACCoM, pp. 312.

Español, S., Martínez, M. y Pattin, M. (2008). La base del movimiento en el habla y en el canto dirigidos a bebés. En M. Jacquier y A. Pereira Ghiena (eds.) Objetividad-Subjetividad y Música. Buenos Aires: SACCoM, pp. 65-72.

Español, S., Martínez, M., Bordoni, M., Camarasa, R. y Carretero, S. (2011). El movimiento en el juego musical. En A. Pereira Ghiena, P. acquier, M. Valles y M. Martínez (Eds.) Musicalidad Humana: Debates actuales en evolución, desarrollo y cognición e implicancias socio-culturales. Buenos Aires: SACCoM, pp. 71-82.

Friberg, A. (2004). A fuzzy analyzer of emotional expression in music performance and body motion. Proceedings of Music and Music Science, pp. 1-13. 
Gainza, V. (1983). La improvisación musical. Buenos Aires: Ricordi.

Garmendia, E. (1981). Educación audioperceptiva. Bases intuitivas en el proceso de formación musical. Libro del maestro. Buenos Aires: Ricordi.

Gendlin, E. (1997). Experiencing and the creation of the meaning. Preface to the paper edition. Evanston: Northwestern University Press. http://www.focusing.org/ecmpreface.html (página visitada el 5/10/11).

Gibson, J. (1979). The ecological approach to visual perception. Boston: Hougton Mifflin.

Grout, D. (1984). Historia de la Música Occidental I. Madrid: Alianza Editorial.

Gushee, L. (1998). La improvisación de Louis Amstrong. En B. Nettl y M. Russell (eds.) In the course of the performance. [En el transcurso de la interpretación. Estudios sobre el mundo de la improvisación musical. (B. Zitman, traductor) Madrid: Akal 2004] Chicago: The university of Chicago Press, pp. 277-316.

Gushee, L. (2009). Improvisation and related terms in middle-period jazz. En G. Solís y B. Nettl (eds.) Musical improvisation: Art, education and society. Urbana and Chicago: Universitiy of Illinois Press, pp. 263-280.

Hall, E. (1976). Beyond culture. New York: Anchor Press/Doubleday.

Hatten,R. (2009). Opening the museum window: improvisation and its inscribed values in canonic works by Chopin and Schumann. En G. Solís y B. Nettl (eds.) Musical improvisation: Art, education and society. Urbana and Chicago: Universitiy of Illinois Press, pp. 281-295.

Hjortsjö, C. (1969). Man's face and mimic language. Lund: Studentlitteratur.

Hofstadter, D. (1981). Temas metamágicos. Investigación y ciencia, 75, pp. 106-115.

Jensenius, A.; Wanderley, M.; Godøy, R. y Leman, M. (2010). Musical gestures: concepts and methods in research. R. Godøy y M. Leman (eds.) Musical gestures: sound, movement, and meaning. London: Routledge. pp. 12-35.

Johnson Laird, P. (2002). How jazz musician improvise. Music perception, 19 (3), pp. 415-442.

Johnson, M. (2007). The Meaning of the Body. Aesthetics of human understanding. Chicago: The University of Chicago Press.

Johnson-Laird, N. P. (1991). Jazz improvisation: a theory at the computational Level. En P. Howell, R. West and I. Cross (Eds.) Representing Musical Structure. Londres y San Diego: Academic Press, pp. 291-325.

Kenny, B. J. \& Gellrich, M. (2002). Improvisation. En R. Parncutt y G. McPherson (eds.) The science and psychology of music performance. Oxford University Press, pp. 117-134.

Kirsh, D. y Maglio, P. (1994). On distinguishing epistemic from pragmatic action. Cognitive Science 18, pp. 513-549. 
Kononenko, N. (2009). When traditional improvisation is prohibited: contemporary Ukranian funeral laments and burial practices. En G. Solís y B. Nettl (eds.) Musical improvisation: Art, education and society. Urbana and Chicago: Universitiy of Illinois Press, pp. 53-71.

Laban, R. (1970/1989). Danza Educativa Moderna. México. Paidós.

Laban, R. (1971). The mastery of movement. Boston. Plays.

Leman, M. (2008). Embodied Music Cognition and Mediation Technology. Cambridge: the MIT Press.

Leman, M. (2010). Music, gesture, and the formation of embodied meaning. R. Godøy y M. Leman (eds.) Musical gestures: sound, movement, and meaning. London: Routledge. pp. 127153.

Levin, R. (2009). Improvising Mozart. En G. Solís y B. Nettl (eds.) Musical improvisation: Art, education and society. Urbana and Chicago: Universitiy of Illinois Press, pp. 143-149.

López Cano, R. (2009) Música, cuerpo, mente extendida y experiencia artística. La gesticulación de Keith Jarret en su Tokio Encore '84. Disponible en www.lopezcano.net (página visitada en 13/09/2011).

Lourens, T.; Van Berkel, R. y Barakova, E. (2010). Communicating emotions and mental states to robots in a real time parallel framework using Laban movement analysis. Robotics and Autonomous Systems 58, pp. 1256-1265.

Malloch, S. (1999). Mother and infants and communicative musicality. Musicae Scientiae (Special Issue 1999-2000), pp. 29-57.

Malloch, S. y Trevarthen, C. (Eds.) (2008). Communicative Musicality: Exploring the Basis of Human Companionship. Oxford: Oxford University Press.

Martínez, I. y Epele, J. (2008). Música y corporalidad. Relaciones de coherencia entre danza y música en coreografías de Ballet y de movimiento libre. En M. Jacquier y A. Pereira Ghiena (Eds.) Objetividad-Subjetividad y Música. Buenos Aires: SACCoM, pp. 339-346.

Martínez, I. y Pereira Ghiena, A. (2011). La experiencia de la música como forma vital. Perfil dinámico, temporal, corporalidad y forma sónica en movimiento. En A. Pereira Ghiena, P. Jacquier, M. Valles y M. Martínez (eds.) Musicalidad Humana: Debates actuales en evolución, desarrollo y cognición e implicancias socio-culturales. Buenos Aires: SACCoM, pp. 521-530.

Matsumoto, D.; Keltner, D.; Shiota, M.; O'Sullivan, M. y Frank, M. (2008). Facial expressions of emotion. En M. Lewis, J. Haviland-Jones y L. Feldman Barrett (eds.) Handbook of emotions. New York: The Guilford Press, pp. 211-234.

Mauléon, C. (2010) El gesto comunicativo del intérprete. En L. Fillottrani y A. Mansilla (Eds.) Tradición y diversidad en los aspectos psicológicos, socioculturales y musicológicos de la formación musical. Bahía Blanca: SACCoM, pp 99-106. 
McNeill, D. (1992). Hand and mind. What gestures reveal about thought. Chicago: University of Chicago Press.

McNeill, D. y Duncan, S. (2000). Growth points in thinking-for-speaking. En D. McNeill (Ed.) Language and Gesture. Cambridge: Cambridge University Press, pp. 141-161.

Michels, U. (1982). Atlas de la Música I. Madrid: Alianza Editorial.

Molina, E. (1998) La improvisación y el lenguaje musical. Disponible en http://musica.rediris.es/leeme/revista/emolina2.html (página visitada el 8/03/2013).

Molina, E. (2008). La improvisación: Definiciones y puntos de vista. Música y Educación, 75, 3, pp. 76-93.

Monson, I. (1996). Saying something: jazz improvisation and interaction. Chicago: University of Chicago Press.

Monson, I. (2009). Jazz as political and musical practice. En G. Solís y B. Nettl (eds.) Musical improvisation: Art, education and society. Urbana and Chicago: Universitiy of Illinois Press, pp. 21-37.

Mota, D.; Loureiro, M. y Laboissière, R. (2013). Analysis of synchronization patterns in clarinet duos using acoustic and kinematic parameters. En F. Shifres, M. Jacquier, D. Gonnet, M. Burcet y R. Herrera (eds.) Nuestro cuerpo en nuestra música. Buenos Aires: SACCoM, pp. 199206.

Murphy, J. (2009). Beyond the improvisation class: learning to improvise in an university jazz studies program. En G. Solís y B. Nettl (eds.) Musical improvisation: Art, education and society. Urbana and Chicago: Universitiy of Illinois Press, pp. 150-179.

Nachmanovitch, S. (1990) Free Play: Improvisation in Life and Art. [Free Play: La Improvisación en la Vida y en el Arte. (A. Steimberg, traductor) Buenos Aires: Paidós 2008]. New York: Penguin-Tarcher.

Naveda, L. (2011). Gesture in Samba: A cross-modal analysis of dance and music from the AfroBrazilian culture. Phd thesis, Ghent University. Disponible en http://www.ipem.ugent.be/samba/SambaProject/Thesis.html (página visitada el 26/09/2013).

Naveda, L. y Leman, M. (2013). Mapping idiomatic elements in the morphology of dance gestures: meter, gender and cultural idiosycracies in the samba dance and music. En F. Shifres, M. Jacquier, D. Gonnet, M. Burcet y R. Herrera (eds.) Nuestro cuerpo en nuestra música. Buenos Aires: SACCoM, pp. 213-224.

Nettl, B. (1974). Thoughts on improvisation. Comparative approach. The musical quarterly, 60, 1, pp. 1-19.

Nettl, M. R. y. B. (1998). In the course of the performance. [En el transcurso de la interpretación. Estudios sobre el mundo de la improvisación musical. (B. Zitman, traductor) Madrid: Akal 2004] Chicago: The university of Chicago Press. 
Norro, M. (2008). Composición en tiempo real: ¿improvisación compuesta, composición improvisada o fenomenología específica? En A. Pereira Ghiena y M. de la P. Jacquier (eds.) Objetividad-Subjetividad y Música. Buenos Aires: SACCoM, pp. 203-216.

Pereira Ghiena, A. (2008). El movimiento corporal y la lectura musical a primera vista. En M. Espejo (ed.) Memorias del Primer Encuentro Internacional de Investigaciones en Música. Tunja. UPTC, pp. 219-228.

Pereira Ghiena, A. (2009). El gesto manual en la tarea de lectura entonada a primera vista. Algunos aportes para su estudio. En P. Asís y S. Dutto (Comp.) La Experiencia Artística y la Cognición Musical. Buenos Aires: SACCoM, s/p.

Pereira Ghiena, A. (2010). El gesto corporal como acción epistémica en la lectura cantada a primera vista. En L. Fillottrani y A. Mansilla (Eds.) Tradición y Diversidad en los Aspectos Psicológicos, Socioculturales y Musicológicos de la Formación Musical. Bahía Blanca: SACCoM, pp. 121-124.

Peters, G. (2009). The Philosophy of Improvisation. Chicago: University of Chicago Press.

Pressing, J. (1984). Cognitive processes in improvisation. W. Crozier y A. Chapman (eds.) Cognitive processes in the perception of art. North-Holland: Amsterdam, pp. 345-363.

Pressing, J. (1987) Improvisation: Methods and Models. En J. Sloboda (Ed.) Generative Processes in Music: The Psychology of Performance, Improvisation, and Composition. Oxford: Clarendon Press, pp. 129-178

Pressing, J. (1988). The micro and marcostructural design of improvised music. Disponible en www.jstor.org/discover/10.2307/40285390?uid=3737512\&uid=2134\&uid=2\&uid=4\&uid=2110 871778973 (página visitada el 25/03/2013).

Pressing, J. (1998). Constreñimientos psicológicos en la destreza y la comunicación improvisatorias. En B. Nettl y M. Russell (eds.) In the course of the performance. [En el transcurso de la interpretación. Estudios sobre el mundo de la improvisación musical. (B. Zitman, traductor) Madrid: Akal 2004] Chicago: The university of Chicago Press, pp. 51-70.

Racy, A. (2009). Why do they improvise? Reflections on meaning and experience. En G. Solís y B. Nettl (eds.) Musical improvisation: Art, education and society. Urbana and Chicago: Universitiy of Illinois Press, pp. 313-322.

Ross, D. (2010). Improved: changing thoughts about learning. Disponible en http://digitool.library.mcgill.ca/webclient/StreamGate?folder id=0\&dvs=1402519536226 121 (página consultada el 26/08/2013).

Ross, D. (2011). Activating Bodies of Knowledge: Improvisation, Cognition, and Sports Education. Disponible en http://www.criticalimprov.com/article/view/1314/2234 (página visitada el 25/06/2013). 
Ross, D. (2011). Activating bodies of kwnoledge: Improvisation, cognition and sports education. Critical studies in improvisation 7 (2), pp. 1-5.

Sadie, S. (ed.). (1980). The New Grove Dictionary of Music and Musicians. Londres: Macmillan.

Sadie, S. (ed.).(1984). The New Grove Dictionary of Music and Musicians. Londres: Macmillan.

Sawyer, K. (2006). Group creativity: musical performance and collaboration. Psychology of Music, 34, 2, pp. 148-165.

Schögler B. (1999). Studying temporal co-ordination in jazz duets. Disponible en http://skoogmusic.com/nuggets/wp-content/uploads/2012/02/MUSICAE.pdf (página consultada el 10/06/2013).

Schögler, B. y Trevarthen, C. (2007). To sing and dance together. En S. Bråten (Ed.) On Being Moved. From mirror neurons to empathy. Amsterdam: John Benjamin's Publishing Company, pp. 281-302.

Shifres, F. y Wagner, V. (2008). Movimiento, intención y "sentido sentido" en la ejecución musical cantada. En M. de la P. Jacquier y A. Pereira Ghiena (eds.) Objetividad-Subjetividad y Música. Buenos Aires: SACCoM, pp. 25-35.

Slawek, S. (1998). No parar: términos, prácticas y procedimientos de improvisación en la música instrumental hindustani. En B. Nettl y M. Russell (eds.) In the course of the performance. [En el transcurso de la interpretación. Estudios sobre el mundo de la improvisación musical. (B. Zitman, traductor) Madrid: Akal 2004] Chicago: The university of Chicago Press, pp. 317-346.

Slawek, S. (2009). Hindustani sitar and jazz guitar music: a foray into comparative improvology. En G. Solís y B. Nettl (eds.) Musical improvisation: Art, education and society. Urbana and Chicago: Universitiy of Illinois Press, pp. 200-220.

Smith, C. (1998). Un sentido de lo posible. Miles Davis y la semiótica de la interpretación improvisada. En B. Nettl y M. Russell (eds.) In the course of the performance. [En el transcurso de la interpretación. Estudios sobre el mundo de la improvisación musical. (B. Zitman, traductor) Madrid: Akal 2004] Chicago: The university of Chicago Press, pp 249-276.

Solís, G. y Nettl, B. (eds.) (2009). Musical improvisation: Art, education and society. Urbana and Chicago: Universitiy of Illinois Press.

Stern, D. (2010). Forms of vitality. Exploring dynamic experience in Psychology, the Arts, Psychoterapy and Development. Oxford: Oxford University Press.

Stubley, E. (1992). Philosophical foundations. En R. Colwel (Ed.) Handbook of research in Music Teaching and learning. New York: Schirmer Books, pp.3-20. 
Terrazas, W. (2006). La improvisación y la enseñanza de la técnica contemporánea en la flauta traversa. En http://www.redesmusica.org/no1improv.html (página visitada el 8/03/2013).

Varela, F. (1988). Conocer. Las ciencias cognitivas: tendencias y perspectivas. Cartografía de las ideas actuales. Barcelona: Gedisa.

Varela, F.; Thompson, E.; y Rosch, E. (1991). The embodied mind: cognitive science and human experience. Londres: MIT Press.

Wanderley, M. (2002). Quantitative Analysis of Non-Obvious Performer Gestures. In I. Wachsmuth and T. Sowa (eds.) Gesture and Sign Language in Human-Computer Interaction. Springer Verlag, pp. 241-253.

Wanderley, M. M., Vines, B. W., Middleton, N., McKay, C., and Hatch, W. (2005). The Musical Significance of Clarinetists' Ancillary Gestures: An Exploration of the Field. Journal of New Music Research 34, 1, pp. 97-113.

Weisberg, R. (1987). Creatividad. El genio y otros mitos. Barcelona: Labor.

Woodring Goertzen, V. (1998). Preparando el escenario: los preludios de Clara Schumann. En B. Nettl y M. Russell (eds.) In the course of the performance. [En el transcurso de la interpretación. Estudios sobre el mundo de la improvisación musical. (B. Zitman, traductor) Madrid: Akal 2004] Chicago: The university of Chicago Press, pp. 227-248. 